NBER WORKING PAPER SERIES

\title{
REGULATING CONGLOMERATES IN CHINA: EVIDENCE FROM AN ENERGY CONSERVATION PROGRAM
}

\author{
Qiaoyi Chen \\ Zhao Chen \\ Zhikuo Liu \\ Juan Carlos Suárez Serrato \\ Daniel Xu \\ Working Paper 29066 \\ http://www.nber.org/papers/w29066
NATIONAL BUREAU OF ECONOMIC RESEARCH
1050 Massachusetts Avenue
Cambridge, MA 02138
July 2021

We are very grateful for discussions from Stefan Lamp, Mar Reguant, Nick Ryan, and Shaoda Wang and for comments from Hunt Allcott, Soren Anderson, Prabhat Barnwal, Raj Chetty, Julie Cullen, David Cutler, Michael Davidson, Michael Dinerstein, Matt Gentzkow, Ed Glaeser, Ken Gillingham, Josh Gottlieb, Michael Greenstone, Caroline Hoxby, Kelly Jones, Matthew Kahn, Louis Kaplow, Lawrence Katz, Stephanie Kestelman, Justin Kirkpatrick, Thibaut Lamadon, Ashley Langer, Shanjun Li, Neale Mahoney, Justin Marion, Leslie Martin, Magne Mogstad, Ben Olken, Edson Severnini, Joe Shapiro, Felix Soliman, Michael Song, Stefanie Stantcheva, Chris Timmins, Reed Walker, Heidi Williams, Xiaodong Zhu, and seminar participants at American University, ASSA, Barcelona Summer Forum, Cowles Foundation Summer Conference, Fudan University, FRB of Atlanta, Harvard, Helsinki GSE, Michigan State University, NBER Public, NBER China, Paris School of Economics, Peking University, SHUFE, Stanford University, University of Chicago, University of Toronto, UCSC, UCSD, University du Quebec a Montreal, University of Oxford, University of Michigan, and the 9th Mannheim Conference on Energy and the Environment. We thank IntSig Information for providing China's Administrative Registration Data (CARD). All errors remain our own. The views expressed herein are those of the authors and do not necessarily reflect the views of the National Bureau of Economic Research.

NBER working papers are circulated for discussion and comment purposes. They have not been peer-reviewed or been subject to the review by the NBER Board of Directors that accompanies official NBER publications.

(C 2021 by Qiaoyi Chen, Zhao Chen, Zhikuo Liu, Juan Carlos Suárez Serrato, and Daniel Xu. All rights reserved. Short sections of text, not to exceed two paragraphs, may be quoted without explicit permission provided that full credit, including $\odot$ notice, is given to the source. 
Regulating Conglomerates in China: Evidence from an Energy Conservation Program Qiaoyi Chen, Zhao Chen, Zhikuo Liu, Juan Carlos Suárez Serrato, and Daniel Xu NBER Working Paper No. 29066

July 2021

JEL No. H23,L51,O44,Q48

\begin{abstract}
$\underline{\text { ABSTRACT }}$
We study a prominent energy regulation affecting large Chinese manufacturers that are part of broader conglomerates. Using detailed firm-level data and difference-in-differences research designs, we show that regulated firms cut output and shifted production to unregulated firms in the same conglomerate instead of improving their energy efficiency. Conglomerate spillovers account for $40 \%$ of the output loss of regulated firms and substantially reduce aggregate energy savings. Using a structural model, we show that alternative polices that use public information on business networks could lower the shadow cost of the regulation by more than $40 \%$ and increase aggregate energy savings by $10 \%$.
\end{abstract}

Qiaoyi Chen

Fudan University

600 Guoquan Rd

Shanghai

China

17110680004@fudan.edu.cn

Zhao Chen

China Center for Economic Studies

Fudan University

Shanghai, 200433

China

zhaochen@fudan.edu.cn

Zhikuo Liu

China Center for Economic Studies

School of Economics

Fudan University

600 Guoquan Rd, Shanghai China

liuzhikuo@fudan.edu.cn
Juan Carlos Suárez Serrato

Department of Economics

Duke University

213 Social Sciences Building

Box 90097

Durham, NC 27708

and NBER

jc@jcsuarez.com

Daniel Xu

Department of Economics

Duke University

213 Social Science Bldg

419 Chapel Drive

Box 90097

Durham, NC 27708-0097

and NBER

daniel.xu@duke.edu

An online appendix is available at http://www.nber.org/data-appendix/w29066 
Balancing economic growth with the negative side effects of industrialization - such as carbon emissions and pollution - is a central problem of governments in emerging economies. Nowhere is this problem more important or consequential than in China. As Figure 1 shows, energy regulation is of national and global importance given that the industrial energy use of China overshadowed that of other leading economies in the early years of the 21st century.

This paper studies the effects of a large program aimed at curbing the energy use of Chinese industrial firms. The regulation that we study - the "Top 1,000" program - targeted the largest energy-consuming firms in the most energy-intensive industries. The regulation was designed following examples of "voluntary agreement" programs in developed countries that relied on the belief that firms could significantly reduce their energy use by improving their energy efficiency. The implementation of the program was adjusted to Chinese institutions and constraints, with the result that in practice, lowering energy consumption became the main regulatory objective. Understanding the effects of this regulation is central to broader questions of energy conservation in China. This is both because the firms regulated by this program accounted for $47 \%$ of total industrial energy use in China in 2004 and because the perceived success of the regulation led the government to significantly expand the program in later years.

This paper asks four questions that characterize the effectiveness of the Top 1,000 program. Importantly, these questions account for the fact that, as in several developing countries, industrial firms in China are often part of much larger business networks. ${ }^{1}$ First, how does the regulation impact the production and energy use of regulated firms and firms that are related through ownership networks? Second, what are the distortionary effects of the regulation and how does the ability to shift production within a conglomerate lower the cost of the program for regulated firms? Third, how do conglomerate and market spillovers alter the effects of the policy on industrial energy use and welfare? Finally, can the government use information on conglomerate networks to improve energy regulation?

We answer these questions by combining difference-in-differences research designs with an industry equilibrium model featuring conglomerate production. First, using a difference-indifferences strategy, we estimate that regulated firms reduced their energy use by $12 \%-16 \%$. Regulated firms achieved these reductions by lowering output; we find no impact on their energy efficiency. Second, we use detailed data on business networks to study whether conglomerates reallocated production across related firms. Using a second difference-in-differences design, we find that unregulated firms in the same conglomerate as regulated firms increased both output and energy use. This result uncovers an important margin of adjustment that allowed Chinese conglomerates to shift $40 \%$ of the output decline in regulated firms to unregulated affiliates.

\footnotetext{
${ }^{1}$ Ramachandran et al. (2013) describe the growing importance of conglomerates in India, China, and Latin America.
} 
Third, we specify and estimate a model of conglomerate production that matches our setting and the estimated impacts of the policy. We quantify that the ability of conglomerates to shift production lowered the shadow cost of the regulation from $11.2 \%$ of input costs to $8.7 \%$. We also evaluate the welfare effects of the program and quantify that the Top 1,000 program improves welfare when the social cost of carbon exceeds $\$ 160 .^{2}$ Finally, we show that the government can use public information on conglomerate networks to design a conglomerate-level regulation that would increase energy savings by $10 \%$ for the same welfare cost.

Overall, we find that while the regulation reduced the energy consumption of large firms, the promise of achieving these savings through improved energy efficiency failed to materialize. Instead, regulated firms reduced their energy use by decreasing their output and by reallocating part of the lost economic activity across business networks, which significantly lowered the policy's impact on energy reduction. While the ability to shift production lowered the shadow cost for regulated conglomerates, the Top 1,000 program distorted the within-conglomerate allocation of production. The government can alleviate this distortion by using publicly available data on business networks to improve the design of energy regulation.

We develop these results in three steps. First, we implement a difference-in-differences strategy using firms in similar industries that were regulated in later years as controls. We use an event-study specification to show that Top 1,000 firms and unregulated firms had similar trends prior to the regulation. We estimate that regulated firms reduced their energy use by about $12 \%-16 \%$. These estimates are robust to inclusion of industry-by-year and province-by-year fixed effects and of controls for firm characteristics. Since the regulated firms consumed 670 million tons of coal equivalent (tce) in 2004, taking these results at face value would imply a direct reduction in energy use amounting to close to 100 million tce annually. However, we also document that these firms saw a decline in output of between $10 \%$ and $23 \%$, and we do not find meaningful or statistically significant changes in energy efficiency. The lack of gains in energy efficiency suggest two hypotheses. The first is that firms had limited potential to increase energy efficiency from a technological perspective-i.e., that there was no "low-hanging fruit" (e.g., Allcott and Greenstone, 2012). A second hypothesis is that firms were able to escape the regulatory burden by shifting production to related parties.

Our second set of analyses leverages detailed business registration data to map the conglomerate networks of regulated firms. If regulated firms were able to escape the regulation by shifting production to related parties, we would expect to see an increase in both the output and energy use of firms linked to regulated firms through ownership networks. We test this hypothesis using

\footnotetext{
${ }^{2}$ The Top 1,000 program had the stated goal of reducing industrial energy use to lower emissions that contribute to global warming. While energy use reductions also lower local pollution, pollution reduction was not a stated goal of the program (Price et al., 2010). Our welfare analyses evaluate the program's objective to reduce aggregate energy use.
} 
a difference-in-differences strategy that compares unregulated but related firms to unregulated and unrelated firms. To ensure that these two groups of firms are similar, we use a matching procedure based on pre-regulation characteristics to find a suitable set of control firms. These analyses show that after the reform, regulated conglomerates shifted production to affiliates that were not subject to the regulation. Specifically, we find an increase in firm output of $13 \%$ and similar increases in other measures such as profits, sales, capital, labor, and energy use. ${ }^{3}$ Importantly, we find increases in the economic activity of related firms only when their line of business coincides with the narrowly defined (4-digit) industry classification of the regulated firm. As a placebo test, we show that related firms in other industries did not see an increase in economic activity. Because related firms are smaller than regulated firms, we calculate that conglomerates were able to shift $40 \%$ of the output decline in regulated firms to related parties. We corroborate the finding that conglomerates were not able to fully shift the production decline in Top 1,000 firms to affiliates by showing that unregulated and unrelated firms also increase output as a result of the regulation. These results show that a complete assessment of the effects of the Top 1,000 program must take into account both within-conglomerate and market-level leakage.

Our last set of analyses use an industry equilibrium model of conglomerate production that accounts for within-conglomerate spillovers to related firms as well as for market spillovers. The model clarifies the interpretation of our difference-in-differences estimates, computes the shadow cost of the regulation at the conglomerate level, and quantifies the aggregate and welfare effects of the Top 1,000 program. We estimate the model parameters by matching moments of the firm size distribution and patterns of within-conglomerate allocation of production prior to the regulation. We then use our reduced-form estimates as out-of-sample validations of the model, which show that our estimated model is able to replicate the estimated effects of the policy.

Our estimated model quantifies the shadow cost of the Top 1,000 program at $8.7 \%$ of input costs. The ability of conglomerates to shift production across related firms decreased the shadow cost of the program. The shadow cost of the program would have been $11.2 \%$ in a hypothetical case where the government prevented conglomerate-level leakage. The shadow cost of the program would have been $40 \%$ smaller had the government instead regulated the total energy use of the conglomerate.

We then use the model to quantify the aggregate and welfare effects of the Top 1,000 program. Accounting for market and conglomerate leakage, we calculate that the program reduced aggregate energy use by $4 \%$, an annual decrease of about 48 million tce. A calibration of the social cost of energy-related emissions shows that the program raises welfare as long as the social cost of carbon exceeds $\$ 160$ per ton of carbon. Using the model, we show that expanding the

\footnotetext{
${ }^{3}$ In Appendix $\mathrm{C}$ we show that the program did not significantly shift production to more polluted or populated areas. For this reason, our model and welfare analyses abstract from spatial implications of the policy.
} 
program by increasing the number of regulated firms or by tightening energy saving targets leads to similar trade-offs. A government facing administrative constraints would thus prefer to tighten the stringency of the regulation rather than increase the number of regulated firms.

The model allows us to compare the aggregate and welfare effects of incomplete regulations, such as the Top 1,000 program, to policies that would be preferable absent political or administrative constraints, such as a universal energy tax. First, we show that the government can increase aggregate energy savings by $10 \%$ for the same welfare cost by leveraging publicly available data on the ownership networks of regulated conglomerates. By targeting conglomerates instead of firms, such a regulation would avoid distorting the within-conglomerate allocation of production. Second, the model shows that a conglomerate-level regulation closely approximates the effects of a size-dependent energy tax that applies to all affiliates in conglomerates with Top 1,000 firms. Finally, we find that this size-dependent tax is only slightly inferior to a universal energy tax. These results highlight the promise of using information on the conglomerate networks of large Chinese manufacturers to improve the design of energy regulations.

Finally, we show that our model results are robust to using a wide range of alternative model specifications and parameter values. First, we extend the model to consider the possibility that firms responded to the regulating by improving their energy efficiency. Consistent with our empirical results, we find that firms faced significant costs of improving their energy efficiency. Second, we extend the model to allow for preexisting differences in energy efficiency between regulated and unregulated firms. Finally, we show that our results are robust to alternative assumptions of parameter values and model specifications. Across these wide-ranging assumptions, we estimate that the SCC that rationalizes the policy is between $\$ 112$ and $\$ 196$.

This paper contributes to our understanding of whether energy regulations and interventions aimed at improving energy efficiency are effective in developing countries (e.g., Duflo et al., 2013, 2018; Greenstone and Jack, 2015; Ryan, 2018; Ito and Zhang, 2020). ${ }^{4}$ In the Chinese context, the government's use of high-powered incentives that tie environmental performance to cadre promotion has been shown to provide a strong mechanism to enforce environmental policies (Kahn et al., 2015; Jia, 2017; He et al., 2020). In their discussion of recent efforts to curb energy use in China, Auffhammer and Gong (2015) note that the Top 1,000 program along with its expanded version in later years are the "most significant national programs" focusing on energy efficiency and energy conservation. Using industry-level data, Ke et al. (2012) argue that the

\footnotetext{
${ }^{4}$ See Gillingham et al. (2018) for a review of this literature in the context of developed countries. While this literature mostly focuses on non-industrial energy use, some of the rationales explaining the under-investment in energy efficiency - such as imperfect information or behavioral biases - may also apply to firms. For instance, Anderson and Newell (2004) show that, while some US firms adopt energy conservation projects in response to energy audits, economic considerations play an important role in explaining why not all firms adopt these projects. In our setting, the ability of firms to escape the burden of the regulation by shifting production to related firms adds to the potential explanations for under-investment in energy efficiency.
} 
Top 1,000 program led to significant declines in the energy intensity of regulated sectors. By using detailed firm-level data and tracing the effects of the regulation along business ownership networks, our results provide a fundamental reassessment of the effectiveness of the Top 1,000 program.

The result that the Top 1,000 program impacted economic activity in regulated and unregulated firms contributes to the literature studying the economic costs of environmental regulations. In the US, researchers have documented significant effects of environmental regulations on emissions and economic activity (e.g., Greenstone, 2002; Greenstone et al., 2012; Walker, 2013; Shapiro and Walker, 2018; Curtis, 2018). Colmer et al. (2020) find that French firms that are subject to the European Union's emissions trading scheme do not experience significant declines in production and that their declines in energy do not spill over to unregulated firms. He et al. (2020) show that Chinese firms that face more stringent regulations experience significant decreases in productivity. Our paper contributes to our understanding of the economic cost of energy regulation in China, which consumes the lion's share of global industrial energy.

Researchers have also documented that regulations can have spillover effects along firm networks. For instance, Hanna (2010) finds that multinational firms respond to domestic environmental regulations by increasing their investment in foreign countries, and Gibson (2019) and Soliman (2020) find that firms may also shift economic activity to unregulated plants in counties that are subject to less stringent regulations. Conglomerate spillovers are particularly important in our setting since the Top 1,000 program targeted very large firms with elaborate ownership networks. Our detailed business registration data provide a unique view into how this regulation affected the production decisions of large Chinese conglomerates and how conglomerate spillovers impacted the effectiveness of the regulation. Our model leverages these spillovers to quantify the marginal cost of the regulation, using the fact that conglomerates incur a loss when they distort the within-conglomerate allocation of production (see, e.g., Anderson and Sallee, 2011).

Our paper also takes into account the roles of leakage and market competition in environmental regulation. Research has shown that emissions leakage to unregulated firms can significantly alter the effects and design of environmental policies (e.g., Fowlie, 2009; Holland, 2012; Fischer and Fox, 2012; Bushnell et al., 2014; Baylis et al., 2014; Fowlie and Reguant, 2021). We abstract from strategic interactions between firms in a setting with monopolistic competition since we study manufacturing industries with a large number of firms that compete in national markets. ${ }^{5}$ This paper quantifies the aggregate and welfare effects of the Top 1,000 program by combining microdata on the operations of Chinese industrial firms, transparent research designs that identify direct and spillover effects of a prominent energy regulation, and an industry equilibrium

\footnotetext{
${ }^{5}$ Studies of energy regulation with strategic interaction often focus on concentrated industries (see, e.g., Mansur, 2007; Ryan, 2012; Fowlie et al., 2016).
} 
model that is consistent with the estimated effects of the program. The combination of these approaches accounts for market competition and leakage effects and shows that conglomerate spillovers are a distinct force that plays a quantitatively important role in the context of China and that feasible conglomerate-level regulations can improve the regulation of energy.

This paper is organized as follows. Section 1 describes the policy context and the data that we use to measure firm responses to the regulation and the ownership networks of regulated firms. Section 2 estimates direct effects of the Top 1,000 program on regulated firms, and Section 3 estimates indirect effects on unregulated firms that belong to the business networks of regulated firms. Section 4 describes our model of conglomerate regulation, and Section 5 estimates the model parameters. Section 6 uses the model to quantify the shadow cost of the policy and to analyze the aggregate and welfare effects of the regulation. Section 7 explores extensions of the model, and Section 8 concludes.

\section{$1 \quad$ Policy Background and Data}

This section describes the Top 1,000 energy savings program. We also describe the different datasets that we use to measure economic activity and energy use as well as our strategy to map the ownership networks of Chinese conglomerates.

\subsection{The Top 1,000 Program}

To save energy and reduce related carbon emissions, the Chinese government's 11th Five-Year Plan (11FYP) set an ambitious goal of reducing the country's energy intensity - defined as energy consumption per unit of GDP_-by 20\% between 2006 and 2011 (Price et al., 2010). Since the industrial sector accounts for $70 \%$ of total energy consumption, the government designed policies that focused on nine energy-intensive industries, which accounted for $80 \%$ of the country's industrial energy use. One of these key initiatives was the Top 1,000 Energy Saving Program, which targeted the firms with the highest energy consumption in the most energy-intensive industries.

The Top 1,000 program was first announced by the National Development and Reform Commission in April 2006, and the corresponding monitoring and assessment measures were released in 2007. The name "Top 1,000" refers to the 1,008 industrial firms in the nine energy-intensive industries with energy consumption above 180 thousand tce in 2004. The total energy consumption of these 1,008 super-firms was 670 million tce in 2004, accounting for $47 \%$ of China's industrial energy consumption and $33 \%$ of its total energy consumption. Importantly, since the policy was announced in 2006 and selected firms based on their retrospective 2004 energy consumption, it was not possible to manipulate the list of program participants. Moreover, the list of firms 
regulated by the program did not change during the five-year period. Table 1 reports the number of firms and their share of energy consumption in each of the regulated industries. Among Top 1,000 firms, those in the iron and steel, chemical, and electric power industries accounted for around $63 \%$ of the firms and $68 \%$ of the regulated energy consumption in 2005 .

The Top 1,000 program was designed based on the belief that Chinese industries could significantly increase energy efficiency at a low cost (e.g., McKinsey \& Co., 2009). The program was influenced by voluntary agreement programs in developed countries and had two stated goals: to significantly increase the energy efficiency of these super-firms and to save 100 million tce in energy consumption by 2011. Given the program's quick implementation, many aspects of voluntary agreement programs (such as providing technological expertise or financing energy efficiency improvements) played a relatively minor role (Price et al., 2010). In practice, firms were regulated based on energy use only and not on energy efficiency.

To implement the policy, the central government assigned a target reduction in energy use to each provincial government. In turn, local officials assigned individual quotas to each of the Top 1,000 firms. These firms were subject to annual energy audits carried out by a third party and also faced potential additional audits from the Ministry of Industry and Information Technology and the National Energy Administration. Leaders of provincial governments and state-owned enterprises were then evaluated on whether these energy saving targets were met. As a result, local government officials monitored and enforced the energy saving targets of Top 1,000 firms very closely. ${ }^{6}$ The effect of this strict supervision is evident in Table A.1, where we report the results of the government's annual assessment. This table shows a very high compliance rate. In fact, the total energy saving target was achieved in 2008, two years ahead of schedule. At the end of the 11FYP, the government estimated energy savings of 165.49 million tce, far beyond the original target of 100 million tons. ${ }^{7}$

Due to this perceived success under the 11FYP, the Top 1,000 program was expanded into the "Top 10,000" Energy Savings Program during the 12th Five-Year Plan (12FYP) in 2012. In this case, "Top 10,000" refers to 16,078 energy-intensive firms with energy consumption above 10 thousand tce in 2010. These firms account for $60 \%$ of China's total energy consumption. As in the Top 1,000 program, firms among the Top 10,000 were required to improve their energy efficiency with a goal of saving a total of 250 million tce during the 12FYP. Our primary analysis

\footnotetext{
${ }^{6}$ Under the "one-vote veto" criteria, officials would not be considered for promotions or awards if the province or any of the local Top 1,000 firms did not achieve their targets. Similarly, the leaders of state-owned enterprises that did not meet the target did not receive annual bonuses. In interviews with executives of Top 1,000 firms, we confirmed that local officials had the power to stop production at regulated firms if the firm did not meet its energy target. In this way, the Chinese setting contrasts with other developing country settings where the design of incentives for energy auditors plays a key role (e.g., Duflo et al., 2013, 2018).

${ }^{7}$ While government estimates of compliance may be subject to misreporting (Karplus et al., 2020), our analyses rely on multiple measures of output and energy use from survey and administrative data that are unrelated to the government's evaluation of the program.
} 
focuses on Top 1,000 firms between 2001 and 2011. Since the industrial firms in the Top 10,000 (but not in the Top 1,000) were also energy intensive but were not regulated during the 11FYP, they serve as useful controls for our empirical analysis. ${ }^{8}$

\section{$1.2 \quad$ Firm Data}

Our empirical analyses combine several rich datasets that describe production and energy use at these firms. The first dataset that we use is the list of firms in the Top 1,000 and Top 10,000 programs from the National Development and Reform Commission. We merge these lists with the Annual Survey of Industrial Firms (ASIF) from the National Bureau of Statistics (2001-2009 and 2011). ${ }^{9}$ This dataset provides detailed information on a firm's industry, address, ownership, output, and financial information and covers all industrial firms with annual revenue above 5 million RMB (approximately 800,000 USD).

We complement these data with two additional datasets. First, we collect detailed information on firm energy consumption from 2001 to 2010 from China's Environmental Statistics Database (CESD) provided by China's Ministry of Environmental Protection. The CESD data are subject to audits by environmental protection agencies at both local and national levels. Second, we merge data from the Annual Tax Survey (ATS) for 2009 and 2010. One advantage of using multiple datasets is that we can cross-check our data to ensure our results are not driven by misreporting or other data quality issues. In Figure A.1, we show that firms report similar output and coal consumption in the CESD and tax data, which are collected independently and are not used to evaluate compliance with energy and environmental policies.

Panel A of Table 2 reports summary statistics for the Top 1,000 and Top 10,000 firms in our sample. This sample includes about 8,700 observations for Top 1,000 firms and 81,000 observations for Top 10,000 firms over a period of 10 years. Our combined datasets therefore capture the majority of the economic activity in the Top 1,000 and Top 10,000 firms. Because the CESD reports energy consumption only from primary sources (e.g., coal, oil, gas), our analyses of energy use and energy efficiency exclude firms in industries that rely mainly on electricity. ${ }^{10}$ For this reason, the sample of firms with energy consumption data is smaller.

As we show in Panel A of Table 2, Top 1,000 firms are larger, older, more likely to be state owned, and more export oriented than Top 10,000 firms. This table also shows that Top 1,000

\footnotetext{
${ }^{8}$ An important consideration is whether firms that were later part of the Top 10,000 expected that the Top 1,000 program would be expanded. This is unlikely to be the case since the details of the program were developed after the 12FYP by the National Development and Reform Commission, which did not announce the Top 10,000 program until 2012.

${ }^{9}$ Appendix A describes our merged data. As is well known in the literature, data for the 2010 ASIF display a number of irregularities and are often excluded from statistical analyses. As we show below, our results are robust to using administrative tax data on production and energy use for 2009 and 2010.

${ }^{10}$ In practice, we exclude industries where electricity consumption accounts for more than $30 \%$ of total energy consumption. As we show below, our results are robust to setting this threshold to between $15 \%$ and $50 \%$.
} 
firms are slightly less energy efficient (defined as the ratio of output to energy use) than Top 10,000 firms. However, this difference is driven mostly by industry differences, since Top 1,000 firms are more likely to be in energy-intensive heavy industries. As we show below, our empirical analyses are robust to controlling for these firm-level characteristics. ${ }^{11}$

\subsection{Mapping Conglomerate Networks}

We identify firms' ownership networks using data from China's Administrative Registration Database (CARD). These data are collected by the State Administration of Industry and Commerce and list the registration information of all firms in China starting in 1980, including firm name, registration number, date of establishment, address, ownership, registered capital and related legal persons. Importantly, the data provide detailed shareholder information, which allows us to construct firm ownership networks at multiple levels.

We construct ownership networks using the four types of linkages displayed in Figure 2. First, we include wholly owned subsidiaries of regulated firms as related parties. Second, we include firms that are at least partially owned by regulated firms. We consider firms to be related if they are owned by a regulated firm by up to two levels of investment relations. Although in practice most related firms are fully owned, we require that the regulated firm own at least $25 \%$ of the related firm at each level of investment. Third, we include shareholders of regulated firms, and we allow up to two levels of shareholder links. Finally, we also include firms that are fully or partly owned by the shareholders of a regulated firm. ${ }^{12}$ We exclude firms that are related only through the state-owned management committee.

Panel B of Table 2 shows that we can identify 46,178 related parties of Top 1,000 firms in the CARD. Since a large number of related parties are service firms or small firms not recorded in the ASIF, we match 7,329 firms in the ASIF. In our baseline regressions, we require related firms to be in the same 4-digit industry as a related Top 1,000 firm. Our main sample of related firms includes 2,466 industrial firms. ${ }^{13}$ Since it is likely very hard to shift production to firms in other narrowly defined industries, we analyze firms within the same 2-digit industry but outside 4-digit industries in a placebo test. A potential concern with CARD data is that some of the related firms may not be engaged in production and may, in fact, be holding companies. By merging the CARD data with the ASIF and the CESD, we ensure that our results are driven by real economic activity in industrial firms.

Panel B of Table 2 also examines the robustness of our network definitions to alternative

\footnotetext{
${ }^{11}$ Section 4 shows that we can also identify the effects of the policy using a within-conglomerate difference-indifferences research strategy that compares firms with similar conglomerate-level characteristics.

${ }^{12}$ We again allow two levels of investment, and we require ownership to be at least $25 \%$ at each level. Figure A.2 depicts all the possible links that we consider.

${ }^{13}$ Omitting firms in unrelated industries is unlikely to affect our results since super-firms like Top 1,000 firms would not be able to shift production to service firms or very small firms.
} 
assumptions. Allowing for up to six levels of relations does not have a large effect on our sample of related firms in the same 4-digit industry. Decreasing the ownership requirements to $20 \%$ has a small effect on the number of related firms, and the number of related parties is similar when we increase the ownership ratio to $51 \%$. These results suggest that within narrowly defined industries, firm ownership networks are very compact. Importantly, our measure of firm networks uses data from 2018, after the policy was implemented. Therefore, our business networks include any firms that may have been acquired by regulated conglomerates as a result of the regulation. ${ }^{14}$ Moreover, it is important to note that regulated firms could not escape the regulation by splitting into smaller firms. Since local policymakers face regional energy use targets, they have strong incentives to ensure that any initially regulated firm meets its energy target. If firms split, the energy use targets would accompany the firms after any such separation.

The merged CARD and ASIF data reveal some interesting patterns. First, we find that Top 1,000 firms have an average of 2.45 related parties in narrowly defined industries. Second, since Top 1,000 firms are, in most cases, the largest firms in each industry, their related parties are smaller. On average, the output of related firms is $19.3 \%$ of the output of regulated firms. These facts imply that conglomerates may have had significant scope to substitute production across related firms. ${ }^{15}$ However, it is also unlikely that related parties could fully make up for production declines in Top 1,000 firms. Third, firms within conglomerates have an interesting relative size distribution. To produce Panel A of Figure 3, we compute each firm's size relative to the largest firm in the group; we then plot the average relative size by firm rank. A striking fact of this graph is that the average relative size within a conglomerate declines sharply with firm rank: the second-largest firm in a conglomerate is only $29 \%$ as large as the largest firm, on average. Interestingly, the decline in relative firm size is almost geometric, a fact that we use in our structural model. Finally, Panel B of Figure 3 shows the relation between the output of the largest firm and the number of firms in a conglomerate. The fact that conglomerates with more firms also have larger leading firms suggests that the number of firms in a conglomerate might depend on technological efficiencies shared by all firms in a conglomerate.

\footnotetext{
${ }^{14}$ Using the ownership change information in the CARD, we estimate that between 2007 and 2018 , less than $4 \%$ of related firms experienced significant ownership changes - defined as an ownership transfer of more than $25 \%$ to or from firms that are not in the same conglomerate.

${ }^{15}$ In Chen et al. (2021), we show that most related parties of regulated firms are located in the same province as the regulated firm. For this reason, we do not expect substitution of production across related parties to significantly affect the provincial distribution of energy use or related pollution. In Section 2 , we also show that the program did not significantly alter the allocation of production across cities with different levels of emissions and population density.
} 


\section{Effects of the Policy on Regulated Firms}

As detailed in Section 1, the Top 1,000 program mandated that firms reduce their energy use. To study the effects of the policy, we compare the activities of regulated firms relative to those of other large firms operating in energy-intensive industries. Specifically, we use firms that became regulated after 2011 as part of the Top 10,000 program as controls. Because related firms in the same conglomerate as a regulated Top 1,000 firm may be indirectly affected by the policy, we remove these firms from the set of control firms.

The identifying assumption of this difference-in-differences analysis is that absent the Top 1,000 regulation, the energy use and output of Top 10,000 firms would have trended similarly to those of Top 1,000 firms. To provide evidence that these firms had similar trends prior to the implementation of this regulation, we use firm data from the CESD to estimate an event-study analysis of the form:

$$
Y_{i j k t}=\sum_{\tau \neq 2006}^{2010} \beta_{\tau} \times \text { Treat }_{i} \times \text { Year }_{\tau}+\alpha_{i}+\eta_{j t}+\delta_{k t}+\varepsilon_{i j k t}
$$

where $Y_{i j k t}$ is a dependent variable for firm $i$ in industry $j$, province $k$ and year $t$. Treat is a treatment group indicator that equals 1 for Top 1,000 firms and 0 for Top 10,000 firms. The coefficients $\beta_{\tau}$ from this specification represent differences in the dependent variable between Top 1,000 and Top 10,000 firms in each year. Given that the policy evaluation began in 2007, we identify the effects of the policy relative to performance before 2006. We include firm-level fixed effects $\alpha_{i}$ and year fixed effects in all regressions, and we show that our result are robust to inclusion of (2-digit) industry-by-year fixed effects $\eta_{j t}$ and province-by-year fixed effects $\delta_{k t}$. We cluster standard errors at the firm level. ${ }^{16}$

Figure 4 presents a visual implementation of our difference-in-differences estimation strategy. Panel $\mathrm{A}$ in Figure 4 displays the $\beta_{\tau}$ coefficients when the outcome variable is firm-level energy use (total coal consumption equivalent). This figure shows that prior to the implementation of the regulation, our treatment and control firms had similar trends. Additionally, this figure makes clear that the policy did indeed succeed in lowering the energy use of regulated firms relative to that of unregulated firms. ${ }^{17}$ Panel B of this figure compares these year-by-year effects to the

\footnotetext{
${ }^{16}$ While the setting of the Top 1,000 program may seem amenable to a regression discontinuity design, in practice, there are few treated and control firms at the energy use threshold, which makes such an approach unfeasible.

${ }^{17}$ One potential concern is that our results may be contaminated by mean reversion. Because firms were regulated based on their 2004 energy use, one possibility is that regulated firms had idiosyncratically large levels of energy use in 2004 that reverted to lower levels in later years. As this and other similar graphs show, the outcomes for 2004 are not significantly different from those for 2001-2003, nor do we see large differences from the outcomes for 2005-2006.
} 
overall trend in energy consumption. ${ }^{18}$ As this figure shows, the program successfully arrested the explosive growth in the energy use of regulated firms.

We quantify the effects of the policy by estimating difference-in-differences specifications of the form:

$$
Y_{i j k t}=\beta \text { Treat }_{i} \times \text { Post }_{t}+X_{i t}^{\prime} \gamma+\alpha_{i}+\eta_{j t}+\delta_{k t}+\varepsilon_{i j k t},
$$

where Post $_{t}$ is an indicator that equals one after 2006. In addition to different fixed effects, some specifications control for firm characteristics $X_{i t}$, which include indicators for state-owned firms and exporting firms, measures of profitability (e.g., return on assets), and firm age. Panel A of Table 3 shows that on average, the total energy consumption of regulated firms decreased by 12\%-16\%. These estimates are stable across specifications that include different levels of fixed effects and firm controls. To interpret the magnitude of this effect, recall that regulated firms consumed 670 million tce in 2004. The coefficients in Table 3 therefore imply annual reductions in energy use of close to 100 million tce, or about $20 \%$ of the total industrial energy use of the European Union.

To discern whether this reduction in energy use was driven by changes in economic activity or in energy efficiency, we now estimate the effects of the program on firm output (i.e., revenue). Panels C-D of Figure 4 show that after the reform, firm output in regulated firms also decreased significantly. Indeed, Panel B of Table 3 reports declines in output of between $10 \%$ and $23 \%$, depending on the specification. Accounting for the declines in output implies that the policy had limited impacts on energy efficiency. Panels E-F of Figure 4 show that we cannot reject the null hypothesis that the policy had no impact on energy efficiency. Based on the specification with both industry- and province-by-year fixed effects of Panel C of Table 3, the 95\% confidence interval rules out that the policy increased energy efficiency by more than $4 \%$, which is significantly below the government's goal of improving energy efficiency by $20 \%$. Contrary to the hypothesis that there was "low-hanging fruit" to be harvested in terms of energy efficiency, our results show that over a period of five years, regulated firms were not able to significantly improve their energy efficiency.

We now explore the robustness of the effects of the Top 1,000 program on regulated firms. First, as we discuss in Section 1, these analyses exclude industries that rely primarily on electricity. Table A.3 shows that our results are robust to excluding more or fewer industries based on their electricity use. Second, our results are robust to the sample of firms in our regression and to the exclusion of new firms and those that exit during our sample period. ${ }^{19}$ Third, one

\footnotetext{
${ }^{18}$ For visual clarity, Panels B, D, and F in Figure 4 follow Ohrn (2018) by plotting trends for the control group that have the same average level in the preperiod as the treated group.

${ }^{19}$ Table A.4 shows that the effects of the program on regulated firms are robust to narrowing the sample to include only firms that existed before 2006 and after 2010. Table A.5 shows that our results are also robust to using an almost-balanced panel where we require that firms have no more than one missing year in the data. Note
} 
potential concern is that our results may be influenced by other, concurrent policies. Appendix $\mathrm{B}$ clarifies that this is not the case by showing that our estimates are independent of the effects of other pollution monitoring policies. As we show in Table A.6, these policies did not significantly impact the operations of Top 1,000 firms, and our results are robust to excluding firms that are part of these other programs. Finally, we explore the potential for heterogeneous effects across industries. Given the small number of regulated firms in each industry, we estimate heterogeneous effects across broad industry groups. Table A.7 shows similar effects of the program across different industry groups. ${ }^{20}$

The effects of the policy on regulated firms paint a picture of mixed success. On the one hand, the regulation succeeded in achieving a meaningful reduction in the energy use of energyintensive firms. However, this reduction did not come about through a significant increase in energy efficiency, which - while not directly targeted - was one of the underlying intents of the policy. The next section studies whether conglomerates avoided the burden of the regulation by shifting economic activity to related parties.

\section{Spillover Effects of the Policy through Ownership Networks}

Regulated firms have strong incentives to shift production to related parties. By shifting production, conglomerates can partially offset declines in economic activity in regulated firms. Such shifting also allows conglomerates to comply with the letter of the regulation-if not with its intent - without having to invest in potentially costly improvements to energy efficiency.

To measure the empirical importance of conglomerate spillovers, we use CARD data on the ownership networks of regulated firms to identify firms that may have indirectly expanded as a consequence of the Top 1,000 regulation. We then use matching methods to identify control firms that were (1) not part of the Top 1,000 program, (2) not related to a regulated firm, and (3) in the same industry and of similar size (measured in output) in the years prior to the regulation. Using these firms as controls, we then conduct event-study and difference-in-differences analyses using specifications similar to those in Equations (1) and (2). ${ }^{21}$ In this setting, the Treat $_{i}$ variable is now an indicator of whether a firm is related to a Top 1,000 firm. As we discuss in Section 1,

that due to the survey nature of the CESD data, our sample is substantially smaller in this case. Nonetheless, these results show that our estimates are not driven by firms entering the sample or ceasing operations.

${ }^{20}$ We also explore the effects of the program on other outcomes. In Table A.8 and Figure A.3, we show that regulated firms experienced a decline in the probability of investing after the regulation was enacted. Additionally, we test the Porter and van der Linde (1995) hypothesis by examining whether firms became more innovative after the regulation. Figure A.4 shows no increase in the filing of patents related to energy efficiency in regulated firms.

${ }^{21}$ Specifically, we use one-to-one matching within 4-digit industries based on the Euclidean distance in output levels before the policy. To ensure that matches are comparable to related firms, we drop $5 \%$ of observations with the least comparable matches. As we show below, our results are robust to using alternative matching methods. 
we focus our study of spillovers on related firms in the same 4-digit industry as the regulated firm. This restriction follows from the logic that only firms selling products similar to those of the regulated firms may be able to make up for the production decline in Top 1,000 firms.

Figure 5 plots the results of these event-study analyses using ASIF data. Panel A shows that prior to the regulation, related firms had output trends similar to those of unrelated firms. After the regulation, firms related to Top 1,000 firms saw significant increases in output that persisted for several years. The last column of Panel A of Table 4 shows that related firms expanded by $13 \%$, on average, after the regulation. This table also shows that we obtain very similar results across specifications with different levels of fixed effects and with firm-level controls.

To gauge the magnitude of these spillover effects, it is important to account for the number of related parties of each regulated firm and for their relative size. On average, Top 1,000 firms have 2.45 related parties. However, since the average related firm is only $19.3 \%$ as large as its regulated counterpart, we calculate that conglomerates could only shift close to $41 \%$ of the output decline in regulated firms. ${ }^{22}$ This result is informative for a couple of reasons. First, this result shows that conglomerates were not able to fully circumvent the regulation. Second, combined with the null effect of the program on the energy efficiency of regulated firms, this result shows that firms were unable or unwilling to increase their energy efficiency in production processes even if this meant losing profits to competitors.

The result that related firms display an increase in economic activity is robust to a number of checks. First, we show that we obtain similar results when we use the entropy balancing method of Hainmueller (2012) to find controls for related firms (see Figure A.5 and Tables A.9-A.10). ${ }^{23}$ Second, we show that only those related firms operating in regulated firms' own narrowly defined industries - and that could thus possibly produce substitute output - increased their economic activity. Indeed, Panel B of Figure 5 and Panel B of Table 4 show no impact on the output of related firms operating outside the 4-digit industry of the regulated firm (but still in the same 2-digit industry). This placebo test rules out the possibility that firms related to large conglomerates saw increases in economic activity after 2007, say, in response to the financial crisis or other shocks or trends. Third, these results are robust to alternative definitions of ownership networks. Table A.11 shows similar spillover effects when we drop related firms

\footnotetext{
${ }^{22}$ Using the estimate on related firms from column (4) of Panel A of Table 4 of $12.7 \%$, we calculate that the overall increase in related firms amounted to $6 \%(\approx 2.45 \times 19.3 \% \times 12.7 \%)$ of the output of regulated firms. This increase is $41 \%$ of the comparable $14.5 \%$ decrease from column (4) of Panel B of Table 3. Using estimates from the specifications in columns (3), we obtain an estimate of $27 \%$. (i.e., $27 \% \approx 2.45 \times 19.3 \% \times 11.8 \% / 20.4 \%$ ). We can also gauge the sensitivity of this estimate to the measurement of business networks. Supposing that regulated firms had an average of 3 related firms, spillovers would account for $51 \%$ of the output decline in regulated firms.

${ }^{23}$ Our estimates of spillover effects are also not driven by the entry and exit of related firms. To find a suitable control, our matching analysis requires firms to have existed prior to 2006. Moreover, because we map business networks in 2018, our estimates include the effects on firms that joined regulated business groups after the program.
} 
with ownership changes between 2007 and 2018, when we restrict the sample by requiring 51\% ownership at each link, and when we expand the sample to include 6 levels of relations and $20 \%$ ownership stakes. Fourth, these results are robust to dropping firms in power generation (see Table A.12 and Figure A.6). Finally, we assuage concerns that our results may be affected by data quality issues by showing similar effects when we rely on tax data to measure the output of related firms (see Figure A.7 and Table A.13). ${ }^{24}$

We now explore the potential for heterogeneous spillovers across related firms. Panel $\mathrm{C}$ of Table 4 shows that related firms in higher terciles of the size distribution display larger increases in output. This result suggests that larger related firms were more able to expand or, alternatively, that these firms had larger installed production capacity. As in our analysis of regulated firms, we explore potential heterogeneous effects across industries. Table A.15 shows no significant differences in how related firms in different industries responded to the program. Finally, we explore the possibility that the regulation shifted economic production and related emissions to more populated or more polluted areas. As we show in Appendix C, the spillover effects of the regulation do not disproportionately shift production to areas with higher population density or with higher preexisting levels of industrial emissions.

Having established that conglomerates shifted output across related parties, we now explore whether these firms also saw changes in energy use and energy efficiency. Panels $\mathrm{C}$ and $\mathrm{D}$ of Figure 5 report these results using data from the CESD. Panel C shows that related firms saw an increase in energy use after the regulation. Panel A of Table 5 shows that energy use in related firms increased by 30\%-32\% after the regulation. Note that the number of observations in this panel is smaller than that in Panel A of Table 4. This is because related firms are overall smaller and only the larger related firms are included in the CESD. These larger effects are consistent with our results in Panel $\mathrm{C}$ of Table 4 showing larger spillover effects on larger related firms. While the available data include firms across all affected industries, caution is warranted in ascribing these increases in energy use to all related firms. Panel D of Figure 5 and Panel $\mathrm{B}$ of Table 5 show that these firms did not experience statistically significant changes in energy efficiency.

Overall, we find robust evidence that conglomerates shifted production across related parties. On average, this shifting behavior allowed conglomerates to recover about $40 \%$ of the output reduction in regulated firms. As we show in Section 6, the ability to shift production to related firms diminishes the aggregate energy savings and lowers the shadow cost of the regulation.

\footnotetext{
${ }^{24}$ We also find positive spillover effects on other measures of economic activity. Table A.14 shows estimates of positive spillover effects on sales, profits, capital and labor (see Figure A.8 for corresponding event studies).
} 


\section{Market-level Spillovers}

Since related parties could not make up the entire output loss of Top 1,000 firms, other firms in regulated industries may have been indirectly affected by the energy saving program due to reduced competition. To examine this indirect effect of the regulation, we estimate the following difference-in-differences specification:

$$
Y_{i j t}=\beta \text { spillover }_{j} \times \text { Post }_{t}+X_{i t}^{\prime} \gamma+\alpha_{i}+\tau_{t}+\varepsilon_{i j t}
$$

where spillover $_{j}$ is the proportion of the total energy saving targets of Top 1,000 firms for industry $j$ in total energy consumption of industry $j$ in 2004. To interpret the coefficient $\beta$ as the average spillover effect, we normalize the spillover $_{j}$ variable by the average exposure across regulated industries. Since the variation in the independent variable is at the industry-year level, we do not include industry-by-year fixed effects in this regression. We instead use firm fixed effects and year fixed effects only and we additionally control for overall output and energy use at the industry-year level. ${ }^{25}$ Finally, to ensure that market-level spillovers are not contaminated by ownership-network spillovers, we exclude firms related to Top 1,000 firms from this specification.

Figure 6 shows that unregulated firms in industries with stricter regulation increased their output significantly after the policy was implemented. Table 6 shows that across all industries, the average market-level spillover led to a $7 \%-8 \%$ increase in the output of unregulated firms. The regressions in the first two columns of this table include both regulated and unregulated industries. We find similar increases (8\%) when we include only firms in regulated industries. In this case, the identifying variation is driven solely by differences in regulation intensity across industries. ${ }^{26}$

These results yield a couple of insights. First, the findings further confirm our previous estimates that related parties were not able to make up for the full output loss of Top 1,000 firms. Second, a full accounting of the spillover effects of the regulation needs to include both withinconglomerate spillovers and market-level spillovers. Third, a potential limitation of the differencein-differences analyses is that their interpretation depends on the strength of conglomerate and market spillovers. The next section builds on these insights by proposing a model of conglomerate production. The model clarifies the interpretation of our reduced-form estimates in the presence of market and conglomerate spillovers, computes the aggregate effects of the Top 1,000 program, and allows us to consider the effects of alternative policies.

\footnotetext{
${ }^{25}$ Note that the variation in spillover $_{j}$ is absorbed in our previous specifications that include industry-by-year fixed effects. By controlling for industry-level aggregates, the coefficient $\beta$ in Equation 3 captures the impact of the regulation on the market share of unregulated firms.

${ }^{26}$ As with our previous analyses, we confirm that our results are not driven by firm entry. Specifically, in Table A.16, we report similar estimates of market-level spillovers when we restrict the sample to firms in operation prior to 2006.
} 


\section{A Model of Conglomerates with Regulation}

This section presents an industry equilibrium model of conglomerate production that is consistent with the cross-sectional data patterns and reduced-form responses to the policy of energy regulation. Appendix D provides detailed derivations of the model results.

\subsection{Demand and Technology}

Our industry equilibrium model draws the structure of product differentiation and monopolistic competition from Melitz (2003). We consider an individual sector with an exogenous aggregate expenditure $R$. The representative consumer has CES preferences over a continuum of varieties $\omega \in \Omega:$

$$
U=\left[\int_{\omega \in \Omega} q(\omega)^{\rho} d \omega\right]^{1 / \rho},
$$

where $q(\omega)$ represents the consumption level of variety $\omega$ and $\sigma=1 /(1-\rho)>1$ denotes the elasticity of substitution between varieties. ${ }^{27}$

Utility maximization by the representative consumer yields the following residual demand curve for each variety $\omega$ :

$$
q(\omega)=R P^{\sigma-1} p(\omega)^{-\sigma},
$$

where $P=\left[\int_{\omega \in \Omega} p(\omega)^{1-\sigma} d \omega\right]^{\frac{1}{1-\sigma}}$ is the aggregate price index. ${ }^{28}$

We define a conglomerate in our model by the presence of a variety $\omega$ that can be manufactured by multiple affiliates. ${ }^{29}$ Each conglomerate starts with a central producer - the model counterpart of a Top 1,000 firm. Conglomerates have heterogeneous production efficiencies $\phi$, which are drawn from the distribution $G(\phi)$ with density $g(\phi)$.

Production at each affiliate $i$ requires capital $k_{i}$, energy $e_{i}$, and variable inputs $l_{i}$. Energy and variable inputs are combined using Leontief technology $\tilde{l}_{i}=\min \left\{l_{i}, e_{i} \nu_{i}\right\}$, where $\nu_{i}$ is the affiliate's energy efficiency. The assumption that energy and variable inputs are perfect complements follows recent work in this area (e.g., van Biesebroeck, 2003; Fabrizio et al., 2007; Gao and Van Biesebroeck, 2014; Ryan, 2018). ${ }^{30}$ Production at affiliate $i$ is then $q_{i}=\phi_{i} \tilde{l}_{i}^{\alpha_{l}} k_{i}^{\alpha_{k}}$, which is

\footnotetext{
${ }^{27}$ Since the regulated firms produce raw and intermediate materials, one can view the representative consumer as a stand-in for the downstream industry.

${ }^{28}$ This market structure implicitly assumes that this industry is not characterized by dominant firms that may act strategically. This is a reasonable assumption in our setting since we study manufacturing industries that, even when narrowly defined, feature a large number of firms and that serve a national market.

${ }^{29}$ This assumption implies that the outputs of related firms are perfect substitutes. We relax this assumption in Section 7.4, where we allow the outputs of related firms to be imperfect substitutes.

${ }^{30}$ Fabrizio et al. (2007); Gao and Van Biesebroeck (2014) adopt this assumption from van Biesebroeck (2003) in the context of energy generation. Gao and Van Biesebroeck (2014) study the case of China. Ryan (2018) estimates a production function with energy using data from India and finds that energy and unskilled labor are close to being perfect complements.
} 
subject to decreasing returns to scale, i.e., $\alpha=\alpha_{k}+\alpha_{l}<1$. The decreasing-returns-to-scale assumption is consistent with the literature on span of control. Intuitively, conglomerates may operate more firms as a way to escape decreasing returns to scale and as a way to share production knowledge $\phi$ across firms. However, as we show in Panel A of Figure 3, conglomerates are not able to replicate the same scale across related firms. To match this fact, we assume that the productivity of the $i^{\text {th }}$ affiliated firm is $\delta^{i-1} \phi$. This assumption can be interpreted as either a limit on the span of managerial control or as a measure of imperfect knowledge-sharing across firms. Finally, each manufacturing establishment incurs a fixed outlay of capital denoted by $f$. This assumption is motivated by the fact that conglomerates have a finite number of affiliates.

We consider the conglomerate's problem in two stages. Prior to the regulation, conglomerates observe their productivity $\phi$ and optimally choose the number of affiliated firms $n$ and the amount of capital $\left\{k_{i}\right\}_{i=1}^{n}$ and variable inputs $\left\{l_{i}\right\}_{i=1}^{n}$ for each affiliate. ${ }^{31}$ After the regulation, since capital is quasifixed, the conglomerate adjusts its variable inputs to maximize profits. We initially assume energy efficiency is constant and fixed (i.e., $\nu_{i}=1$ for all firms) but consider costly investments to improve energy efficiency and heterogeneous efficiencies in Sections 7.1 and 7.2.

\subsection{Profit Maximization}

The conglomerate takes the prices of energy $p_{e}$, capital $r$, and the variable input bundle $w$ as given. Given the Leontief technology, the conglomerate sets $l_{i}=e_{i}$ so that the cost of intermediate inputs is $w+p_{e}$. Holding the number of affiliates $n$ constant, the conglomerate maximizes

$$
\pi(\phi, n)=\max _{\left\{l_{i}\right\}_{i=1}^{n},\left\{k_{i}\right\}_{i=1}^{n}}\left\{R^{1-\rho} P^{\rho}\left[\sum_{i=1}^{n} \phi \delta^{i-1} k_{i}^{\alpha_{k}} l_{i}^{\alpha_{l}}\right]^{\rho}-\left(w+p_{e}\right) \sum_{i=1}^{n} l_{i}-r \sum_{i=1}^{n} k_{i}\right\} .
$$

For a firm $i$, the first-order conditions for $l_{i}$ and $k_{i}$ imply that $l_{i}=\frac{\alpha_{l}}{\alpha_{k}} \frac{r}{\left(w+p_{e}\right)} k_{i}$. Substituting this expression and comparing the first-order conditions for $k_{1}$ and $k_{i}$, we obtain the following result.

Proposition 1 (Within-Conglomerate Distribution). Absent regulation, the inputs and the output of producers in a conglomerate follow a decreasing geometric sequence given by

$$
\frac{q_{i}}{q_{1}}=\frac{k_{i}}{k_{1}}=\frac{l_{i}}{l_{1}}=\frac{e_{i}}{e_{1}}=\delta^{\frac{i-1}{1-\alpha}} .
$$

The within-conglomerate distribution described in Proposition 1 is broadly consistent with the empirical pattern in Panel A of Figure 3, where the average output of the second-largest affiliate in a conglomerate is less than $30 \%$ of that of the largest one and where the output of other affiliated producers in the conglomerate decreases exponentially with their rank $i$. Equation 5 links this distribution to two model parameters. First, the size gap among affiliates is larger if

\footnotetext{
${ }^{31}$ Conglomerates can choose $n=0$, which we interpret as an exit decision.
} 
within-group knowledge depreciation is more severe (lower $\delta$ ). Second, if firms are closer to having constant-returns-to-scale production ( $\alpha$ is closer to one), the conglomerate concentrates more activity in its top producer, which increases the dispersion of the within-group size distribution.

To consider the choice of total capital $K_{n}=\sum_{i}^{n} k_{i}$, define the conglomerate's total productivity $\phi \Delta_{n}=\phi\left[\sum_{i=1}^{n}\left(\delta^{i-1}\right)^{\frac{1}{1-\alpha}}\right]^{1-\alpha}$ and the constant $C_{\pi}=(1-\alpha \rho)\left[\left(\frac{\rho \alpha_{l}}{w+p_{e}}\right)^{\alpha_{l} \rho}\left(\frac{\rho \alpha_{k}}{r}\right)^{\alpha_{k} \rho}\right]^{\frac{1}{1-\alpha \rho}}$. We reformulate Equation 4 using the results of Proposition 1 so the optimal choice of capital $K_{n}$ solves

$$
\pi(\phi, n)=\max _{K_{n}}\left\{\frac{R^{1-\rho} P^{\rho} C_{\pi}^{1-\alpha \rho}}{(1-\alpha \rho)^{1-\alpha \rho}}\left(\frac{\rho \alpha_{k}}{r}\right)^{-\alpha \rho}\left(\phi \Delta_{n}\right)^{\rho} K_{n}^{\alpha \rho}-r\left(\frac{\alpha}{\alpha_{k}}\right) K_{n}\right\} .
$$

The optimal capital $K_{n}$ and the firm profits for a conglomerate of size $n$ are then

$$
K_{n}=\frac{R^{\frac{1-\rho}{1-\alpha \rho}} P^{\frac{\rho}{1-\alpha \rho}} C_{\pi}}{(1-\alpha \rho)} \frac{\rho \alpha_{k}}{r}\left(\phi \Delta_{n}\right)^{\frac{\rho}{1-\alpha \rho}} \quad \text { and } \quad \pi(\phi, n)=R^{\frac{1-\rho}{1-\alpha \rho}} P^{\frac{\rho}{1-\alpha \rho}} C_{\pi}\left(\phi \Delta_{n}\right)^{\frac{\rho}{1-\alpha \rho}}
$$

Consider now the optimal number of affiliates. The conglomerate adds an affiliate if

$$
\pi(\phi, n+1)-\pi(\phi, n)-f r=R^{\frac{1-\rho}{1-\alpha \rho}} P^{\frac{\rho}{1-\alpha \rho}} C_{\pi} \times\left[\left(\phi \Delta_{n+1}\right)^{\frac{\rho}{1-\alpha \rho}}-\left(\phi \Delta_{n}\right)^{\frac{\rho}{1-\alpha \rho}}\right]-f r>0 .
$$

Adding a new affiliate can improve the conglomerate's revenue and profit by lowering its overall marginal cost curve. On the other hand, the conglomerate incurs a fixed cost of $f r$ when adding a new affiliate. While the marginal benefit of adding a new affiliate is increasing in $\phi$, it is also decreasing in the number of existing affiliates $n$. Since the fixed cost is the same for all affiliates, Equation 6 guarantees the existence of a cutoff value $\phi_{n}$, where conglomerates with efficiency $\phi>\phi_{n}$ operate at least $n$ affiliated producers.

Proposition 2 (Optimal Conglomerate Size). Without regulation, the optimal number of firms in a conglomerate $n$ is nondecreasing in its fundamental efficiency $\phi$. For $n>1$, a conglomerate chooses to have $n$ affiliated producers when $\phi_{n} \leq \phi<\phi_{n+1}$, where

$$
\phi_{n+1}=\frac{(f r)^{\frac{1-\rho \alpha}{\rho}}}{R^{\frac{1-\rho}{\rho}} P C_{\pi}^{\frac{1-\rho \alpha}{\rho}}\left(\Delta_{n+1}^{\frac{\rho}{1-\rho \alpha}}-\Delta_{n}^{\frac{\rho}{1-\rho \alpha}}\right)^{\frac{1-\rho \alpha}{\rho}}} .
$$

Let $\pi(\phi)=\max _{n} \pi(\phi, n)-n f r$ be the profit for a conglomerate of efficiency $\phi$ at the optimal number of affiliates. The prediction from Proposition 2 is consistent with the observation in Panel B of Figure 3 that conglomerates with higher efficiency have, on average, a larger number of affiliated firms.

\subsection{Equilibrium and Welfare}

The unique equilibrium of the model is characterized by product-market clearing, the zero cut-off profit condition, and the free entry condition. 
With $M$ denoting the mass of active firms, the aggregate price index is given by

$$
P=\left[\int_{\phi_{1}}^{\infty} p(\phi)^{1-\sigma} \frac{g(\phi) M}{1-G\left(\phi_{1}\right)} d \phi\right]^{\frac{1}{1-\sigma}} .
$$

Conglomerates operate whenever

$$
\pi(\phi) \geq 0 \Rightarrow \phi \geq \phi_{1}=\frac{(f r)^{\frac{1-\rho \alpha}{\rho}}}{R^{\frac{1-\rho}{\rho}} P C_{\pi}^{\frac{1-\rho \alpha}{\rho}}} .
$$

Equation 9 shows that only firms with $\phi>\phi_{1}$ choose to participate in the market. ${ }^{32}$

To enter the market, an entrepreneur pays an entry cost $r f_{e}$. Upon entry, the efficiency of the conglomerate $\phi$ is realized. Since the conglomerate operates only if $\phi>\phi_{1}$, the free entry condition is given by

$$
\int_{\phi_{1}}^{\infty} \pi(\phi) g(\phi) d \phi-r f_{e}=0 .
$$

An equilibrium is given by the exit threshold $\phi_{1}$ and the mass of active conglomerates $M$ such that (1) conglomerates make optimal allocation and size decisions, (2) the product market clears, and (3) the zero profit and free entry conditions (Equations 9-10) are satisfied.

Welfare depends on consumption utility and on the utility costs of carbon emissions from energy use. The CES preferences of the representative consumer imply that indirect utility is given by $\frac{R}{P}$, where $R$ is total expenditure. Utility is decreasing in total emissions $\beta E$, where $E$ denotes aggregate energy use and $\beta$ captures the carbon dioxide emitted per unit of energy. We assume that welfare takes the form

$$
W=\left(\frac{R}{P}\right)^{1-\kappa}\left(\frac{1}{\beta E}\right)^{\kappa},
$$

where the parameter $\kappa$ captures the social welfare losses from emissions. ${ }^{33}$

\subsection{Effects of the Top 1,000 Program}

We denote outcomes in the unregulated equilibrium with an asterisk to differentiate them from those in the regulated equilibrium. Since the Top 1,000 program targeted very large firms, we assume that only conglomerates with $\phi$ above an efficiency level $\tilde{\phi}$ are subject to the regulation. The regulation sets a proportional input quota for the largest firm in each conglomerate, which is the model counterpart of a Top 1,000 firm. Specifically, the energy use of regulated firms cannot exceed $\bar{e}_{1}(\phi)=\xi e_{1}^{*}(\phi)$, where $\xi<1$ and $e_{1}^{*}$ is the unregulated optimal energy use. At the time of

\footnotetext{
${ }^{32} \phi_{1}$ is the minimum efficiency for a single-firm conglomerate, so that $\pi\left(\phi_{1}\right)=0$.

${ }^{33}$ See Shapiro (2021) for a similar formulation of social welfare. Since we find that the regulation does not significantly shift the geographic distribution of energy use, our welfare measure does not account for the location of emissions (e.g., as in Shapiro, 2016).
} 
the regulation, the conglomerate's capital allocations $\left\{k_{i}^{*}\right\}_{i=1}^{n}$ are quasifixed, but it can respond by adjusting its use of inputs $\left\{l_{i}, e_{i}\right\}_{i=1}^{n}$. Our model characterizes firm-level, conglomerate-level, and industry-wide effects of the program.

We first study how the regulation impacts firm-level production decisions. To do so, we substitute the result from Proposition 1 that $k_{i}=\delta^{\frac{i-1}{1-\alpha}} k_{1}$ into Equation 4 , define $\phi^{*}=\phi\left(k_{1}^{*}\right)^{\alpha_{k}}$, and let $\lambda$ be the Lagrange multiplier associated with the regulatory constraint. ${ }^{34}$ The first-order conditions for $l_{i}(1 \leq i \leq n)$ are then

$$
\frac{\partial \pi}{\partial l_{i}}=\underbrace{R^{1-\rho} P^{\rho}}_{\text {Market Demand }} \underbrace{\rho\left[\phi^{*} \sum_{i=1}^{n} \delta^{\frac{(i-1)\left(1-\alpha_{l}\right)}{1-\alpha}} l_{i}^{\alpha_{l}}\right]^{\rho-1}}_{\text {Residual Revenue }} \underbrace{\phi^{*} \delta^{\frac{(i-1)\left(1-\alpha_{l}\right)}{1-\alpha}} \alpha_{l}\left(l_{i}\right)^{\alpha_{l}-1}}_{\text {Marginal Product }}=w+p_{e}+\underbrace{\lambda(\phi) \mathbb{I}[i=1]}_{\begin{array}{c}
\text { Shadow Cost } \\
\text { of Regulation }
\end{array}}
$$

An important insight of this expression is that conglomerates internalize the marginal product of inputs across firms through the residual revenue term, which is common to all firms in the conglomerate. The impact of energy regulations on the residual revenue term is key to understanding the difference between within-conglomerate and market-level spillovers.

This equation shows that the regulation distorts the allocation of inputs within a conglomerate by adding a shadow cost $\lambda(\phi)$ to the input of the regulated firm. Because conglomerates with more affiliates can shift more production to related parties, conditional on being regulated, more efficient conglomerates (those with a higher $\phi$ ) are subject to a smaller shadow cost $\lambda(\phi)$. Since only conglomerates with $\phi>\tilde{\phi}$ are part of the Top 1,000 program, the regulation also distorts input use across conglomerates.

The following proposition shows that the regulation leads conglomerates to allocate more inputs to the unregulated firms than in the case without the regulation.

Proposition 3 (Within-Conglomerate Distribution under Regulation). Under the Top 1,000 regulation, the inputs and the output of producers follow the sequences given by

$$
\begin{gathered}
\frac{e_{j}}{e_{2}}=\frac{l_{j}}{l_{2}}=\frac{q_{j}}{q_{2}}=\delta^{\frac{j-2}{1-\alpha}} \text { for } j>2, \\
\frac{e_{i}}{e_{1}}=\frac{l_{i}}{l_{1}}=\delta^{\frac{i-1}{1-\alpha}} \times\left[1+\frac{\lambda(\phi)}{w+p_{e}}\right]^{\frac{1}{1-\alpha_{l}}} \text { and } \frac{q_{i}}{q_{1}}=\delta^{\frac{i-1}{1-\alpha}} \times\left[1+\frac{\lambda(\phi)}{w+p_{e}}\right]^{\frac{\alpha_{l}}{1-\alpha_{l}}} \text { for } i>1 .
\end{gathered}
$$

Even though conglomerates substitute production across firms, the regulation leads to an overall reduction in the conglomerate's output. The following proposition describes the conglomeratelevel effects of the regulation on output and energy use.

\footnotetext{
${ }^{34}$ Note that $k_{1}^{*}=K_{n}^{*}\left(\Delta_{n}\right)^{\frac{-1}{1-\alpha}}$.
} 
Proposition 4 (Conglomerate-level Distortions from the Regulation). Under the Top 1,000 regulation, the energy use $e(\phi, n)$ and the output $q(\phi, n)$ of regulated conglomerates are given by

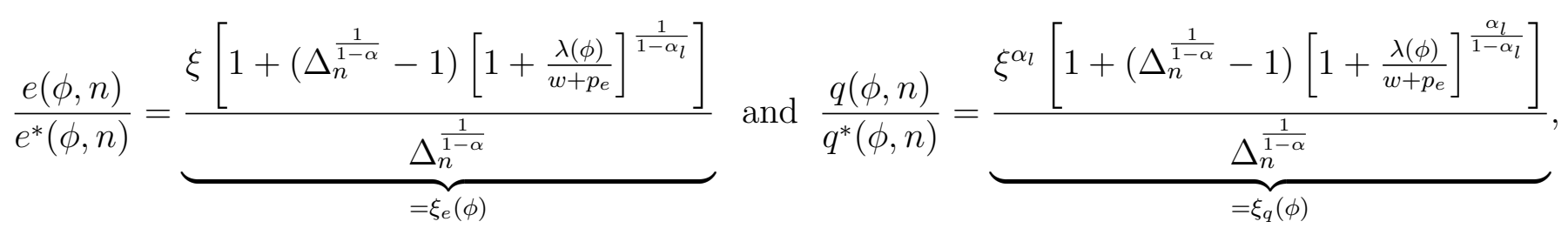

where $e^{*}(\phi, n)$ and $q^{*}(\phi, n)$ are the unregulated counterparts of energy use and output and where $\xi_{e}(\phi)$ and $\xi_{q}(\phi)$ describe the effective input and output wedges.

The term $\xi_{e}(\phi)$ captures the net effect on energy use by combining the reduction in energy use at the regulated firm $(\xi)$ with the increase in related firms, which is governed by $\lambda(\phi)$. The denominator follows from the insight of Proposition 1 that in the unregulated case, the conglomerate-level input and output are $\Delta_{n}^{\frac{1}{1-\alpha}}$ times the input and output of the largest firm. The term $\xi_{q}(\phi)$ has a similar intuition, and it translates the effects of input changes on output through the exponent $\alpha_{l}$.

We now characterize the equilibrium effects of the regulation.

Proposition 5 (Equilibrium under Regulation). The equilibrium price level under the Top 1,000 regulation solves the following system of nonlinear equations:

$$
\begin{aligned}
\left(\frac{P}{P^{*}}\right)^{-\rho} & =\left(1-s_{\tilde{\phi}}\right)\left(\frac{P}{P^{*}}\right)^{\frac{\alpha_{l} \rho^{2}}{1-\alpha_{l} \rho}}+s_{\tilde{\phi}} \mathbb{E}_{e}\left[\xi_{q}(\phi)^{\rho} \mid \phi>\tilde{\phi}\right] \\
1+\frac{\lambda(\phi)}{w+p_{e}} & =(\xi)^{\alpha_{l}-1}\left(\frac{P}{P^{*}}\right)^{\rho} \xi_{q}(\phi)^{\rho-1},
\end{aligned}
$$

where $s_{\tilde{\phi}}$ is the share of energy in regulated conglomerates prior to the regulation and $\mathbb{E}_{e}$ denotes the expectation with respect to the energy-use distribution from the unregulated equilibrium. Additionally, the aggregate change in energy use is given by

$$
\frac{E}{E^{*}}=\left(1-s_{\tilde{\phi}}\right)\left(\frac{P}{P^{*}}\right)^{\frac{\rho}{1-\alpha_{l} \rho}}+s_{\tilde{\phi}} \mathbb{E}_{e}\left[\xi_{e}(\phi) \mid \phi>\tilde{\phi}\right] .
$$

Equation 13 shows that the equilibrium price depends on two forces. First, prices increase as regulated firms reduce their output by $\xi_{q}(\phi)$. Second, unregulated firms respond to this price increase by increasing their output. The relative importance of these forces depends on the share of energy in regulated conglomerates $s_{\tilde{\phi}}$.

Equation 14 describes the shadow cost of the regulation in terms of the equilibrium price effect $\frac{P}{P^{*}}$ and the conglomerate-level output wedge $\xi_{q}(\phi)$. This equation follows from the firstorder conditions of both the regulated and unregulated cases and from the results of Proposition 3. Given $\frac{P}{P^{*}}$, Equation 14 and Proposition 4 define an implicit function for $\lambda(\phi)$. Interestingly, 
the shadow cost $\lambda(\phi)$ and the conglomerate-level wedge $\xi_{q}(\phi)$ are step functions of $\phi$. While these functions depend on the number of affiliates in a conglomerate $n$, they are constant across conglomerates of the same size but with different values of $\phi .^{35}$ Intuitively, this result is a consequence of the fact that the energy cap in the regulation is proportional to the firm's prior energy use, which itself depends on $\phi$.

The equilibrium under the regulation is then determined by a single shadow cost for every value of $n$ along with the equilibrium price $\frac{P}{P^{*}}$, which greatly facilitates the computation of the new equilibrium. Equation 15 then shows that the equilibrium effect on energy depends on the net change in conglomerate energy use $\xi_{e}(\phi)$ and the market leakage to unregulated firms.

These results characterize the welfare effects of the program since Equation 11 implies that

$$
\frac{d \ln W}{1-\kappa}=-\ln \left(\frac{P}{P^{*}}\right)-\frac{\kappa}{1-\kappa} \ln \left(\frac{E}{E^{*}}\right) .
$$

Propositions 4 and 5 show that the equilibrium effects of the regulation on the industry-level price $\frac{P}{P^{*}}$ and on aggregate energy use $\frac{E}{E^{*}}$ are closely related to the conglomerate-level distortions $\left(\xi_{q}(\phi)\right.$ and $\left.\xi_{e}(\phi)\right)$, which themselves depend on the shadow cost to regulated firms $\lambda(\phi)$. As we show in Section 6, these model quantities are closely related to our empirical estimates from Section 2-3. This framework also allows us to study the effects of alternative policies. For instance, a universal energy tax would have $s_{\tilde{\phi}}=1$ and a constant $\xi_{q}$ for all firms. In Section 6, we compare the Top 1,000 program to a universal energy tax, a size-dependent energy tax (i.e., $s_{\tilde{\phi}}<1$ ), and alternative forms or regulations, including ones that mirror the Top 10,000 program.

\section{Model Estimation}

This section estimates the key parameters of the model to quantitatively match the data patterns for the period prior to the regulation. We validate our estimated model by showing that it matches the untargeted difference-in-differences estimates of the effects of the Top 1,000 program.

\subsection{Parameterization and Estimation}

We briefly describe the set of structural parameters of the model and how they are identified by the data. We start by setting the values of two parameters based on previous estimates. We follow the literature by calibrating the elasticity of substitution $\sigma=4$ (Melitz and Redding, 2015, i.e., $\rho=0.75)$. We use the estimate of returns to scale of $\alpha=0.9$ from Burnside et al. (1995), who use energy data to proxy for utilized capital, and set $\alpha_{l}=0.8$ to match the cost share of

\footnotetext{
${ }^{35}$ As we show in Appendix D.2, this result follows by substituting $\xi_{q}(\phi)$ into the expression for $\lambda(\phi)$ in Proposition 5 and noting that this expression varies across firms depending on the term $\Delta_{n}$ only.
} 
variable inputs in the data. ${ }^{36}$ Finally, we parameterize the conglomerate efficiency distribution $G(\phi)$ with a log-normal distribution with mean zero and standard deviation $\sigma_{m}$.

The model is characterized by the three parameters that we estimate: $\left(\delta, \phi_{1}, \sigma_{m}\right)$, which include the within-conglomerate size depreciation $\delta$, the conglomerate-level survival threshold $\phi_{1}$, and the dispersion of the efficiency distribution $\sigma_{m}$. Given values of $\phi_{1}$ and the market expenditure $R$, Equations 8 and 9 pin down $f$. The entry cost $f_{e}$ is then determined by the conglomerate free-entry condition. ${ }^{37}$

We estimate the parameters $\theta=\left(\delta, \phi_{1}, \sigma_{m}\right)$ using the method of moments. For a candidate value of $\theta$, we solve the model and compute the following moments: (1) the share of firms in three bins of firm revenue (5-20 million RMB, 20-100 million RMB, and greater than 100 million RMB); (2) the share of firm output in the same three bins; (3) the average output of the second, third, and fourth largest affiliates relative to the top firm in the conglomerate; and (4) the fraction of firms with revenue below 1 million RMB. Our data moments describe the equilibrium prior to the regulation using the ASIF and manufacturing census data for 2004. Intuitively, the parameter $\sigma_{m}$ is pinned down by the moments (1) and (2) describing the firm size and firm output distribution. The parameter $\delta$ is determined by the within-conglomerate output distribution moments (3). The last moment (4) helps pin down $\phi_{1}$. Our estimate of $\theta$ is given by

$$
\hat{\theta}=\underset{\theta \in \Theta}{\arg \min }\left[m_{d}-m(\theta)\right]^{\prime} W\left[m_{d}-m(\theta)\right]
$$

where $m_{d}$ are the data moments, $m(\theta)$ are the moments generated by the model, and $W$ is the identity matrix. ${ }^{38}$

Table 7 reports the results of the estimation. We estimate that $\delta=0.90$, which means that the productivity of the second largest firm in the conglomerate is close to $90 \%$ of that in the largest firm. Recall that Equation 5 shows that the output of affiliates depreciates in rank by the factor $\delta^{\frac{1}{1-\alpha}}$. This relation implies that the output of the second largest firm is close to $35 \%$ of the largest firm (cf., $29 \%$ in the data) and that of the third largest is close to $13 \%$ (cf. $20 \%$ in the data), which matches the pattern in Panel A of Figure 3. We also estimate that $\sigma_{m}=1.24$ and $\phi_{1}=0.61$. To interpret these estimates, note that they imply a conglomerate entry cost

\footnotetext{
${ }^{36}$ Conventional estimates of returns to scale range from 0.85 to 0.95 , depending on aggregation and time period. In Section 7.3, we show that the aggregate and welfare effects of the program are robust to reestimating the model based on different values of $\rho$ and $\alpha$.

${ }^{37}$ To pin down $f_{e}$, first note that Equations 7 and 9 imply that $\phi_{n+1}=\phi_{1} /\left(\Delta_{n+1}^{\frac{\rho}{1-\rho \alpha}}-\Delta_{n}^{\frac{\rho}{1-\rho \alpha}}\right)^{\frac{1-\rho \alpha}{\rho}}$ and that $\pi(\phi)=\left[\left(\frac{\Delta_{n} \phi}{\phi_{1}}\right)^{\frac{\rho}{1-\rho \alpha}}-n\right] r f$. The conglomerate free-entry condition is then $f_{e}=\int_{\phi_{1}}\left[\left(\frac{\Delta_{n} \phi}{\phi_{1}}\right)^{\frac{\rho}{1-\rho \alpha}}-n\right] f g(\phi) d \phi$ which is determined by our fixed and estimated parameters.

${ }^{38}$ We use the identity matrix since the sample size for the moments describing the size and output distribution is much larger than the sample size for the moments describing the relative size of firms within conglomerates. We calculate standard errors using a bootstrap covariance matrix of the moments that incorporates this information.
} 
of $f_{e}=8.9$ million RMB (or about 1.1 million USD), which is reasonably commensurate with average profit in the economy. The per-firm operating fixed cost is determined by the average sales per conglomerate in the data, which implies that $f=44,000$ RMB. Panel A of Figure 7 shows that our model does a good job of fitting both the observed firm-size distribution and the concentration of output prior to the regulation.

\subsection{Model Response to the Top 1,000 Program}

We need two additional parameters to implement the Top 1,000 program in our model. As discussed in Section 4, our version of the regulation targets conglomerates with efficiency level $\phi$ above $\tilde{\phi}$. We choose the threshold $\tilde{\phi}$ to match the share of total energy consumed by regulated firms within energy-intensive industries. Given our estimated parameters, the model implies a value of $\tilde{\phi}=9.29$, which reproduces the fact that regulated firms account for $56 \%$ of total energy consumption in energy-intensive industries. Finally, we take the policy intensity $\xi$ from the 11 FYP, which targeted an energy reduction of $20 \%$. For this reason, we set $\xi=0.8$. Table 7 collects the model parameters.

We now use our estimated model to compute the effects of the Top 1,000 program. As in Section 4.4, we assume conglomerates take the number of affiliates and capital allocation as given. The new industry equilibrium ensures that (1) regulated conglomerates allocate variable inputs optimally (as in Equation 12), (2) unregulated firms increase output to respond to the increase in market prices, and (3) the product market clears (as in Equation 8).

Panel B of Figure 7 compares our difference-in-differences estimates to simulated model analogues. The model does a remarkable job of matching the estimated effects on firm output. This is true for regulated firms, related firms, and market-level spillovers. The model prediction of the change in input use of regulated firms is within the $95 \%$ confidence interval of our empirical estimate, but the model has a hard time fitting the effect on the energy use of related firms. This may reflect the fact that, as we discuss in Section 3, this estimate is based on a smaller sample of larger firms and may not be representative of the overall response. However, the model does a good job of matching the effects of the program on the energy efficiency of both regulated and related firms. Overall, these results show that our model can reproduce the effects of the regulation on the output of regulated, related, and unrelated firms, which is remarkable since these are all out-of-sample predictions of the model.

\subsection{Using the Model to Interpret Difference-in-Differences Estimates}

An important force in the model is that unregulated firms are impacted by the regulation through the market spillover. This force contributes to the effects of the program on the equilibrium price 
and aggregate energy use. We now use our model to understand how this market spillover impacts our difference-in-differences estimates.

To see how the regulation in our model connects to our difference-in-differences analysis, note that we can write conglomerate $j$ 's revenue from affiliate $i$ as follows:

$$
\ln \text { Revenue }_{i j}=\underbrace{\ln \left(\text { Production Share }_{i j}\right)}_{\text {Allocation Effect }}+\underbrace{\rho \ln \left(\sum_{i \in j} q_{i j}\right)}_{\text {Residual Revenue }}+\underbrace{\ln \left(R^{1-\rho} P^{\rho}\right)}_{\text {Market Demand }},
$$

where Production Share $_{i j}=q_{i j} / \sum_{i \in j} q_{i j} .{ }^{39}$ Equation 17 clarifies the three ways in which the Top 1,000 program impacts the revenue of regulated firms. First, when firm $i$ is regulated, the conglomerate is forced to reallocate inputs to other firms, which lowers the production share in regulated firms. Panel A of Table 8 reports that in our model, the share of production in regulated firms within a conglomerate decreases by $12.9 \%$. Second, since the marginal cost goes up at the conglomerate level, the market share of the conglomerate's variety decreases, which lowers the group's residual revenue. Table 8 shows that regulated conglomerates see their residual revenue decrease by $3.7 \%$. Finally, the Top 1,000 program impacts the industry-level price $P$. This price increase has a countervailing effect on the revenue of the regulated firm and lessens the overall decline by $2.6 \%$. Combining these three forces, our model implies that regulated firms decreased their output by $14 \%$.

Equation 17 also characterizes the impact of the regulation on the control firms in our difference-in-differences analyses. Since these firms are not regulated or related to Top 1,000 firms, the regulation does not impact the within-conglomerate allocation of production. Control firms see an increase in their residual and firm-level revenue as the market reallocates demand. Table 8 shows that the residual revenue of control firms increases by $3.9 \%$. As in the case of regulated firms, unregulated firms also benefit from the equilibrium impact on market demand.

This discussion clarifies that our difference-in-differences estimates differ from the total effect on Top 1,000 firms along two margins. First, the difference-in-differences estimator captures both the within- and across-conglomerate reallocation of production. This leads to an overestimate of the effect of the program on regulated firms of 3.9\%. Second, since the market effect cancels out, the difference-in-differences estimator does not capture the countervailing effect on the industrylevel price, which further overestimates the effect of the program by $2.6 \% .{ }^{40}$

Similarly, our model allows us to decompose the estimates of the spillover effects of the regulation through ownership networks. Panel B of Table 8 shows that related firms share the residual revenue and market effect terms but have a positive allocation effect as their share of

\footnotetext{
${ }^{39}$ Equation 17 follows by multiplying conglomerate $j$ 's inverse residual demand by affiliate $i$ 's production.

${ }^{40}$ Note that the first channel arises from the impact of the regulation on the control firms. The second channel is an aggregate effect that is not identified by a difference-in-differences research design.
} 
production within the conglomerate increases. The total effect on related firms is an output increase of $19.3 \%$. The effects on control firms is the same as that in Panel A. By ignoring the positive market effect and subtracting the residual revenue effect on control firms, the differencein-differences estimator understates the spillover effect on related firms by $6.5 \%$.

In addition to clarifying the interpretation of our reduced-form estimates, our model also motivates an alternative approach that does not the depend on the residual revenue or market effects. Specifically, consider a within-conglomerate difference-in-differences estimator where treated firms are the regulated Top 1,000 firms and the control firms are unregulated firms in the same conglomerate. Because Equation 17 shows that the residual revenue and market effect are common to a given conglomerate, this estimator captures only the allocation effects of the program. Figure 8 implements this within-conglomerate difference-in-differences approach. This figure plots the results from an event-study specification similar to Equation 1 but where we additionally include conglomerate-by-year fixed effects. Consistent with our previous results, we find a significant decline in the output of Top 1,000 firms relative to that of other firms in their same conglomerates. Table 9 reports estimates of these relative declines of between $-31.5 \%$ and $-36.7 \%$. As with our previous reduced-form effects, Panel B of Figure 7 shows that the model matches this within-conglomerate effect very well. Moreover, Panel C of Table 8 confirms that this effect is a combination of the allocation effects on regulated and related firms.

These insights highlight the importance of interpreting quasirandom estimates through the lens of a model that accounts for within- and across-conglomerate reallocation of production as well as equilibrium impacts on industry-level prices.

\section{Policy Analysis}

This section uses our estimated model to capture the effects of the Top 1,000 program by quantifying the shadow cost to regulated firms, the aggregate effects on prices and energy use, and the implied welfare trade-off of the program. We then consider the effects of alternative policies including program expansions (e.g., the Top 10,000 program) and the possibility that the government can use information on business networks to improve energy regulation.

\subsection{Effects of the Top 1,000 Program}

Given that the shadow cost is the fundamental building block of our model outcomes, we first quantify this cost of the policy. 


\subsubsection{Shadow Cost of the Policy}

To compute the shadow cost of the policy, we solve for the regulated equilibrium as in Proposition 5. Panel A of Figure 9 plots the implied shadow cost as a function of efficiency $\phi$. The blue line plots the shadow cost of our computed Top 1,000 program. This shadow cost is zero for firms with $\phi<\tilde{\phi}$ and jumps to an average of $8.7 \%$ for regulated firms. Since the shadow cost has the same scale as the cost of variable inputs, we can interpret this value as an equivalent tax on variable inputs. While $8.7 \%$ might seem like a small number, recall that inputs constitute a large tax base, especially relative to profits. ${ }^{41}$

A somewhat surprising feature of Panel A of Figure 9 is that the shadow cost appears to be constant with respect to conglomerate productivity $\phi$. Panel B of Figure 9 zooms in to show the different shadow costs for regulated firms (i.e., $\phi>\tilde{\phi}$ ). As we discuss in Section 4 , the shadow cost is constant for conglomerates with the same number of related firms. This result follows from the fact that the regulation is based on previous energy use, which is proportional to firm productivity. When $\phi$ crosses the thresholds that define conglomerate size (Proposition 2), we see that the shadow cost drops as conglomerates with more affiliates are more able to escape the burden of the regulation. However, the differences in shadow costs are very small in comparison to the overall difference between regulated and unregulated conglomerates. This small impact is driven by the decay in within-conglomerate size, which implies that the marginal $\left(n^{\text {th }}\right)$ affiliate may not be able to supplant a large fraction of the combined activity of all the other affiliates (1 through $n-1)$ in the conglomerate.

We now validate the magnitude of the shadow cost using an additional implication of the model. Recall the insight from Proposition 3 that the shadow cost is related to the withinconglomerate output distribution after the regulation. Based on this insight, we can write the output difference between the Top 1,000 firm and related firms as follows:

$$
\begin{aligned}
\ln \text { Revenue }_{\text {Top1000,jt }}-\ln \text { Revenue }_{\text {Related }, j t} & =\ln \left(q_{\text {Top1000,j }}\right)-\ln \left(\sum_{i \neq \operatorname{Top} 1000, j} q_{i j}\right) \\
& =-\frac{\alpha_{l}}{1-\alpha_{l}} \ln \left[1+\frac{\lambda(\phi)}{w+p_{e}}\right]-\ln \left(\Delta_{n}^{\frac{1}{1-\alpha}}-1\right) .
\end{aligned}
$$

By definition, $\lambda(\phi)=0$ prior to the regulation, and $\Delta_{n}$ is constant over time. Therefore, taking a time difference of this expression shows that the within-conglomerate difference-in-differences estimation identifies the term $-\frac{\alpha_{l}}{1-\alpha_{l}} \ln \left[1+\frac{\lambda(\phi)}{w+p_{e}}\right]$. Using the estimate in the first column of Table 9 of $-34.3 \%$ and our value of $\alpha_{l}=0.80$, we estimate a shadow cost of $8.95 \% .{ }^{42}$ Given that

\footnotetext{
${ }^{41}$ Indeed, in models with constant marginal cost and with a similar value of $\sigma$, inputs are $(\sigma-1)=3-$ times as large as profits. An equivalent profit tax would then be $26.1 \%$.

${ }^{42}$ This calculation follows from $1+\frac{\lambda(\phi)}{w+p_{e}}=\exp \left\{-\beta \frac{1-\alpha_{l}}{\alpha_{l}}\right\}=\exp \left\{0.343 \frac{1-0.8}{.8}\right\}=1.0895$. In principle, we identify the average value of this quantity across firms. However, as we show in Figure 9 , there is little variation in $\lambda(\phi)$.
} 
the shadow cost plays an important role in our quantification exercises of the aggregate effects of the program, it is reassuring that our estimated magnitude is consistent with the reduced-form pattern of within-conglomerate reallocation of production.

Our model allows us to consider how different mechanisms impact the shadow cost of the program. The top line of Panel A of Figure 9 shows that shutting down the market and conglomerate spillovers would increase the shadow cost to $15.6 \%$. That is, the equilibrium price increase and the ability to shift production to related firms lowered this mechanical effect by almost 50\%. The model also allows us to isolate how the ability of conglomerates to shift production to related firms lowered the shadow cost of the regulation. The second line from the top in Panel A of Figure 9 plots the shadow cost under the assumption that market prices adjust but that regulated firms are not able to shift production to related parties. In this case, the shadow cost of the regulation would be $11.2 \%$ of input costs, which is about $30 \%$ larger than the level in the baseline case. ${ }^{43}$ These calculations showcase the importance of accounting for both market and conglomerate spillovers in the measurement of the shadow cost of the regulation.

\subsubsection{Aggregate and Welfare Effects of the Program}

The analysis so far has focused on the distortionary aspects of the regulation. We now evaluate the aggregate and welfare effects of the policy by considering the social welfare function of a government concerned with both decreases in energy-use-related emissions and the impact of distortions to production on consumption. ${ }^{44}$

We compute the aggregate effects of the program by solving the equilibrium conditions in Proposition 5. Panel A of Figure 10 plots the effects of the Top 1,000 program in the space of price increase and energy reduction. The red diamond in this figure shows that the Top 1,000 program led to a price increase of about 3.5\% and an aggregate energy use reduction of close to $4 \%$. Equation 15 helps us understand how we obtain a $4 \%$ aggregate reduction in energy use. First, we find that-including within-conglomerate reallocation-regulated conglomerates reduced their energy use by $1-\mathbb{E}_{e}\left[\xi_{e}(\phi) \mid \phi>\tilde{\phi}\right]=5.8 \%$. Second, the unregulated conglomerates increased their energy use by close to $6.5 \%$. Finally, we obtain the aggregate $4 \%$ decline by using the fact that the share of energy in regulated conglomerates is $s_{\tilde{\phi}}=86 \% .{ }^{45}$ Thus, even though we find in Section 2 that Top 1,000 firms reduced their energy use by close to 100 million tce,

\footnotetext{
${ }^{43}$ This counterfactual assumes that, similar to unregulated firms, the production of related firms responds to equilibrium price increases. Restricting production in related firms to pre-regulation levels further increases the shadow cost to $14 \%$.

${ }^{44}$ To match the short-run nature of our empirical analysis, we focus our discussion on the short-run effects of the policy, ignoring the entry of new conglomerates. Later changes to regulations and the overall environment also complicate the simulation of long-run impacts.

${ }^{45}$ The energy increase for unregulated firms is given by $\left(\frac{P}{P^{*}}\right)^{\frac{\rho}{1-\alpha_{l} \rho}}=(1.035)^{\frac{0.75}{1-0.8 * 0.75}} \approx 1.065$. Recall that regulated firms account for $56 \%$ of energy use; accounting for related firms in the same conglomerate raises this fraction to $86 \%$. The aggregate effect is then $-4 \%=\ln (1.06 * 0.14+0.942 * 0.86)$.
} 
the annual aggregate reduction - including conglomerate and market leakage — was closer to 48 million tce. ${ }^{46}$

While reducing energy use improves welfare by lowering related carbon emissions, the overall effects of the program on welfare also depend on how the program impacts consumption. According to Equation 16, welfare increases when the aggregate price-to-energy use elasticity (i.e., $\left.\frac{-\ln \left(\frac{P}{P^{*}}\right)}{\ln \left(\frac{E}{E^{*}}\right)}\right)$ is smaller than $\frac{\kappa}{1-\kappa}$. Given our aggregate estimates of the effects of the Top 1,000 program, we find that the program raises welfare as long as $\frac{\kappa}{1-\kappa}<\frac{3.5}{4}=0.875$. That is, the Top 1,000 program raises welfare as long as the government is willing to accept a $0.875 \%$ price increase for every $1 \%$ reduction in energy use.

To obtain a more concrete interpretation of this condition, we calibrate $\kappa$ by building on the Cobb-Douglas intuition that exponents are related to expenditure shares. This intuition implies that we can approximate $\kappa$ as follows:

$$
\kappa=\frac{\text { Social Cost of Carbon } \times \text { Carbon Emissions }}{\text { Aggregate Income } \times 0.8} .
$$

The adjustment factor 0.8 comes from the fact that the Chinese government declared in the $11 \mathrm{FYP}$ that relative to its policy goals, the government was underspending on reducing emissions by $20 \%$. We implement this equation with 2006 data on overall emissions in China (6.38 billion tons of carbon) and national income (2.752 trillion USD). We can then compute a value of $\kappa$ that corresponds to an estimate of the social cost of carbon (SCC). In the US, the Biden administration has recently proposed using an SCC of $\$ 51$ (IWG, 2021), although researchers have recently argued for a higher value of $\$ 125$ (Carleton and Greenstone, 2021). In contrast, Germany has proposed an SCC value of $\$ 218$.

Figure 10 implements this calibration by plotting black indifference curves where $\kappa$ varies according to different values of the SCC. That is, for a given SCC value, these lines plot combinations of price and energy use changes that yield the same effect on welfare. The red diamond in this figure shows that the Top 1,000 program lies on the indifference curve that corresponds to an SCC of $\$ 160$. This implies that this policy is desirable from a welfare perspective only if policymakers use relatively higher values of the SCC.

\subsection{Alternative Policies}

We now use the model to consider alternative policies. We first explore different ways in which the Top 1,000 program could be expanded or contracted. This exercise is motivated by the fact that the Chinese government expanded the program to include more than 14,000 firms in the

\footnotetext{
${ }^{46}$ In Appendix D.2.3, we connect the model solution to our reduced-form estimates by showing that we can solve an approximate version of the equilibrium using the value of $\lambda$ that is implied by the within-conglomerate difference-in-differences results.
} 
Top 10,000 program in 2012. We then explore the effects of alternative regulations and energy taxes to examine the degree to which the government can improve the regulation of energy.

We explore two ways to change the scope of the Top 1,000 program. First, we consider the effect of varying the regulation threshold $\tilde{\phi}$, which changes the number of firms affected by the program. The blue dots in Panel A of Figure 10 show the effects of changing the size threshold, $\tilde{\phi}$. The first blue dot (left of the red diamond) considers the effect of decreasing the number of regulated firms to cover only $50 \%$ of the energy use in the regulated industry (relative to the current $56 \%$ ). The second blue dot lowers $\tilde{\phi}$ so that the regulation instead covers $60 \%$ of the industry's energy use. As would be expected, we find larger energy decreases when the program covers a larger fraction of overall energy use. However, Figure 10 shows that expanding or contracting the number of firms in the program does not alter the fundamental trade-off that the government faces between price increases and reductions in energy use.

An alternative way to change the scope of the Top 1,000 program is to increase or decrease the energy use quota $\xi$. The maroon squares in Panel A of Figure 10 plot the effects of policies where $1-\xi$ varies in $5 \%$ increments between $5 \%$ and $30 \%$. Larger values of $1-\xi$ lead to both larger price increases and larger energy reductions. Taking both changes into account, we find that the implied SCC increases with the required energy reduction and equals $\$ 165$ when $1-\xi=30 \%$. This result is valuable since the government may be concerned about the administrative costs of regulating a larger number of firms. Since increasing $\xi$ and lowering $\tilde{\phi}$ have similar welfare effects, it may therefore be desirable to place stricter energy use limits on fewer firms if the government lacks the capacity or the funds to conduct additional energy audits.

We now consider the effects of an alternative policy that targets the energy use of all firms in a given conglomerate. ${ }^{47}$ The orange crosses in Panel B of Figure 10 plot the effects of this type of regulation for different values of $\xi$. These policies have the benefit that they do not distort the within-conglomerate distribution of production. Panel A of Figure 9 shows that regulating conglomerates has a lower shadow cost of $4.9 \%$ (instead of $8.7 \%$ ). Such a policy is preferable to the Top 1,000 program from a welfare perspective since it can achieve larger energy use reductions for a given price increase. As we show in Panel B of Figure 10, this type of regulation can yield a $4.36 \%$ reduction in aggregate energy use for the same price increase as the Top 1,000 program. This is a 10\% increase from the energy reduction of the Top 1,000 program, which corresponds to additional energy savings of 5 million tce. This policy improves welfare as long as the SCC $\geq \$ 152$. While this program would involve monitoring additional firms, the number of firms related to Top 1,000 firms is less than $20 \%$ of the number of firms in the Top 10,000 program. These results show that the government can improve the regulation of energy by using

\footnotetext{
${ }^{47}$ We derive equilibrium conditions under these alternative regulations in Appendix E. To make this case comparable, we model the effects of a regulation that limits the conglomerate-level use of energy to the levels of the Top 1,000 program. That is, we set $\xi$ to values corresponding to $\xi_{e}(\phi)$ in the Top 1,000 program.
} 
publicly available data on business networks to target conglomerates and that doing so would be more effective than regulating additional unrelated firms, as with the Top 10,000 program.

Finally, we consider the effects of energy taxes. We first model the effects of a tax that affects only firms in conglomerates with Top 1,000 firms (i.e., with $\phi>\tilde{\phi}$ ). Panel A of Figure 9 shows that we would obtain the same energy reduction as that under the Top 1,000 program by taxing inputs at $4.9 \%{ }^{48}$ The green circles in Panel B of Figure 10 show that the effects of this energy tax are very close to those of the conglomerate-level regulation. ${ }^{49}$ We further consider the effects of a universal energy tax such that $s_{\tilde{\phi}}=100 \%$ instead of $86 \%$. Panel B of Figure 10 shows that while a universal energy tax yields a slight improvement over the size-dependent tax $(\mathrm{SCC}=\$ 151)$, both the size-dependent tax and the conglomerate-level regulations imply very similar welfare trade-offs.

The preferred policy solution for most economists on the regulation of carbon emissions related to energy use is a universal carbon tax. In practice, this policy may not be feasible given legal, administrative, or political constraints. The results in this section inform the efficacy and design of a prominent real-world policy that regulates quantities and has incomplete coverage. We find that the government can achieve similar aggregate effects by either expanding the program through stricter regulations for current firms or increasing the number of firms in the program. While the former has narrower coverage and generates larger inequities between regulated and unregulated firms, the latter may require an increase in administration costs. We also find that the government can improve the regulation of energy by targeting the ownership networks of regulated firms. This policy increases aggregate energy savings by $10 \%$ without increasing welfare costs. Moreover, this policy can be implemented with publicly available data, has a lower administrative cost than the Top 10,000 program, and implies a welfare trade-off close to that under a universal energy tax.

\section{$7 \quad$ Extensions and Robustness}

This section explores four extensions of our model. First, we consider the possibility of firms responding to the regulation by investing in energy efficiency. Second, we consider how preexisting differences in energy efficiency across firms may alter the overall energy savings from the program. Third, we study the robustness of our welfare calculations to alternative parameter-

\footnotetext{
${ }^{48}$ As with the Top 1,000 regulation, the shadow cost of the conglomerate-level regulation decreases slightly as the number of related firms increases. In contrast, the shadow cost of the size-dependent energy tax is constant for all firms affected by it. Since energy costs are close to $15 \%$ of variable input costs for Top 1,000 firms, the equivalent energy tax would be closer to $32.7 \%\left(\approx \frac{4.9 \%}{15 \%}\right)$.

${ }^{49}$ It is worth noting that our quantification lacks two features that often motivate the use of taxes over regulation. First, in our calculations, the revenue from the tax is not rebated to consumers; this calculation ignores potential "double dividend" effects. Second, firms in our setting have homogeneous abatement costs; in a setting with heterogeneous abatement costs, a tax would additionally reallocate production to "cleaner" firms.
} 
izations of the model. Finally, we extend our model to allow imperfect substitution between products produced by firms in a given conglomerate.

\subsection{Endogenous Energy Efficiency}

Our baseline analysis assumes that in the short run, firms do not make any investments to improve their energy efficiency. This assumption is consistent with our empirical results in Sections 23. Following the intent of the Top 1,000 program, we now extend our model to allow firms to respond by adjusting their energy efficiency. Appendix G.1 provides additional details of this model extension.

We assume that the conglomerate can improve energy efficiency at firm $i, \nu_{i}$, by spending $l_{i} c\left(\nu_{i}\right)$, where $c^{\prime}\left(\nu_{i}\right)>0$ and $c^{\prime \prime}\left(\nu_{i}\right) \geq 0$. We can then restate the regulated conglomerate's problem as

$$
\pi(\phi, n)=\max _{\left\{l_{i}\right\}_{i=1}^{n},\left\{\nu_{i}\right\}_{i=1}^{n}}\left\{R^{1-\rho} P^{\rho}\left[\phi^{*} \sum_{i=1}^{n} \delta^{\frac{(i-1)\left(1-\alpha_{l}\right)}{1-\alpha}} l_{i}^{\alpha_{l}}\right]^{\rho}-\sum_{i=1}^{n} l_{i}\left(w+\frac{p_{e}}{\nu_{i}}+c\left(\nu_{i}\right)\right)\right\}
$$

where we omit the cost of fixed capital. Absent the regulation, the conglomerate sets $c^{\prime}\left(\nu^{*}\right) \nu^{* 2}=$ $p_{e}$ for all firms. This result implies that Propositions 1-2 continue to describe the equilibrium prior to the regulation. To simplify the exposition, we assume that $c(\nu)=\frac{\nu^{\gamma}}{1+\gamma}$, where $\gamma \geq 1$. This implies that the effective price of energy inclusive of investments in energy efficiency is $\frac{p_{e}}{\nu^{*}}+c\left(\nu^{*}\right)=c^{\prime}\left(\nu^{*}\right) \nu^{*}+c\left(\nu^{*}\right)=\left(\nu^{*}\right)^{\gamma}$.

Consider now the effects of the regulation. First, note that the Top 1,000 regulation does not impact the choice of $\nu_{i}$ for unregulated firms. We then use these results and the fact that $\nu_{i}=\frac{l_{i}}{e_{i}}$ to restate the conglomerate problem as

$$
\pi(\phi, n)=\max _{\left\{l_{i}\right\}_{i=1}^{n}}\left\{R^{1-\rho} P^{\rho}\left[\phi^{*} \sum_{i=1}^{n} \delta^{\frac{(i-1)\left(1-\alpha_{l}\right)}{1-\alpha}} l_{i}^{\alpha_{l}}\right]^{\rho}-\left(w+\left(\nu^{*}\right)^{\gamma}\right) \sum_{i=1}^{n} l_{i}-l_{1}\left[\frac{1}{1+\gamma}\left(\frac{l_{1}}{\xi e_{1}^{*}}\right)^{\gamma}-\left(\nu^{*}\right)^{\gamma}\right]\right\},
$$

where we substitute the regulatory constraint into the cost of energy efficiency and where we abstract away from the cost of the regulated energy, $p_{e} \xi e_{1}^{*}$, since it is a constant.

The conglomerate's first-order conditions for $l_{i}(1 \leq i \leq n)$, i.e., $\frac{\partial \pi}{\partial l_{i}}$, are then

$$
\underbrace{R^{1-\rho} P^{\rho}}_{\text {Market Demand }} \rho\left[\phi^{*} \sum_{i=1}^{n} \delta^{\frac{(i-1)\left(1-\alpha_{l}\right)}{1-\alpha}} l_{i}^{\alpha_{l}}\right]^{\rho-1} \underbrace{\phi^{*} \delta^{\frac{(i-1)\left(1-\alpha_{l}\right)}{1-\alpha}} \alpha_{l}\left(l_{i}\right)^{\alpha_{l}-1}}_{\text {Residual Revenue }}=w+\left(\nu^{*}\right)^{\gamma}+\underbrace{\left[\left(\frac{l_{1}}{\xi e_{1}^{*}}\right)^{\gamma}-\left(\nu^{*}\right)^{\gamma}\right]}_{\begin{array}{c}
\text { Shadow Cost } \\
\text { of Regulation }
\end{array}} \mathbb{I}[i=1] .
$$

Interestingly, this extension of the model yields very similar results to those in Equation 12. For the case of unregulated firms (i.e, $l_{i}$ for $i>1$ ), we simply substitute $p_{e}$ with the effective price 
of energy: $\left(\nu^{*}\right)^{\gamma}$. The first-order condition for the regulated firm implies that the shadow cost of the regulation is given by

$$
\frac{\lambda(\phi)}{w+\left(\nu^{*}\right)^{\gamma}}=s_{e}\left[\left(\frac{\nu_{1}}{\nu^{*}}\right)^{\gamma}-1\right]
$$

where $s_{e}$ is the share of variable input costs accounted for by energy and where energy efficiency at the Top 1,000 firm improves by $\frac{\nu_{1}}{\nu^{*}}$ relative to that in the unregulated case. ${ }^{50}$ The results of Proposition 3 continue to hold using this definition of the shadow cost of the regulation, which captures the incremental cost of improving energy efficiency in the regulated firm.

This framework allows us to infer how costly it would have been for regulated firms to have improved their energy efficiency. We implement this calculation using our estimated model parameters. Our estimated model fundamentals remain valid since Propositions 1-2 continue to describe the unregulated equilibrium and since we estimated the model with data from prior to the regulation. To implement this model extension, we set $s_{e}=15 \%$ based on our data and solve for the new equilibrium for different assumed values of $\gamma$. To find a lower bound for the value of $\gamma$, we compare the improvement in the revenue-to-energy ratio that is predicted by the model with our estimates from Section 2. Since we do not find a statistically significant effect, we use the confidence intervals to guide our calibration of $\gamma \cdot{ }^{51}$ In Appendix G.1, we show that when $\gamma=7.4$, the improvement in the revenue-to-energy ratio of Top 1,000 firms in our model equals $11.6 \%$, which matches the $95 \%$ confidence interval of column (1) in Panel C of Table $3 .{ }^{52}$ The ability to improve the energy efficiency of the regulated firm lowers the shadow cost of the regulation, as it loosens the energy use restriction on the Top 1,000 firm. In this case, the shadow cost is $6.5 \%$ instead of the $8.7 \%$ in our baseline scenario.

This model extension also allows to quantify the aggregate effects of the policy under different assumptions of the costs of improving energy efficiency. Panel A of Figure 11 plots the aggregate effects of the regulation for different values of $\gamma$. This model nests our baseline model under the assumption that $\gamma \rightarrow \infty$. In this case, firms do not improve their energy efficiency, which is consistent with our empirical results. When the cost of improving energy efficiency decreases (lower values of $\gamma$ ), the Top 1,000 program achieves greater energy reductions and results in smaller price increases. Both of these forces imply that the SCC that rationalizes the program also increases with $\gamma$. For our calibrated value of $\gamma=7.4$, the Top 1,000 program reduces aggregate energy use by $5.6 \%$ for a price increase of $2.8 \%$. This calculation also yields a bound

\footnotetext{
${ }^{50}$ The functional form assumption for $c(\nu)$ only simplifies the derivation. Absent this assumption, one can replace $p_{e}$ in Equation 12 with the effective cost of energy $\nu^{*} c^{\prime}\left(\nu^{*}\right)+c\left(\nu^{*}\right)$. Similarly, the shadow cost would be $\lambda(\phi)=\left[\nu_{1} c^{\prime}\left(\nu_{1}\right)+c\left(\nu_{1}\right)\right]-\left(\nu^{*} c^{\prime}\left(\nu^{*}\right)+c\left(\nu^{*}\right)\right)$.

${ }^{51}$ We also show in the appendix that the Top 1,000 program did not lead to improvements in the variable costs-to-energy ratio. Figure A.9 and Table A.18 show a null effect on this measure of energy efficiency for regulated firms, and Figure A.10 and Table A.19 find the same result for related firms.

${ }^{52}$ Alternatively, our model implies a value of $\gamma=12.8$ if we target the $99 \%$ confidence interval of column (4) of Panel C of Table 3.
} 
on the SCC since as we show in Panel B of Figure 11, the program raises welfare for this value of $\gamma$ as long as the $\mathrm{SCC} \geq \$ 112 .^{53}$

We can also use our model to calculate the value of $\gamma$ that would have allowed regulated firms to improve their revenue-to-energy ratio by $20 \%$. We find that firms would have met this energy efficiency improvement target if $\gamma=0.55$. In this case, the shadow cost of the regulation would have been $1.6 \%$. This scenario represents the "low-hanging fruit" perspective according to which small investments can lead to large gains in energy efficiency. While it is possible that firms may find ways to improve their energy efficiency over the long run, our results suggest that firms did not expect to recoup the costs of improving energy efficiency over a five-year period. ${ }^{54}$

\subsection{Heterogeneous Energy Efficiency}

The previous section showed that allowing endogenous investments in energy efficiency does not significantly alter our results. We now explore the possibility that - even prior to the Top 1,000 program - regulated, related, and unrelated firms operated under heterogeneous energy efficiencies.

One possibility is that the government targeted Top 1,000 firms because they were particularly energy inefficient. Similarly, the production increase in unrelated firms may have smaller effects on overall energy use if these firms are more energy efficient. In both of these cases, the regulation may be more effective to the extent that it shifts production to more energy-efficient firms. Alternatively, the Top 1,000 program may lead to smaller reductions in energy use if Top 1,000 firms are more energy efficient than other firms.

Appendix G.2 generalizes our analysis to allow the energy efficiency of related firms to differ from that of Top 1,000 firms by a factor of $\nu_{R}$. Differences in energy efficiency would alter the pattern of production within a conglomerate even prior to the regulation. This is because energy efficiency influences the unit cost of related firms. Differences in energy efficiency would then influence the allocation of production within the conglomerate. We can additionally assume that other unrelated firms have an energy efficiency that differs from that of Top 1,000 firms by a factor of $\nu_{O}$. These differences impact both the response of related and other firms to the regulation and overall energy use. To explore the sensitivity of our results to differences in energy efficiency, we solve the model under different values of $\nu_{R}$ and $\nu_{O}$. We allow for $\nu_{O}$ and $\nu_{R}$ to be up to $20 \%$ lower (which would exacerbate energy leakage) or to be $20 \%$ greater than that of the

\footnotetext{
${ }^{53}$ The result that the conglomerate-level regulation would increase energy savings by $10 \%$ for the same welfare cost is robust to allowing firms to improve their energy efficiency.

${ }^{54}$ The fact that conglomerates were able to shift production to related affiliates lowered the incentive for regulated firms to invest in energy efficiency. Using our baseline calibration of $\gamma=7.4$, we calculate that regulated firms would have increased their revenue-to-energy ratio by $13.8 \%$ if they had not been able to shift production to related firms.
} 
Top 1,000 firms (leading to negative leakage, e.g., Baylis et al., 2014). ${ }^{55}$

Panel B of Figure 11 shows the effect of heterogeneous energy efficiency on our welfare calculations. We first assume that firms related to Top 1,000 firms are $20 \%$ less energy efficient, i.e. $\nu_{R}=0.80$. This case implies a larger welfare loss due to a larger price increase as well as smaller energy savings. Under this assumption, the SCC that rationalizes the program increases to $\$ 191$. Further assuming that other firms are also $20 \%$ less energy efficient, i.e. $\nu_{O}=0.80$, also increases prices, decreases energy savings, and is rationalized by an SCC of $\$ 196$. These calculations show that the within-conglomerate energy leakage is an important contributor to the overall energy effects of the program. If we alternatively assume that Top 1,000 firms are particularly energy inefficient, i.e. $\nu_{R}=\nu_{O}=1.2$, the program can be rationalized with SCC values as low as $\$ 133$. To the best of our knowledge, Top 1,000 firms are not relatively inefficient in comparison to their related firms. Nonetheless, this calculation provides an interesting bound for the welfare effects of the program.

\subsection{Robustness to Alternative Parameters}

The structural model in Section 4 used calibrated values for the decreasing-returns-to-scale parameter $\alpha$ and for $\rho$, which determines the elasticity of substitution $\sigma=\frac{1}{1-\rho}$. This section discusses how our results are affected by changing the values of these parameters. To do so, we first vary the values of these parameters. We then reestimate the structural parameters following the same procedure as in Section 4. Finally, we solve for the regulated equilibrium that is implied by every pair of values of $\alpha$ and $\rho .{ }^{56}$

Panel $\mathrm{C}$ of Figure 11 shows how varying these parameters affects the estimated aggregate effects of the Top 1,000 program and the implied SCC. The red diamond plots the effects of the program under our baseline parameterization that sets $\alpha=0.90$ and $\rho=0.75$. Consider first the effects of fixing $\alpha=0.90$ and setting $\rho$ at either 0.70 (so that $\sigma=3.33$ ) or at 0.90 (so that $\sigma=10)$. These two cases are denoted in Panel $\mathrm{C}$ of Figure 11 by the green circles, which show that the aggregate effects of the policy are barely altered by changing $\sigma$. This result is driven by the fact that when $\sigma$ is larger, the distributions of firm size and output imply a smaller variance of firm productivity $\phi$. Thus, even though we would expect a larger market spillover for a larger value of $\sigma$, this effect is offset by the decrease in the dispersion in firm productivity.

Consider now the effect of fixing $\rho=0.75$ and setting $\alpha$ to either 0.85 or 0.95 . These two cases are denoted in Panel $\mathrm{C}$ of Figure 11 by the blue triangles. In this case, we find that lower

\footnotetext{
${ }^{55}$ Unfortunately, since the CESD surveys larger firms, our data are not able to precisely measure differences in energy efficiency between regulated, related, and other competing firms in the market.

${ }^{56}$ The value of $\alpha_{l}$ is determined by the value of $\alpha$ and the cost share of variable inputs. Additionally, we solve for a new regulation threshold $\tilde{\phi}$ to match the share of energy in regulated firms. Table A.17 reports the estimated model parameters across different specifications.
} 
values of $\alpha$ lead to both larger energy use reductions and larger price increases. The intuition for this result is that when production faces more decreasing returns to scale, conglomerates are less able to substitute production across related firms. Similarly, unregulated firms are less able to respond to the price increase by increasing their own production. Both of these forces lead to larger energy use reductions and price increases.

Across these cases, the reduction in aggregate energy use ranges between $2.9 \%(\alpha=0.95)$ and $4.9 \%(\alpha=0.85)$. In terms of the total reduction in energy use, these values imply annual aggregate energy savings of between 37 and 57 million tce. Since the parameter $\alpha$ governs the extent of energy leakage to related and unregulated firms, it is reasonable that uncertainty in this parameter should generate uncertainty in the aggregate energy use reduction. Interestingly, the change in the aggregate price covaries with the reduction in energy use. As a result, the ratio of the price change to the energy change varies very little. We denote this in the graph by plotting gray lines that correspond to the implied values of the SCC for each case. These lines show that across all these different parameterizations, the implied SCC that rationalizes the policy varies only between $\$ 154$ and $\$ 165$.

Overall, the values of $\alpha$ and $\rho$ do not significantly affect our quantitative assessment of the fundamental trade-off faced by the government.

\subsection{Imperfect Substitution within Conglomerates}

The previous section shows that the welfare effects of the Top 1,000 program are robust to the use of a range of values for the parameters $\rho$ and $\alpha$. This section explores the robustness of our results to allowing the outputs of firms within a conglomerate to be imperfect substitutes. We now assume that conglomerates produce a composite good $q(\omega)=\left(\sum_{i} q(\omega, i)^{\rho_{c}}\right)^{1 / \rho_{c}}$, where $0<\rho<$ $\rho_{c}<1$. This assumption implies that consumers have a larger elasticity of substitution between products of firms in a given conglomerate than across goods produced by different conglomerates, i.e., $\frac{1}{1-\rho}<\frac{1}{1-\rho_{c}}$. As we show in Appendix G.3, many of the results of our baseline model extend to this case after slight modifications. ${ }^{57}$ For instance, we redefine the total productivity of a conglomerate as $\phi \Delta_{n}^{C}$, where $\Delta_{n}^{C}=\left[\sum_{i=1}^{n} \delta^{\frac{(i-1) \rho_{c}}{1-\alpha \rho_{c}}}\right]^{\frac{1-\alpha \rho_{c}}{\rho_{c}}}$.

To operationalize this extension, we first reestimate the model assuming that $\rho_{c}=0.90$. To gain intuition into how this extension impacts our model parameters, note that the share of the conglomerate's revenue from the $i^{t h}$ affiliate is now $\left(\frac{\delta^{i-1}}{\Delta_{n}^{C}}\right)^{\frac{\rho_{c}}{1-\alpha \rho_{c}}}$. Since $\rho_{c}<1$, the withinconglomerate distribution of output in Panel A of Figure 3 implies a lower value of $\delta$. Intuitively, since firms related to Top 1,000 firms are now less productive, the firm faces a greater productivity loss when shifting output to related firms. As a result, we estimate that $\delta=0.80$ when we reestimate the model, which implies a larger shadow cost of the regulation of about $11 \%$.

\footnotetext{
${ }^{57}$ Indeed, we obtain our baseline when $\rho_{c}=1$. Table A.17 reports the estimated model under this extension.
} 
The black square in Panel $\mathrm{C}$ of Figure 11 plots the aggregate effects of the program under the assumption that $\rho_{c}=0.90$. Two features of the model lead to larger decreases in energy use. First, the imperfect substitution of output within the conglomerate limits the extent to which regulated conglomerates can shift production to related firms. Second, the lower value of $\delta$ limits the extent of these spillovers. Both of these forces limit within-conglomerate leakage of energy use. However, these forces also lead to a larger price increase, which exacerbates market leakage by shifting production to unrelated firms. On the whole, we find larger price effects and energy savings. As the black square in Panel C of Figure 11 shows, these effects imply an SCC that is quite close to our baseline estimate.

\section{Conclusion}

This paper studies the effects of a prominent energy conservation program in China. We combine detailed data on energy use and business networks to study the effects of the regulation on both regulated firms and unregulated firms within the same conglomerate. While the program led regulated firms to decrease their energy use, this decrease was driven by a decline in production output and not by an increase in energy efficiency. We show that the program led to large increases in the output and energy use of unregulated firms in the same conglomerate. By shifting production to related firms, regulated conglomerates escaped close to $40 \%$ of the regulation-driven output reduction. The facts that regulated conglomerates were unable to fully shift lost output to related firms and that we find no impacts on the energy efficiency of regulated firms imply that regulated firms found it costly to increase their energy efficiency.

We calculate the shadow cost of the regulation using a model of conglomerate production that matches our setting and the reduced-form effects of the regulation. The model shows that even with the ability to shift some production to related firms, the regulation increased the cost of conglomerate production by $8.7 \%$.

A welfare analysis of the aggregate effects of the policy on consumption and energy use characterizes the social cost of carbon that would be required for the Top 1,000 program to raise welfare. Our results suggest that the program increases welfare as long as the social cost of carbon exceeds $\$ 160$. We characterize uncertainty in this estimate by exploring a number of alternative model specifications and parameter values. Across these wide-ranging assumptions, we find that the SCC value that rationalizes the policy lies between $\$ 112$ and $\$ 196$. We also show that the government can improve the regulation of energy by targeting the energy use of conglomerates. These policies have lower shadow costs and are more effective from a welfare perspective.

Overall, this paper shows that the economic effects and the efficacy of policies that target 
large firms are modulated by substitution along ownership networks. Since ownership networks are public information, the results of our paper reveal a potential avenue for improvement of existing energy regulations. 


\section{References}

Allcott, Hunt and Michael Greenstone, "Is There an Energy Efficiency Gap?," Journal of Economic Perspectives, February 2012, 26 (1), 3-28.

Anderson, Soren T. and James M. Sallee, "Using Loopholes to Reveal the Marginal Cost of Regulation: The Case of Fuel-Economy Standards," American Economic Review, June 2011, 101 (4), 1375-1409.

- and Richard G Newell, "Information programs for technology adoption: the case of energyefficiency audits," Resource and Energy Economics, 2004, 26 (1), 27-50.

Auffhammer, Maximilian and Yazhen Gong, "China's Carbon Emissions from Fossil Fuels and Market-Based Opportunities for Control," Annual Review of Resource Economics, 2015, $7(1), 11-34$.

Baylis, Kathy, Don Fullerton, and Daniel H. Karney, "Negative Leakage," Journal of the Association of Environmental and Resource Economists, 2014, 1 (1/2), 51-73.

Burnside, Craig, Martin Eichenbaum, and Sergio Rebelo, "Capacity Utilization and Returns to Scale," NBER Macroeconomics Annual, 1995, 10, 67-110.

Bushnell, James, Yihsu Chen, and Matthew Zaragoza-Watkins, "Downstream regulation of CO2 emissions in California's electricity sector," Energy Policy, 2014, 64, 313-323.

Carleton, Tamma and Michael Greenstone, "Updating the United States Government's Social Cost of Carbon," Working Paper 2021-04, EPIC 2021.

Chen, Qiaoyi, Zhao Chen, Zhikuo Liu, Juan Carlos Suárez Serrato, and Daniel Yi $\mathbf{X u}$, "Industrial Energy Regulation: The Role of Business Conglomerates in China," $A E A$ Papers and Proceedings, May 2021.

Colmer, Jonathan, Ralf Martin, Mirabelle Muûls, and Ulrich J. Wagner, "Does pricing carbon mitigate climate change? Firm-level evidence from the European Union emissions trading scheme," Discussion Paper, Center for Economic Performance 2020.

Curtis, E. Mark, "Who Loses under Cap-and-Trade Programs? The Labor Market Effects of the NOx Budget Trading Program," The Review of Economics and Statistics, 03 2018, 100 (1), 151-166.

Duflo, Esther, Michael Greenstone, Rohini Pande, and Nicholas Ryan, "Truth-telling by Third-party Auditors and the Response of Polluting Firms: Experimental Evidence from India," The Quarterly Journal of Economics, 2013, 128 (4), 1499-1545.

_, _, _, and _, "The Value of Regulatory Discretion: Estimates from Environmental Inspections in India," Econometrica, 2018, 86 (6), 2123-2160.

Fabrizio, Kira R., Nancy L. Rose, and Catherine D. Wolfram, "Do Markets Reduce Costs? Assessing the Impact of Regulatory Restructuring on US Electric Generation Efficiency," American Economic Review, September 2007, 97 (4), 1250-1277. 
Fischer, Carolyn and Alan K. Fox, "Comparing policies to combat emissions leakage: Border carbon adjustments versus rebates," Journal of Environmental Economics and Management, 2012, 64 (2), 199-216.

Fowlie, Meredith L., "Incomplete Environmental Regulation, Imperfect Competition, and Emissions Leakage," American Economic Journal: Economic Policy, August 2009, 1 (2), 72 112.

- and Mar Reguant, "Mitigating Emissions Leakage in Incomplete Carbon Markets," Journal of the Association of Environmental and Resource Economics, 2021, forthcoming.

_ , _ , and Stephen P. Ryan, "Market-Based Emissions Regulation and Industry Dynamics," Journal of Political Economy, 2016, 124 (1), 249-302.

Gao, Hang and Johannes Van Biesebroeck, "Effects of Deregulation and Vertical Unbundling on the Performance of China's Electricity Generation Sector," The Journal of Industrial Economics, 2014, 62 (1), 41-76.

Gibson, Matthew, "Regulation-Induced Pollution Substitution," The Review of Economics and Statistics, December 2019, 101 (5), 827-840.

Gillingham, Kenneth, Amelia Keyes, and Karen Palmer, "Advances in Evaluating Energy Efficiency Policies and Programs," Annual Review of Resource Economics, 2018, 10 (1), $511-532$.

Greenstone, Michael, "The Impacts of Environmental Regulations on Industrial Activity: Evidence from the 1970 and 1977 Clean Air Act Amendments and the Census of Manufactures," Journal of Political Economy, 2002, 110 (6), 1175-1219.

- and B. Kelsey Jack, "Envirodevonomics: A Research Agenda for an Emerging Field," Journal of Economic Literature, March 2015, 53 (1), 5-42.

_, John A List, and Chad Syverson, "The Effects of Environmental Regulation on the Competitiveness of U.S. Manufacturing," Working Paper 18392, National Bureau of Economic Research September 2012.

Hainmueller, Jens, "Entropy Balancing for Causal Effects: A Multivariate Reweighting Method to Produce Balanced Samples in Observational Studies," Political Analysis, 2012, 20 (1), 25-46.

Hanna, Rema, "US Environmental Regulation and FDI: Evidence from a Panel of US-Based Multinational Firms," American Economic Journal: Applied Economics, July 2010, 2 (3), 158-89.

He, Guojun, Shaoda Wang, and Bing Zhang, "Watering Down Environmental Regulation in China," The Quarterly Journal of Economics, 06 2020, 135 (4), 2135-2185.

Holland, Stephen P., "Emissions taxes versus intensity standards: Second-best environmental policies with incomplete regulation," Journal of Environmental Economics and Management, 2012, 63 (3), 375-387.

Ito, Koichiro and Shuang Zhang, "Reforming Inefficient Energy Pricing: Evidence from China," Working Paper 26853, National Bureau of Economic Research March 2020. 
IWG, "Technical Support Document: Social Cost of Carbon, Methane, and Nitrous Oxide Interim Estimates under Executive Order 13990," United States Government, Interagency Working Group on Social Cost of Greenhouse Gases February 2021.

Jia, Ruixue, "Pollution for Promotion," 21st Century China Center Research Paper No. 201705, 2017, (March 21, 2017).

Kahn, Matthew E., Pei Li, and Daxuan Zhao, "Water Pollution Progress at Borders: The Role of Changes in China's Political Promotion Incentives," American Economic Journal: Economic Policy, November 2015, 7 (4), 223-42.

Karplus, Valerie J., Xingyao Shen, and Da Zhang, "Herding Cats: Firm Non-Compliance in China's Industrial Energy Efficiency Program," The Energy Journal, October 2020, 41 (1), 1944-9089.

Ke, Jing, Lynn Price, Stephanie Ohshita, David Fridley, Nina Zheng Khanna, Nan Zhou, and Mark Levine, "China's Industrial Energy Consumption Trends and Impacts of the Top-1000 Enterprises Energy-Saving Program and the Ten Key Energy-Saving Projects," Energy Policy, 2012, 50, 562 - 569.

Mansur, Erin T, "Prices vs. Quantities: Environmental Regulation and Imperfect Competition," Working Paper 13510, National Bureau of Economic Research October 2007.

McKinsey \& Co., "Unlocking Energy Efficiency in the U.S. Economy," Technical Report 2009.

Melitz, Marc J., "The Impact of Trade on Intra-Industry Reallocations and Aggregate Industry Productivity," Econometrica, 2003, 71 (6), 1695-1725.

- and Stephen J. Redding, "New Trade Models, New Welfare Implications," American Economic Review, 2015, 105 (3), 1105-46.

Ohrn, Eric, "The Effect of Corporate Taxation on Investment and Financial Policy: Evidence from the DPAD," American Economic Journal: Economic Policy, May 2018, 10 (2), 272-301.

Porter, Michael E. and Claas van der Linde, "Green and Competitive," Harvard Business Review, Sept-October 1995, pp. 120-134.

Price, Lynn, Xuejun Wang, and Jiang Yun, "The Challenge of Reducing Energy Consumption of the Top-1000 Largest Industrial Enterprises in China," Energy Policy, 2010, 38 (11), 6485-6498.

Ramachandran, J, K S Manikandan, and Anirvan Pant, "Why Conglomerates Thrive (Outside the U.S.)," Harvard Business Review, 2013, Dec 1, 2013.

Ryan, Nicholas, "Energy Productivity and Energy Demand: Experimental Evidence from Indian Manufacturing Plants," Working Paper 24619, National Bureau of Economic Research May 2018.

Ryan, Stephen P., "The Costs of Environmental Regulation in a Concentrated Industry," Econometrica, 2012, 80 (3), 1019-1061.

Shapiro, Joseph S., "Trade Costs, CO2, and the Environment," American Economic Journal: Economic Policy, November 2016, 8 (4), 220-54. 
_. "The Environmental Bias of Trade Policy*," The Quarterly Journal of Economics, 5 2021, $136(2), 831-886$.

- and Reed Walker, "Why Is Pollution from US Manufacturing Declining? The Roles of Environmental Regulation, Productivity, and Trade," American Economic Review, December 2018, 108 (12), 3814-54.

Soliman, Felix Samy, "Intrafirm Leakage," Technical Report 2020.

van Biesebroeck, Johannes, "Productivity Dynamics with Technology Choice: An Application to Automobile Assembly," The Review of Economic Studies, 01 2003, 70 (1), 167-198.

Walker, W. Reed, "The Transitional Costs of Sectoral Reallocation: Evidence from the Clean Air Act and the Workforce," The Quarterly Journal of Economics, 09 2013, 128 (4), 1787-1835. 


\section{Figures}

Figure 1: Cross-Country Differences in Industrial Energy Use

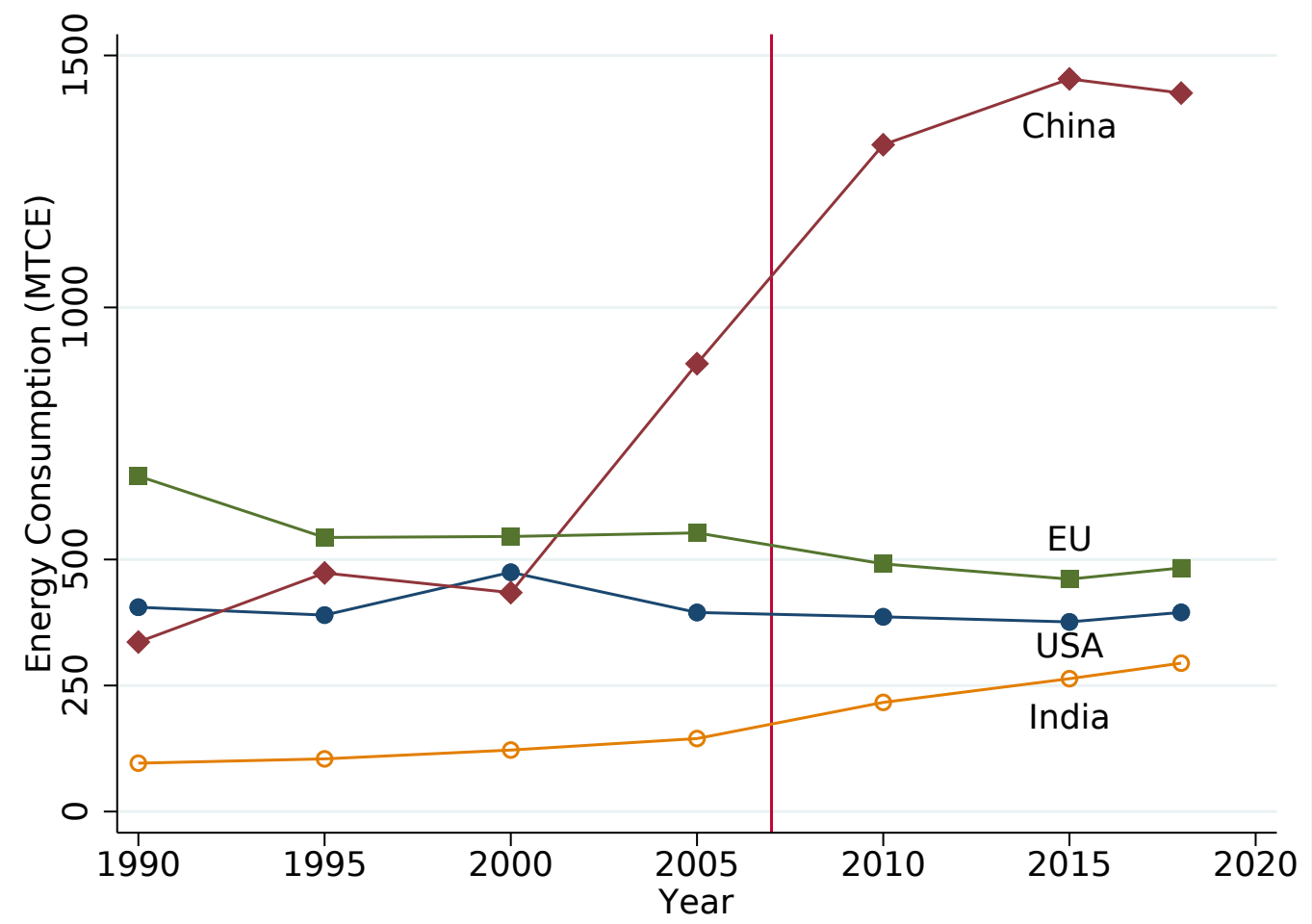

Notes: Authors' calculations using data from the IEA. This figure plots aggregate industrial energy consumption in China, the US, the EU and India from 1990 to 2018 using units of million tons of coal equivalent (MTCE). The industrial energy consumption of China increased dramatically after 2000, by more than threefold, while the industrial energy consumption of the US and EU remained relatively stable with a slight downward trend. The red line marks the start year of the Top 1,000 Energy Saving Program. 


\section{Figure 2: Examples of Firm Relations}

\section{A. Subsidiary}

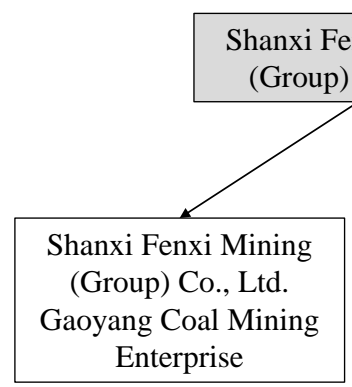

hanxi Fenxi Mining

\section{Shareholder}

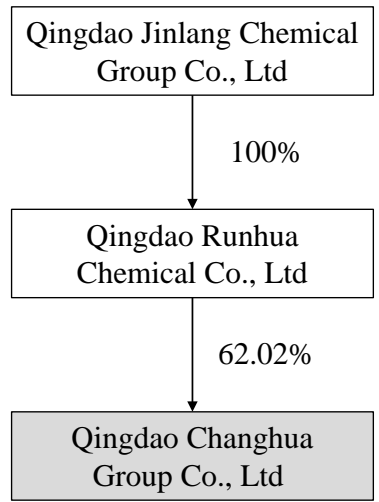

\section{B. Investment}

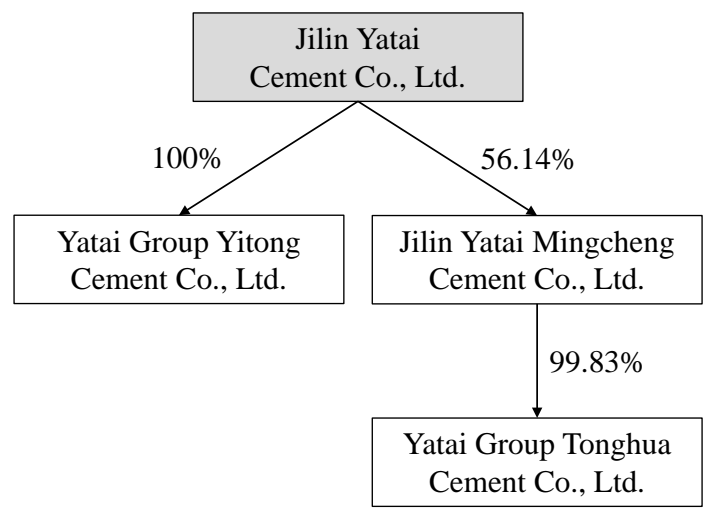

Notes: Authors' calculations using data from CARD. This figure shows examples of related firms, including wholly owned subsidiary firms in Panel A, investment firms in Panel B, shareholder firms in Panel C and shareholder investment firms in Panel D. Firms shaded in gray are part of the Top 1,000 program; firms without shading are part of the same conglomerate. In Panel D, we denote firms not in the same 4-digit industry as the Top 1,000 firm with dashed lines. Ownership share is reported next to each link. See Section 1.3 for the definition of related firms. 


\section{Figure 3: Conglomerate Size and Production Allocation}

\section{A. Relative Firm Size}

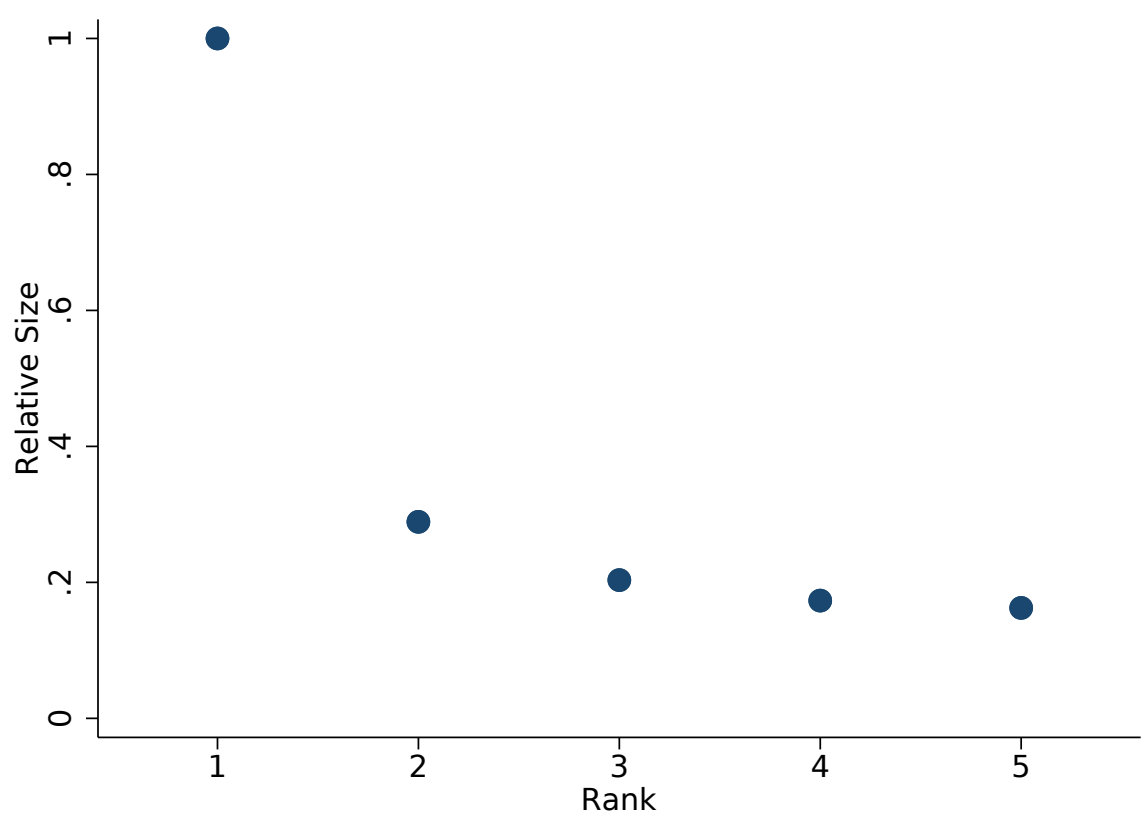

B. Output and Conglomerate Size

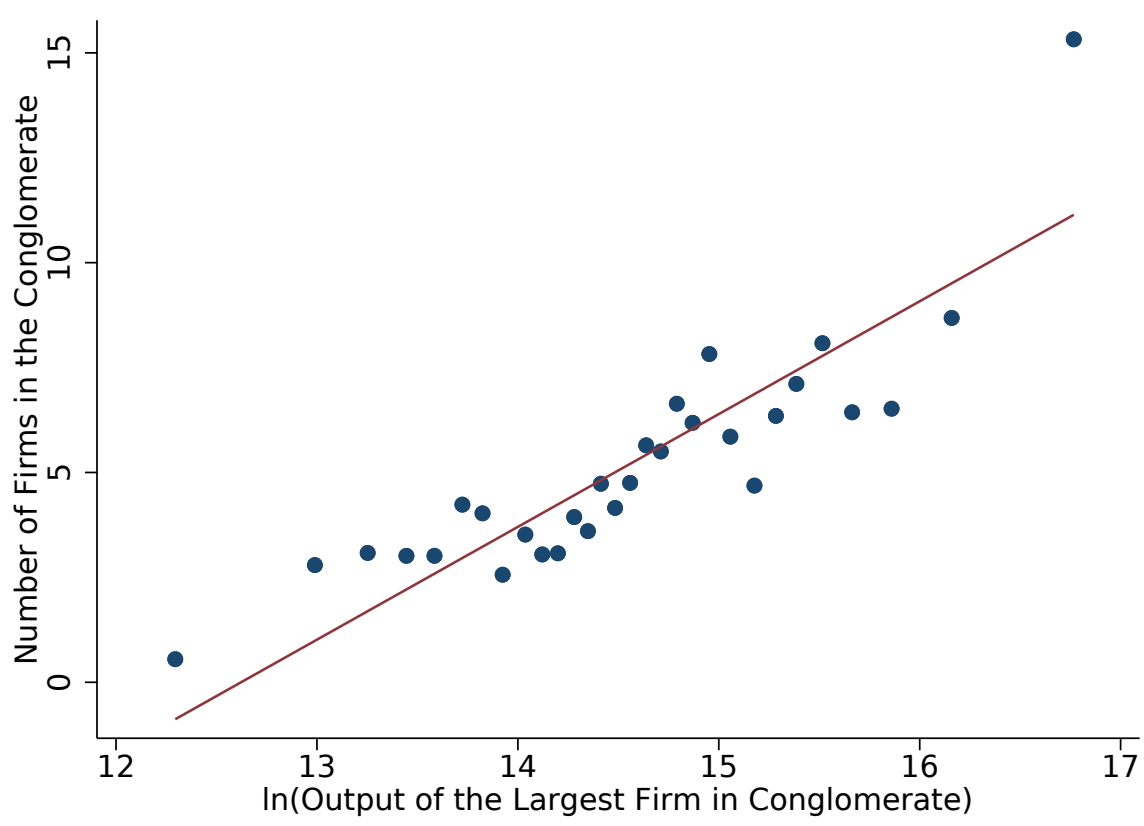

Notes: Authors' calculations using data from ASIF and CARD. This figure shows stylized facts about conglomerate size and relative firm size within conglomerate. Panel A plots the average relative size within a Top 1,000 conglomerate (each firm's size relative to the largest firm in the conglomerate). Firms are ranked by size from the largest to the smallest, and size is measured by industrial output. This figure shows that firm size declines very quickly in a conglomerate, with the second largest firm accounting for only $29 \%$ of the size of the largest. Panel B plots the results of a regression of firm number on log output of the largest firm in a Top 1,000 conglomerate. It shows that conglomerates with larger leading firms usually have more firms. See Section 1.3 for additional discussion 46 


\section{Figure 4: Effects of the Program on Regulated Firms}

A. Energy Use: Coefficients

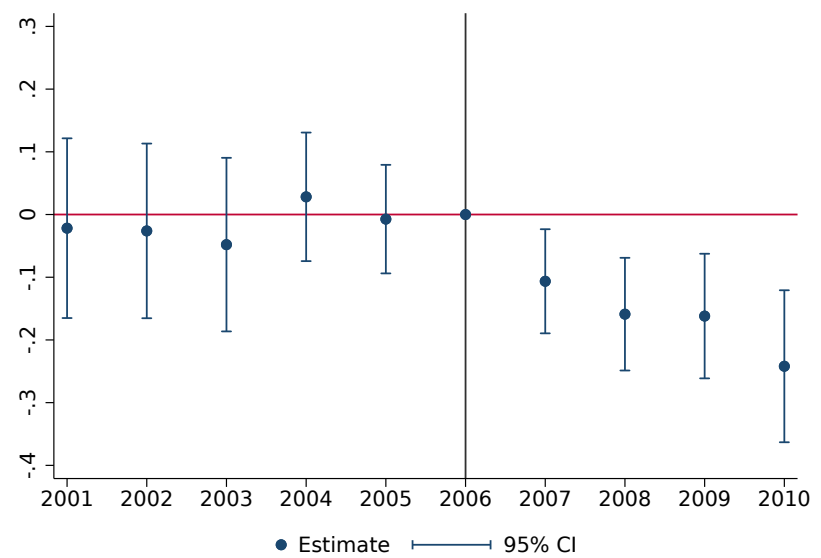

C. Output: Coefficients

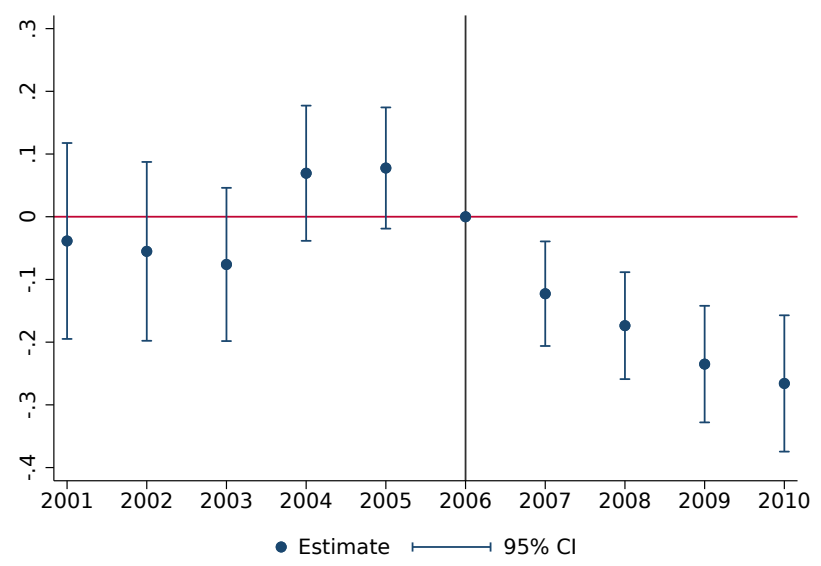

E. Energy Efficiency: Coefficients

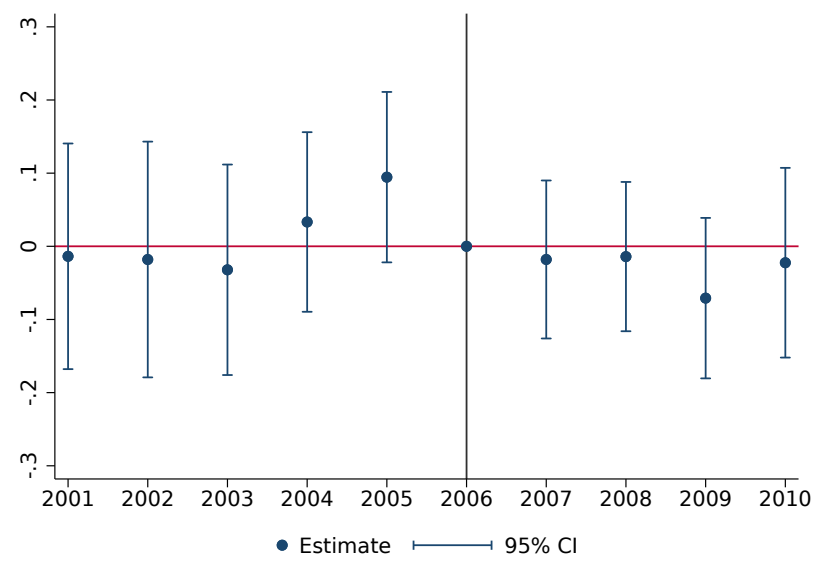

B. Energy Use: Event Study

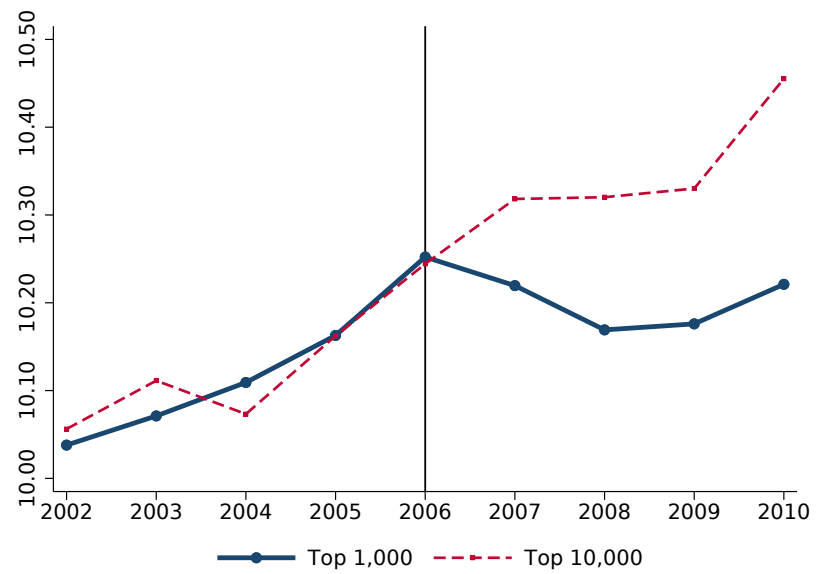

D. Output: Event Study

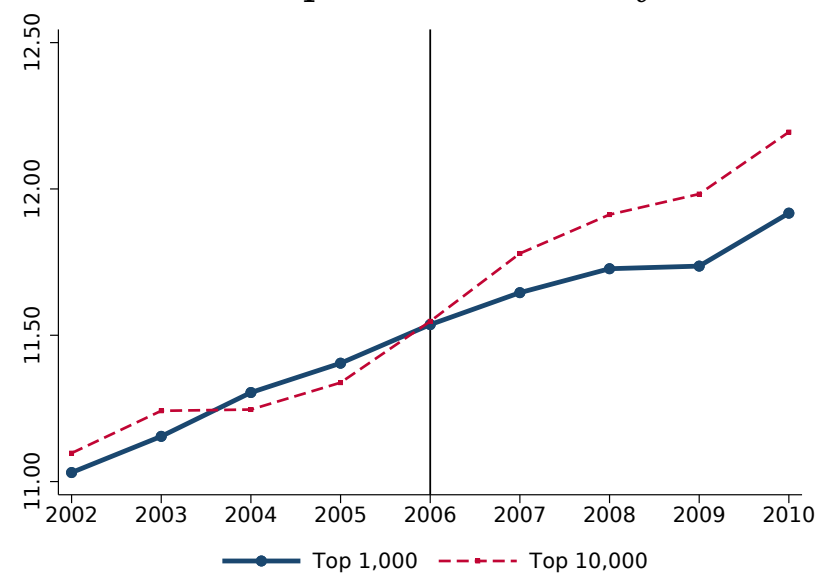

F. Energy Efficiency: Event Study

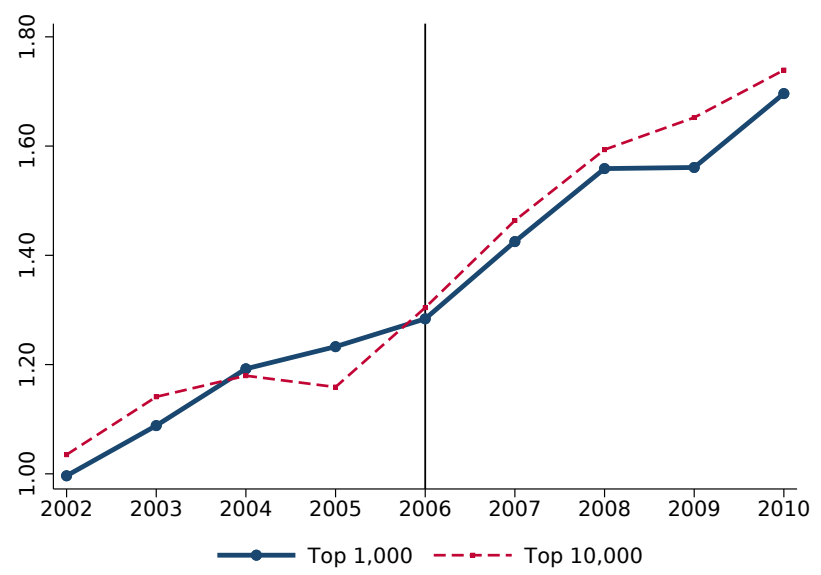

Notes: Authors' calculations using data from the CESD. This figure shows estimates of Equation 1 where the dependent variable is $\log$ firm energy consumption in Panels A and B, $\log$ firm output in Panels C and D, and log firm energy efficiency in Panels E and F. Energy efficiency is defined as output per unit of energy consumption. This figure shows that regulated firms (Top 1,000 firms) decreased their energy consumption and output substantially relative to similar control firms (Top 10,000 firms not related to Top 1,000 firms) after the regulation, while no improvement in energy efficiency in these rqgulated firms can be found. Point estimates are displayed in Table 3. See Section 2 for additional discussion. Standard errors are clustered at the firm level. 


\section{Figure 5: Spillover Effects on Related Firms}

\section{A. Output}

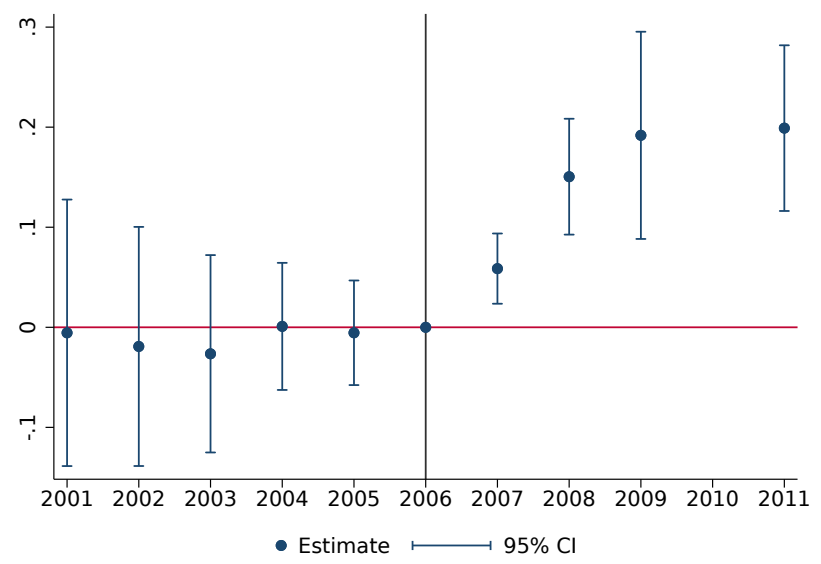

\section{Energy Use}

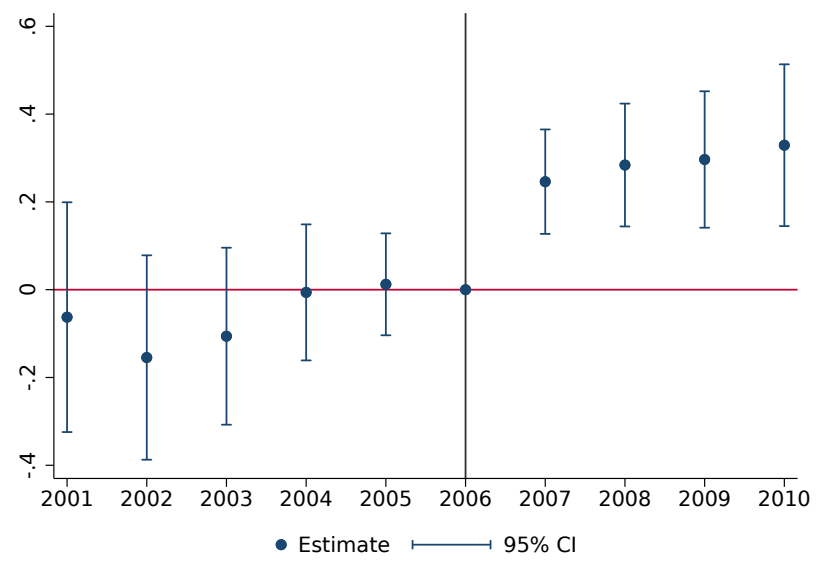

B. Placebo

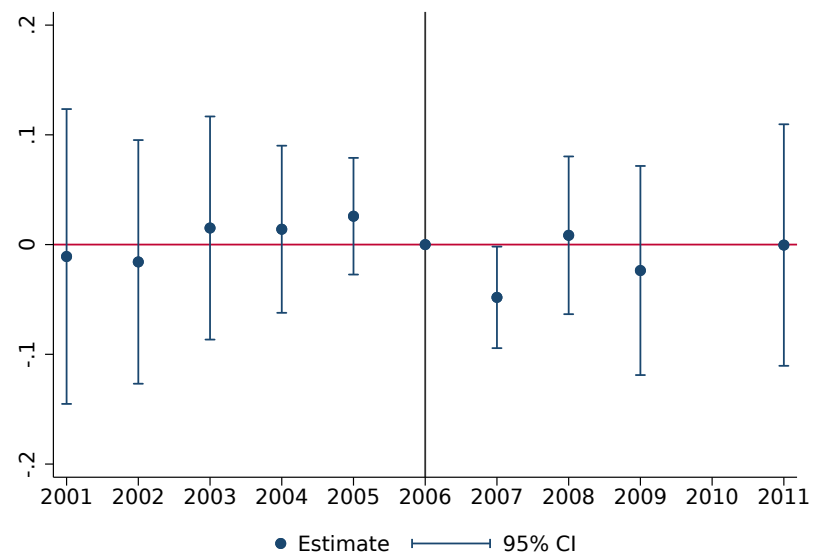

D. Energy Efficiency

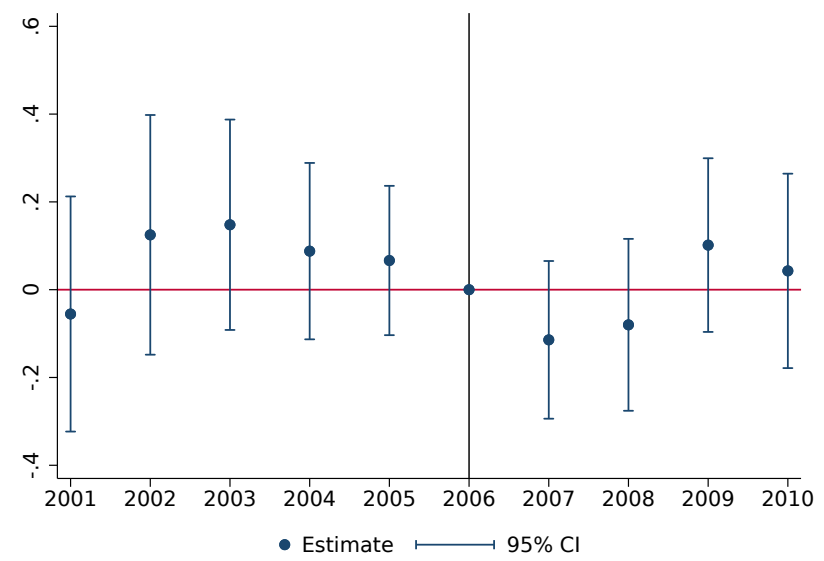

Notes: Authors' calculations using data from ASIF. This figure shows the effects of the Top 1,000 Energy Saving Program on the related parties of regulated firms. Panel A shows that related firms in the same 4-digit industry as regulated firms increased their output significantly after the policy implementation relative to similar control firms and that this effect persisted during the policy period. See Section 3 for a description of the procedure used to identify the comparison firms. The point estimate for Panel A is displayed in Panel A of Table 4. Panel B plots the output results for placebo firms (related firms in the same 2-digit industry but outside the 4-digit industry of regulated firms). This graph shows that placebo firms were not affected by the regulation. The point estimate for Panel B is displayed in Panel B of Table 4. Panels C and $\mathrm{D}$ show that related firms in the same 4-digit industry increased their energy consumption after the regulation but did not improve their energy efficiency relative to similar control firms. The point estimates for Panels C and D are displayed in Table 5. See Section 3 for additional discussion. The results of robustness checks using an alternative matching method are shown in Figure A.5. Standard errors are clustered at the firm level. 


\section{Figure 6: Industry-level Spillovers}

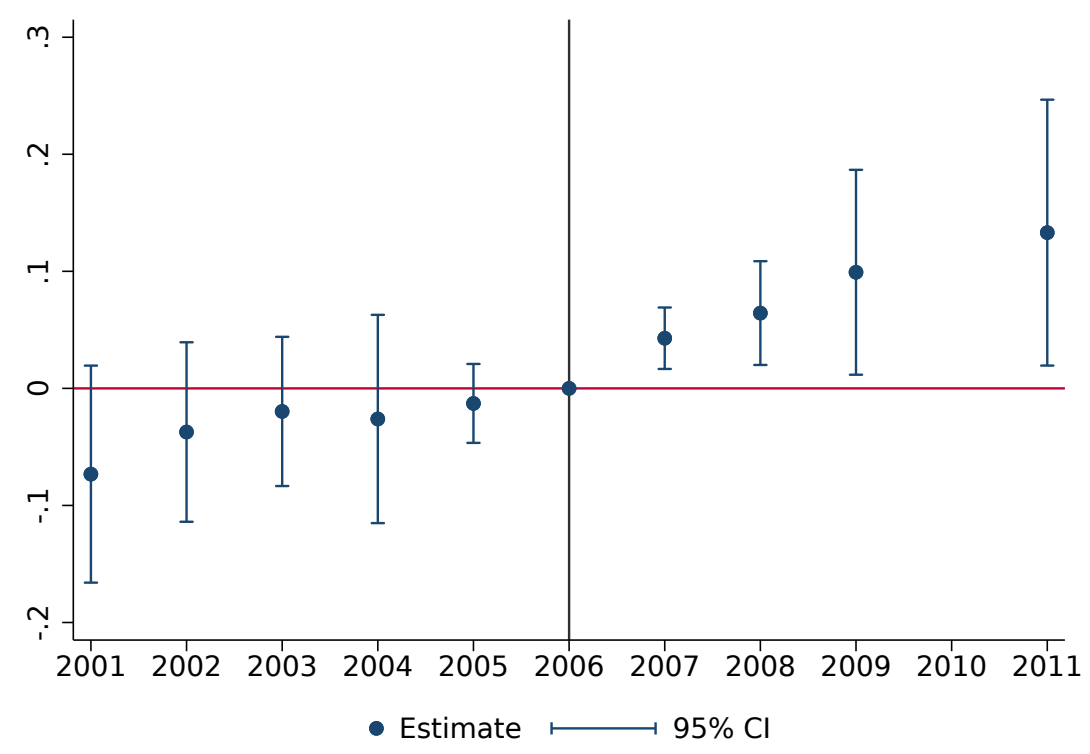

Notes: Authors' calculations using data from the ASIF. This figure shows estimates of Equation 3 where the dependent variable is $\log$ firm output. Consistent with the market spillover hypothesis, we see that unregulated firms in industries with stricter regulation increased their output significantly after the policy was implemented. Coefficient estimates and robustness checks are shown in Table 6 and Table A.16. See Section 3 for additional discussion. Standard errors are clustered at the firm level. 


\section{Figure 7: Structural Model Fit and Out-of-Sample Validation}

\section{A. Moments: Data vs. Model}

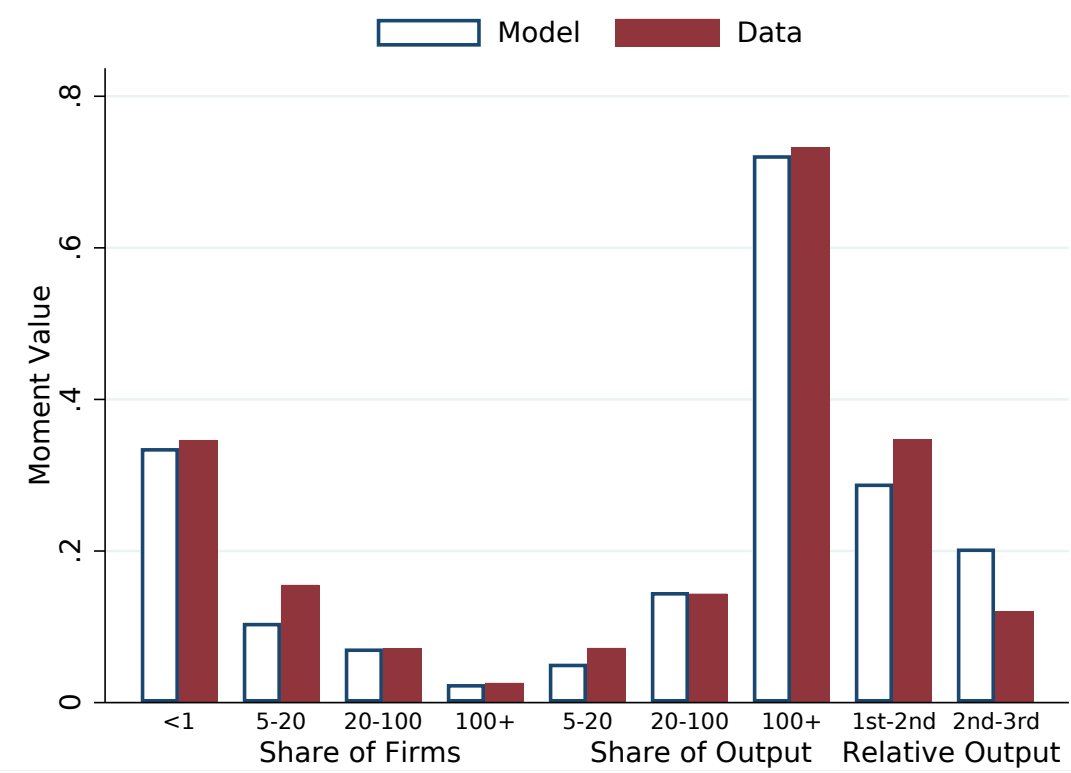

\section{B. Out-of-Sample Validation: Difference-in-Differences Effects of the Program}

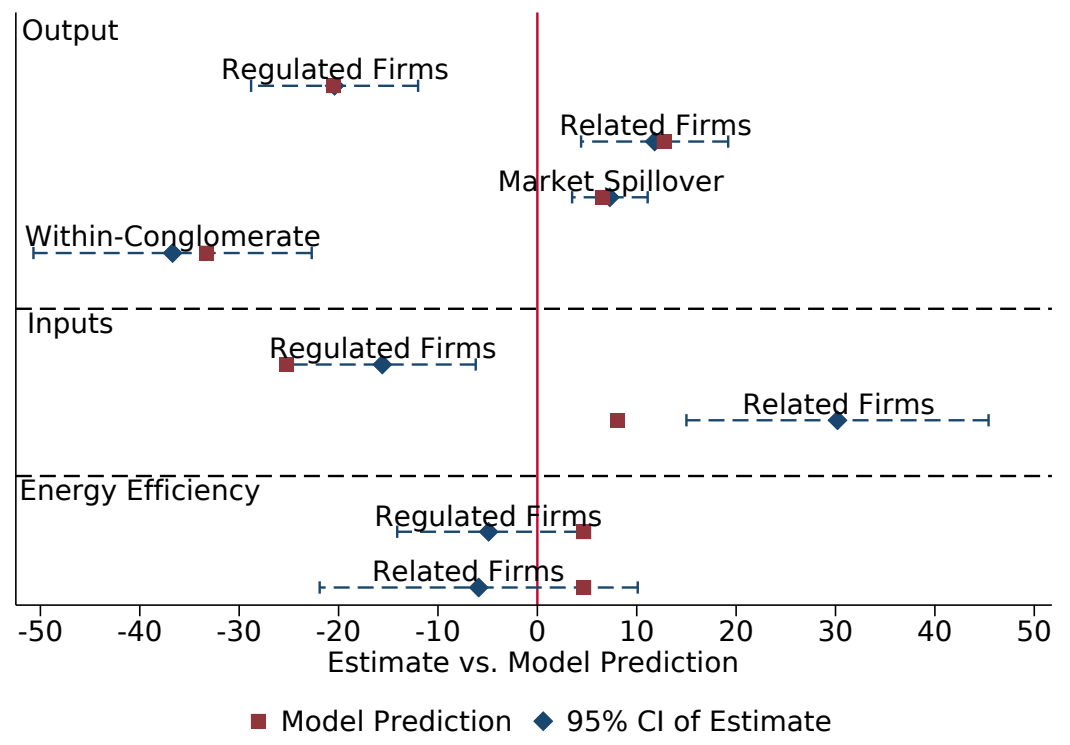

Notes: This figure shows the model fitting for both the firm size distribution prior to the policy and the firm response after the policy. Panel A plots the size distribution of firms predicted by our model in blue bars and the size distribution calculated from the ASIF and economic census of 2004 in red bars. It shows that our model fits the data well for both the observed firm size distribution and the concentration of output prior to the regulation. Panel B plots the firm response predicted by the model in red squares and the firm response obtained from our previous difference-in-differences estimates in blue diamonds. The blue lines span the $95 \%$ confidence interval for our difference-in-differences estimates. This graph shows that our model does a good job of fitting the output, input, and efficiency response of firms, with almost all model-predicted values lying within the $95 \%$ confidence intervals. See Section 5.2 for additional discussion. 


\section{Figure 8: Within-Conglomerate Difference-in-Differences}

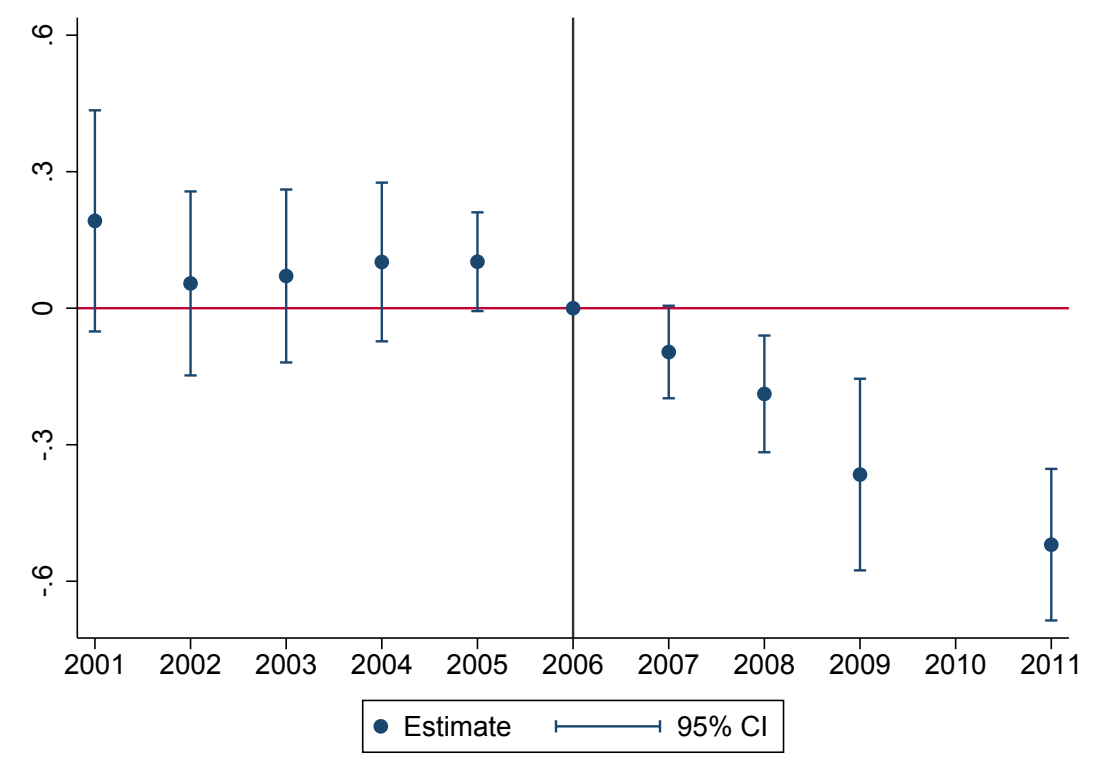

Notes: Authors' calculations using data from the ASIF. This figure plots the output change of regulated firms relative to their (same 4-digit industry) related firms within the same conglomerate. We see a strong and persistent output reallocation following the regulation from regulated firms to their related firms. Point estimates are displayed in Table 9. See Section 5.3 for additional discussion. Conglomerate-by-year fixed effects are included, and standard errors are clustered at the conglomerate level. 
Figure 9: Model-Based Estimates of the Shadow Costs of Regulation

\section{A. Shadow Costs of Alternative Regulations}

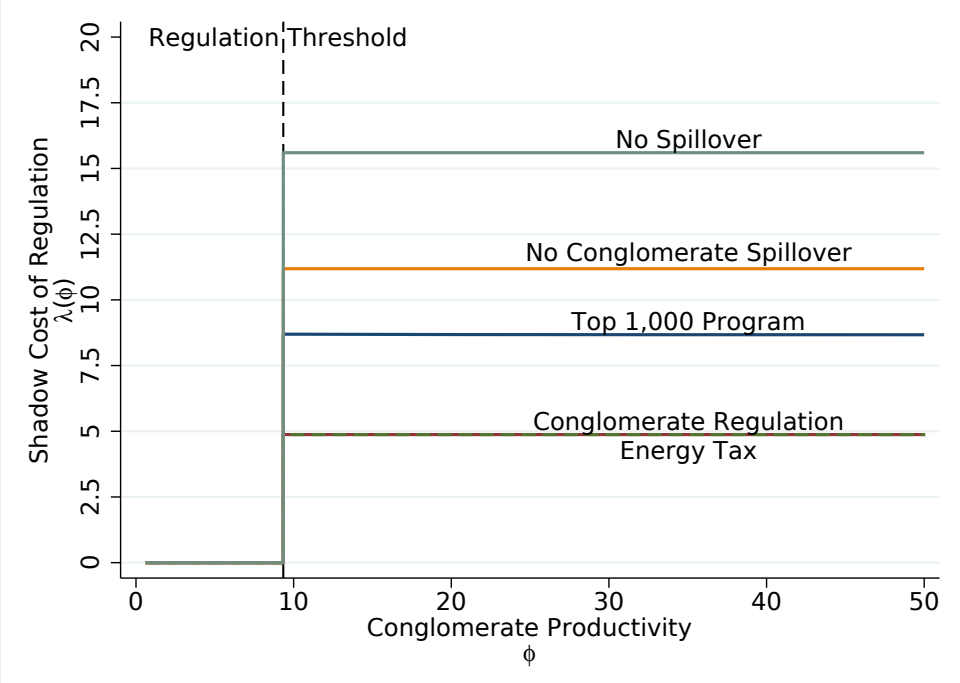

B. Size Distortions in Top 1,000 Program

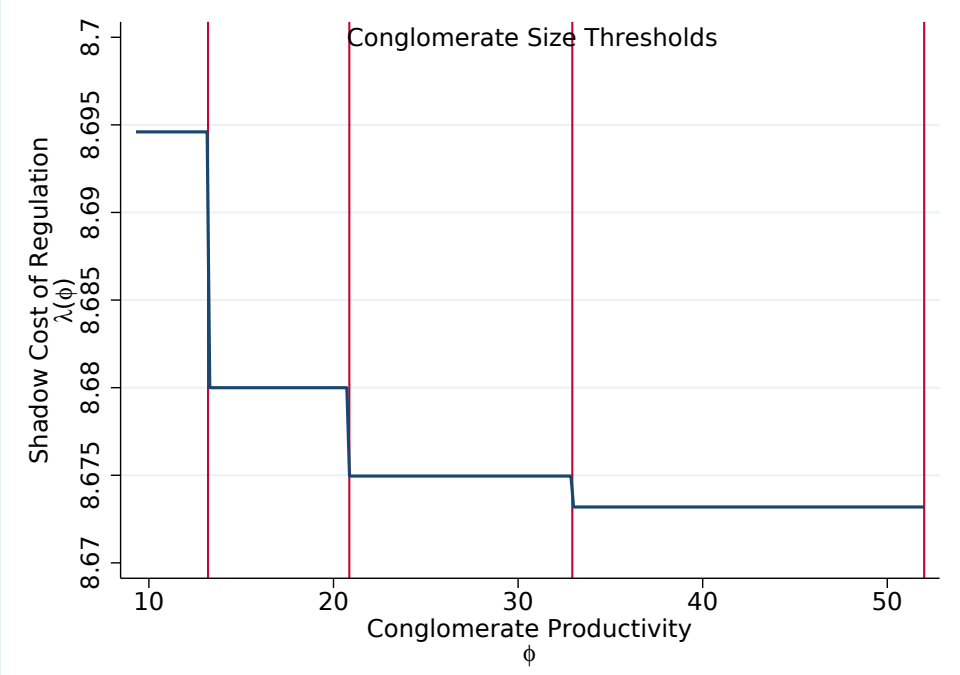

Notes: This figure shows the implied shadow cost of different regulations estimated by our model. Panel A plots the shadow cost of our baseline regulation (the Top 1,000 Energy Saving Program) with the blue line, the shadow cost of the counterfactual in which both conglomerate spillovers and market spillovers are shut down with the gray line, the shadow cost of the counterfactual in which only conglomerate spillovers are shut down with the yellow line, the shadow cost of regulating conglomerates with the same energy saving amount with the green line, and the shadow cost of imposing an energy tax with the same energy saving amount with the dashed red line. For each scenario, we solve the model and calculate the corresponding shadow cost. See Appendix E for the equilibrium conditions under these alternative regulations. We can see that both market spillovers and conglomerate spillovers lower the shadow cost substantially, while regulating conglomerates and imposing an energy tax can further lower the shadow cost by over $40 \%$ with the same amount of energy saving. Panel B zooms in to show the shadow cost under our baseline regulation. We see that shadow costs are no longer constant among different conglomerates as in Panel A. Conglomerates with more firms have a slightly lower shadow cost, while conglomerates with the same number of firms have the same shadow cost. See Section 6.1 and Section 6.2 for additional discussion. 


\section{Figure 10: Welfare Effects of Alternative Regulations}

\section{A. Changes to Top 1,000 Program}

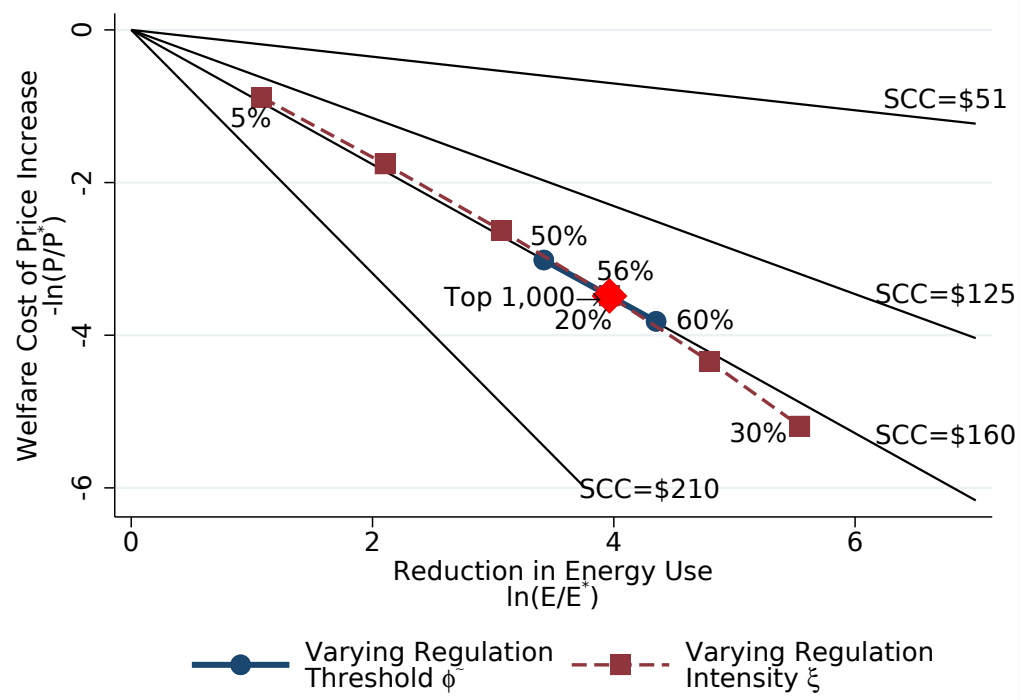

\section{B. Alternative Regulations}

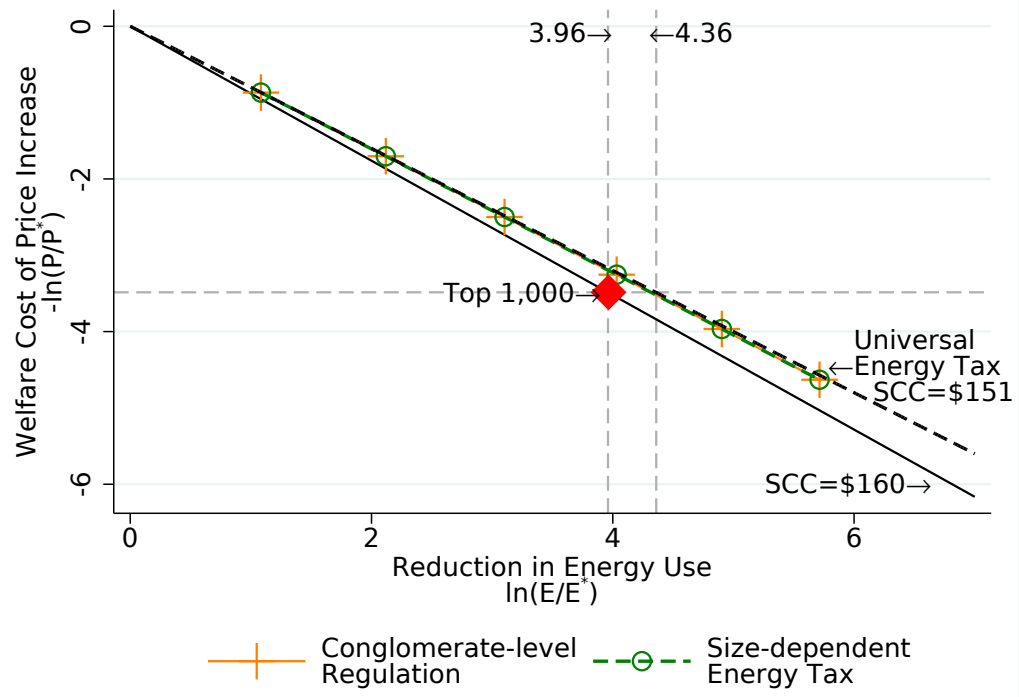

Notes: This figure shows the welfare effects of different regulations measured by the tradeoff between reductions in energy use and the welfare cost of price increases. Panel A shows the welfare effects of the Top 1,000 program. The black lines are indifference curves for different SSCs. The red diamond shows that the Top 1,000 program led to an aggregate energy consumption reduction of close to $4 \%$ and a price level increase of about $3.5 \%$, which can be rationalized with an $\mathrm{SSC}=\$ 160$. The navy line indicates that expanding or contracting policy coverage to cover between $50 \%$ and $60 \%$ of an industry's energy use does not change the fundamental trade-off between reductions in energy consumption and price increases. The crimson line indicates that increasing the input reduction quota from $5 \%$ to $30 \%$ makes this trade-off slightly worse. See Section 6.1 for additional discussion. Panel B shows the welfare effects under alternative types of regulations. Regulating conglomerates and imposing a size-dependent energy tax show a similar trade-off at an $\mathrm{SSC}=\$ 152$, which is a better performance than that of the original policy. A universal energy tax performs even better, with $\mathrm{SSC}=\$ 151$. See Section 6.2 for additional discussion. 
Figure 11: Welfare Effects: Robustness

\section{A. Endogenous Energy Efficiency}

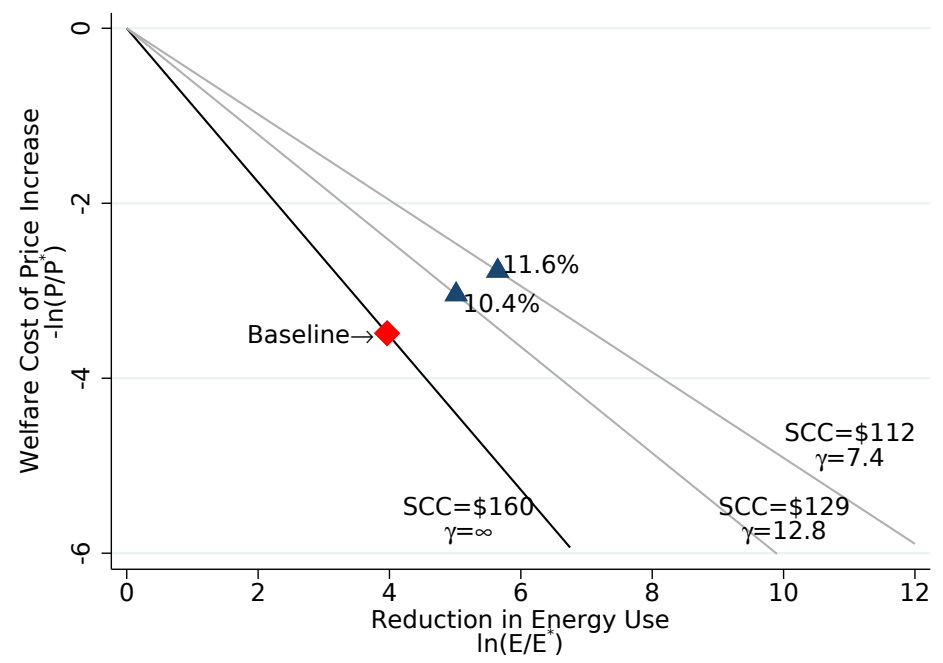

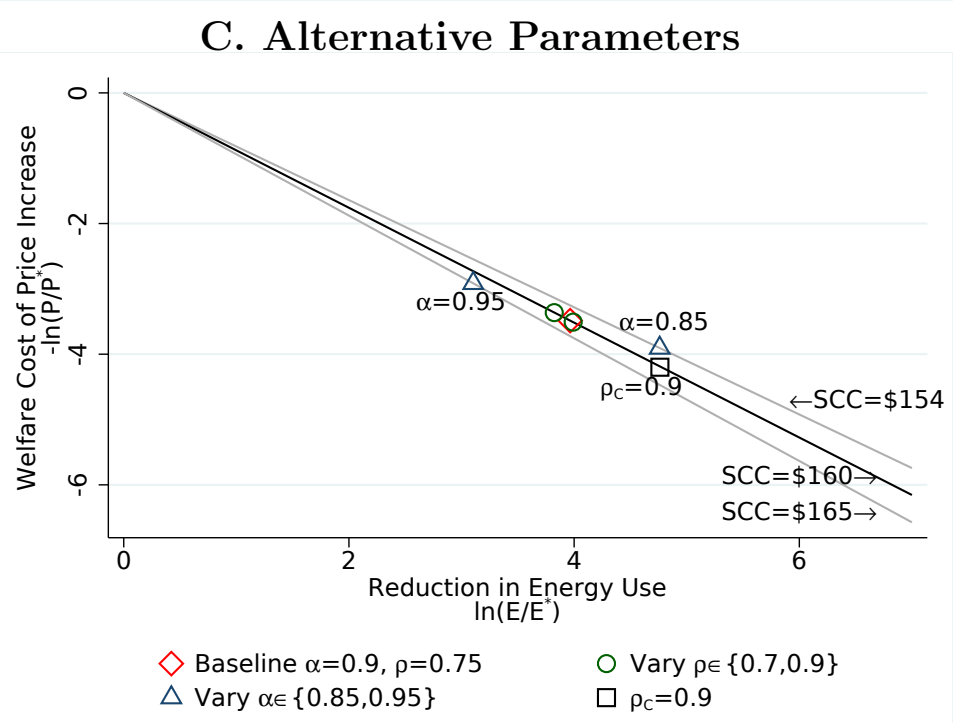

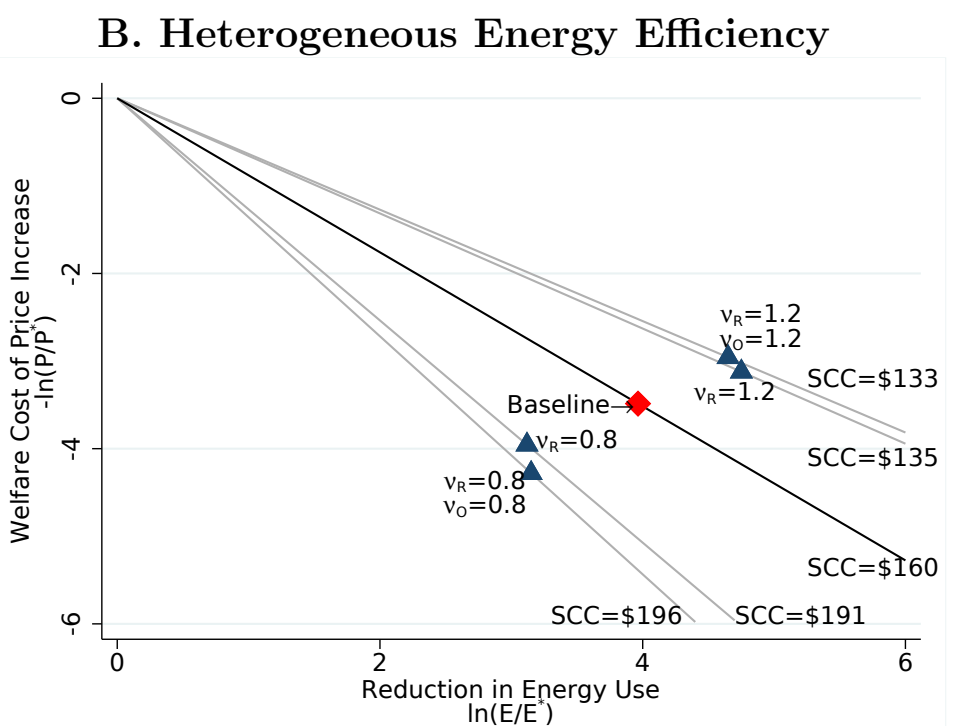

Notes: This figure shows the robustness of the welfare effects of the Top 1,000 program. The black lines plot indifference curves for the baseline value of $\mathrm{SCC}=\$ 160$, and the light gray lines plot values of the SCC according to different extensions. Panel A shows the effects under different values of the parameter $\gamma$, which determines the cost of improving energy efficiency. See Section 7.1 for details. Panel B shows the effects when we assume preexisting differences in energy efficiency. $\nu_{R}>1$ denotes that related firms are more energy efficient than Top 1,000 firms, while $\nu_{O}<1$ denotes that unregulated and unrelated firms are less efficient than Top 1,000 firms and vice versa. See Section 7.2 for details. Panel $\mathrm{C}$ shows the effects when we assume different values of the calibrated parameters. Blue triangles hold $\alpha=0.9$ and vary $\rho \in\{0.7,0.9\}$, while green circles hold $\rho=0.75$ and vary $\alpha \in$ $\{0.85,0.98\}$. See Section 7.3 for details. The black square in Panel $\mathrm{C}$ plots the effects when we assume that the outputs of firms in a conglomerate are imperfect substitutes (i.e., $\rho_{c}=0.9$ ). See Section 7.4 for details. Across these wide-ranging assumptions, the SCC that rationalizes the Top 1,000 program lies between $\$ 112$ and $\$ 196$. 


\section{Tables}

Table 1: Energy Consumption of Top 1,000 Firms in Different Industries

\begin{tabular}{lrrr}
\hline Industry & $\begin{array}{r}\text { Energy Consumption } \\
(10,000 \text { ton coal equiv. })\end{array}$ & $\begin{array}{r}\text { Proportion } \\
(\%)\end{array}$ & Firm Number \\
\hline Iron and Steel & 22528.63 & 30.72 & 249 \\
Electric Power & 16249.64 & 22.16 & 144 \\
Chemical & 10909.29 & 14.88 & 238 \\
Petroleum and Petrochemical & 10581.76 & 14.43 & 98 \\
Mining & 5278.77 & 7.20 & 60 \\
Nonferrous & 2993.08 & 4.08 & 70 \\
Construction Materials & 2913.19 & 3.97 & 93 \\
Pulp and Paper & 961.36 & 1.31 & 24 \\
Textile & 917.57 & 1.25 & 22 \\
\hline
\end{tabular}

Notes: This table reports the number of firms and energy consumption of Top 1,000 firms in each industry in 2005 according to the National Development and Reform Commission (NDRC) and National Bureau of Statistics (NBS) of China (Bulletin on Top 1,000 Firms' Energy Consumption, 2007). The first column shows the industry name, the second column shows the aggregate energy consumption of Top 1,000 firms in each industry in 2005, the third column shows the proportion of energy consumption, and the last column shows the number of firms. A total of 998 of the 1008 Top 1,000 firms are included in this report. 
Table 2: Summary Statistics

A. Firm-level Data

\begin{tabular}{llcccccc}
\hline \multirow{2}{*}{ Source } & \multirow{3}{*}{ Variables } & \multicolumn{3}{c}{ Top 1,000 } & \multicolumn{4}{c}{ Top 10,000 } \\
& & & & \multicolumn{4}{c}{ Excluding Top 1,000) } \\
\cline { 2 - 7 } & & Obs & Mean & SD & Obs & Mean & SD \\
\hline \multirow{4}{*}{ ASIF } & $\ln$ (Output) & 8,745 & 14.15 & 1.58 & 81,547 & 12.18 & 1.60 \\
& Soe & 8,787 & 0.31 & 0.46 & 81,833 & 0.09 & 0.29 \\
& ROA & 8,564 & 0.05 & 0.10 & 79,944 & 0.08 & 0.16 \\
& Age & 8,777 & 23.03 & 20.32 & 81,721 & 12.55 & 13.67 \\
& Export & 8,789 & 0.34 & 0.47 & 81,845 & 0.26 & 0.44 \\
\hline \multirow{4}{*}{ CESD } & $\ln$ (Energy) & 3,419 & 12.37 & 1.48 & 20,207 & 9.84 & 1.58 \\
& $\ln$ (Coal) & 3,419 & 12.41 & 1.47 & 20,207 & 9.91 & 1.59 \\
& $\ln$ (Output) & 3,381 & 13.69 & 1.66 & 20,076 & 11.26 & 1.58 \\
& $\ln$ (Efficiency) & 3,381 & 1.31 & 1.45 & 20,076 & 1.42 & 1.71 \\
\hline
\end{tabular}

\section{B. Conglomerate Networks: Related Parties}

\begin{tabular}{lcccc}
\hline \multirow{2}{*}{ Datasets } & \multicolumn{3}{c}{ Two Levels } & Six Levels \\
\cline { 2 - 4 } & $25 \%$ & $20 \%$ & $51 \%$ & $20 \%$ \\
\hline CARD & 46,178 & 50,846 & 30,096 & 77,783 \\
CARD\&ASIF & 7,329 & 7,907 & 5,061 & 9,832 \\
CARD\&ASIF (same 2-digit industry) & 3,992 & 4,137 & 2,941 & 4,800 \\
CARD\&ASIF (same 4-digit industry) & $\mathbf{2 , 4 6 6}$ & 2,514 & 1,963 & 2,827 \\
\hline
\end{tabular}

Notes: This table reports summary statistics for Top 1,000 firms, Top 10,000 firms, and the conglomerate networks of Top 1,000 firms. Panel A shows the mean characteristics and firm counts with nonmissing data from the ASIF and CESD for Top 1,000 and Top 10,000 firms. We exclude related firms from the same 4-digit industry as Top 10,000 firms for both datasets. Additionally, for the CESD data, we exclude all industries whose electricity consumption accounts for more than $30 \%$ of total industry energy consumption. See Section 1.2 for a detailed data description and the cleaning procedure. Panel B shows the total number of related firms that Top 1,000 firms have under different definitions of related parties. With 2 levels and a $25 \%$ ownership requirement, Top 1,000 firms have 3,992 related firms in the same 2-digit industry in the ASIF and 2,466 related firms in the same 4-digit industry in the ASIF. See Section 1.3 for additional discussion. 
Table 3: Effects of the Program on Regulated Firms

\begin{tabular}{lcccc}
\multicolumn{5}{c}{ A. Energy Use } \\
\hline Variables & \multicolumn{5}{c}{$\ln ($ Energy Use $)$} \\
\hline Treat $\times$ Post & $-0.125^{* * *}$ & $-0.156^{* * *}$ & $-0.156^{* * *}$ & $-0.128^{* * *}$ \\
& $(0.042)$ & $(0.045)$ & $(0.047)$ & $(0.048)$ \\
\hline Observations & 23,607 & 23,602 & 23,151 & 20,571 \\
$R^{2}$ & 0.887 & 0.890 & 0.892 & 0.898 \\
\hline
\end{tabular}

B. Output

\begin{tabular}{|c|c|c|c|c|}
\hline Variables & \multicolumn{4}{|c|}{$\ln ($ Output $)$} \\
\hline Treat $\times$ Post & $\begin{array}{c}-0.096^{* *} \\
(0.040)\end{array}$ & $\begin{array}{c}-0.226^{* * *} \\
(0.041)\end{array}$ & $\begin{array}{c}-0.204^{* * *} \\
(0.042)\end{array}$ & $\begin{array}{c}-0.145^{* * *} \\
(0.042)\end{array}$ \\
\hline Observations & 23,435 & 23,430 & 22,991 & 20,446 \\
\hline$R^{2}$ & 0.881 & 0.887 & 0.889 & 0.893 \\
\hline \multicolumn{5}{|c|}{ C. Energy Efficiency } \\
\hline Variables & \multicolumn{4}{|c|}{$\ln ($ Energy Effiency $)$} \\
\hline Treat $\times$ Post & $\begin{array}{c}0.032 \\
(0.042)\end{array}$ & $\begin{array}{l}-0.069 \\
(0.044)\end{array}$ & $\begin{array}{l}-0.049 \\
(0.046)\end{array}$ & $\begin{array}{l}-0.019 \\
(0.047)\end{array}$ \\
\hline Observations & 23,435 & 23,430 & 22,991 & 20,446 \\
\hline$R^{2}$ & 0.837 & 0.840 & 0.842 & 0.848 \\
\hline Firm FE & $\mathrm{Y}$ & $\mathrm{Y}$ & $\mathrm{Y}$ & $\mathrm{Y}$ \\
\hline Year FE & $\mathrm{Y}$ & $\mathrm{Y}$ & Y & $\mathrm{Y}$ \\
\hline Industry $\times$ Year FE & & $\mathrm{Y}$ & $\mathrm{Y}$ & $\mathrm{Y}$ \\
\hline Province $\times$ Year FE & & & $\mathrm{Y}$ & $\mathrm{Y}$ \\
\hline Firm-level Controls & & & & $\mathrm{Y}$ \\
\hline
\end{tabular}

Notes: Authors' calculations using data from the CESD and ASIF. This table shows estimates of Equation 2 where Treat $\times$ Post is an indicator for regulated firms interacted with an indicator for years after 2006 and the dependent variable is log firm energy consumption in Panel A, log firm output in Panel B, and log firm energy efficiency in Panel C. The estimates in this table correspond to a pooled version of the regression displayed in Figure 4. The coefficient in column (4) means that regulated firms decreased energy consumption by $12.8 \%$ and output by $14.5 \%$, while no significant energy efficiency improvement after the policy implementation can be found. See Section 2 for additional discussion and Table 2 for more information about the data and variables. Standard errors clustered at the firm level are shown in parentheses with p-values below. * $p<0.1, * * p<0.05, * * * p<0.01$. 
Table 4: Spillover Effects on the Output of Related Firms

A. Output

\begin{tabular}{lcccc}
\hline Variables & \multicolumn{4}{c}{$\ln ($ Output $)$} \\
\hline Related $\times$ Post & $0.152^{* * *}$ & $0.147^{* * *}$ & $0.118^{* * *}$ & $0.127^{* * *}$ \\
& $(0.037)$ & $(0.037)$ & $(0.037)$ & $(0.035)$ \\
\hline Observations & 18,423 & 18,420 & 18,418 & 17,905 \\
$R^{2}$ & 0.865 & 0.873 & 0.881 & 0.889 \\
\hline
\end{tabular}

B. Placebo Test on Output

\begin{tabular}{lcccc}
\hline Variables & \multicolumn{4}{c}{$\ln$ (Output) } \\
\hline Related $\times$ Post & -0.026 & -0.025 & -0.015 & -0.003 \\
& $(0.040)$ & $(0.039)$ & $(0.039)$ & $(0.038)$ \\
\hline Observations & 8,923 & 8,921 & 8,905 & 8,730 \\
$R^{2}$ & 0.898 & 0.903 & 0.911 & 0.919 \\
\hline
\end{tabular}

C. Heterogeneous Effects on Output by Firm Size

\begin{tabular}{lcccc}
\hline Variables & \multicolumn{4}{c}{$\ln$ (Output) } \\
\hline Related $\times$ Post(0\%-30\%) & $0.104^{*}$ & $0.109^{* *}$ & 0.048 & 0.078 \\
& $(0.054)$ & $(0.052)$ & $(0.052)$ & $(0.051)$ \\
Related $\times$ Post(30\%-60\%) & $0.130^{* * *}$ & $0.123^{* * *}$ & $0.096^{* *}$ & $0.111^{* *}$ \\
& $(0.047)$ & $(0.045)$ & $(0.046)$ & $(0.043)$ \\
Related $\times$ Post(60\%-100\%) & $0.164^{* * *}$ & $0.156^{* * *}$ & $0.161^{* * *}$ & $0.161^{* * *}$ \\
& $(0.045)$ & $(0.044)$ & $(0.043)$ & $(0.040)$ \\
\hline Observations & 17,691 & 17,691 & 17,689 & 17,212 \\
$R^{2}$ & 0.892 & 0.900 & 0.907 & 0.915 \\
\hline Firm FE & $\mathrm{Y}$ & $\mathrm{Y}$ & $\mathrm{Y}$ & $\mathrm{Y}$ \\
Year FE & $\mathrm{Y}$ & $\mathrm{Y}$ & $\mathrm{Y}$ & $\mathrm{Y}$ \\
Industry $\times$ Year FE & & $\mathrm{Y}$ & $\mathrm{Y}$ & $\mathrm{Y}$ \\
Province $\times$ Year FE & & & $\mathrm{Y}$ & $\mathrm{Y}$ \\
Firm-level Controls & & & & $\mathrm{Y}$ \\
\hline
\end{tabular}

Notes: Authors' calculations using data from the ASIF. This table shows estimates of Equation 2 where Related $\times$ Post is an indicator for related firms interacted with an indicator for years after 2006 and the dependent variable is log firm output. The estimates in Panel A correspond to a pooled version of the regression displayed in Panel A of Figure 5. It shows that related firms in the same 4-digit industries increased output by $11.8 \%-15.2 \%$ after the policy implementation. The estimates in Panel B correspond to a pooled version of the regression displayed in Panel $\mathrm{B}$ of Figure 5 and show that related firms outside the 4-digit industry of regulated firms (but still in the same 2-digit industry) were not significantly affected by the policy. Panel C shows estimates of heterogeneous spillover effects by terciles of firm size. We can see that the related spillovers are greater for larger related firms. See Section 3 for additional discussion. The results of robustness checks with additional matching methods are shown in Table A.9. Standard errors clustered at the firm level are shown in parentheses with p-values below. ${ }^{*} p<0.1,{ }^{* *} p<0.05$, $* * * \quad p<0.01$. 
Table 5: Spillover Effects on Related Firms: Energy Use and Energy Efficiency

\begin{tabular}{|c|c|c|c|c|}
\hline \multicolumn{5}{|c|}{ A. Energy Use } \\
\hline Variables & \multicolumn{4}{|c|}{$\ln ($ Energy Use) } \\
\hline Related $\times$ Post & $\begin{array}{c}0.322^{* * *} \\
(0.075)\end{array}$ & $\begin{array}{c}0.320^{* * *} \\
(0.073)\end{array}$ & $\begin{array}{c}0.302^{* * *} \\
(0.076)\end{array}$ & $\begin{array}{c}0.318^{* * *} \\
(0.094)\end{array}$ \\
\hline Observations & 3,759 & 3,759 & 3,705 & 2,823 \\
\hline$R^{2}$ & 0.916 & 0.919 & 0.927 & 0.926 \\
\hline \multicolumn{5}{|c|}{ B. Energy Efficiency } \\
\hline Variables & \multicolumn{4}{|c|}{$\ln$ (Energy Efficiency) } \\
\hline Related $\times$ Post & $\begin{array}{l}-0.077 \\
(0.078)\end{array}$ & $\begin{array}{l}-0.077 \\
(0.077)\end{array}$ & $\begin{array}{l}-0.059 \\
(0.080)\end{array}$ & $\begin{array}{l}-0.087 \\
(0.099)\end{array}$ \\
\hline Observations & 3,724 & 3,722 & 3,668 & 2,801 \\
\hline$R^{2}$ & 0.866 & 0.870 & 0.880 & 0.867 \\
\hline Firm FE & Y & $\mathrm{Y}$ & $\mathrm{Y}$ & $\mathrm{Y}$ \\
\hline Year FE & Y & $\mathrm{Y}$ & Y & $\mathrm{Y}$ \\
\hline Industry $\times$ Year FE & & $\mathrm{Y}$ & Y & $\mathrm{Y}$ \\
\hline Province $\times$ Year FE & & & Y & Y \\
\hline Firm-level Controls & & & & $\mathrm{Y}$ \\
\hline
\end{tabular}

Notes: Authors' calculations using data from the CESD and ASIF. This table shows estimates of Equation 2 where Related $\times$ Post is an indicator for same 4-digit industry related firms interacted with an indicator for years after 2006 and the dependent variable is log firm energy consumption in Panel A and log firm energy efficiency in Panel B. The estimates in this table correspond to a pooled version of the regression displayed in Panels $\mathrm{C}$ and $\mathrm{D}$ of Figure 5. This figure shows that same 4-digit related firms increased their energy consumption by $30.2 \%-32.2 \%$ after the policy implementation but that their energy efficiency did not improve significantly. See Section 3 for additional discussion. The results of robustness tests with additional matching methods are shown in Table A.10. Standard errors clustered at the firm level are shown in parentheses with p-values below. ${ }^{*} p<0.1,{ }^{* *} p<0.05,{ }^{* * *} p<0.01$. 
Table 6: Industry-level Spillovers

\begin{tabular}{lcccc}
\hline Variables & \multicolumn{4}{c}{$\ln ($ Output $)$} \\
\cline { 2 - 5 } & \multicolumn{3}{c}{ All Sample } & Energy-Intensive Industries \\
\hline Spillover $\times$ Post & $0.081^{* * *}$ & $0.073^{* * *}$ & $0.083^{* * *}$ & $0.084^{* *}$ \\
& $(0.022)$ & $(0.019)$ & $(0.023)$ & $(0.027)$ \\
\hline Observations & $2,557,940$ & $2,557,940$ & 843,313 & 843,313 \\
$R^{2}$ & 0.840 & 0.856 & 0.831 & 0.848 \\
\hline Firm FE & $\mathrm{Y}$ & $\mathrm{Y}$ & $\mathrm{Y}$ & $\mathrm{Y}$ \\
Year FE & $\mathrm{Y}$ & $\mathrm{Y}$ & $\mathrm{Y}$ & $\mathrm{Y}$ \\
Industry-level Controls & $\mathrm{Y}$ & $\mathrm{Y}$ & $\mathrm{Y}$ & $\mathrm{Y}$ \\
Firm-level Controls & & $\mathrm{Y}$ & & $\mathrm{Y}$ \\
\hline
\end{tabular}

Notes: Authors' calculations using data from the ASIF. This table shows estimates of Equation 3 where Spillover $\times$ Post is an indicator for industry-level exposure to the Top 1,000 program interacted with an indicator for years after 2006 and the dependent variable is log firm output. Exposure to Top 1,000 program is defined as the proportion of total energy saving targets of Top 1,000 firms relative to the total energy consumption in 2004 for each industry. The estimates in this table correspond to a pooled version of the regression displayed in Figure 6. The results show that the average market-level spillover led to a $7.3 \%-8.4 \%$ increase in the output of unregulated firms. See Section 3 for additional discussion. Standard errors clustered at the firm level are shown in parentheses with p-values below. ${ }^{*} p<0.1,{ }^{* *} p<0.05,{ }^{* * *} p<0.01$.

Table 7: Structural Model Parameters

\begin{tabular}{|c|c|c|c|}
\hline Parameter & & Value & Target \\
\hline \multicolumn{4}{|l|}{ 1. Fixed Values } \\
\hline Elasticity of substitution & $\sigma=\frac{1}{1-\rho}$ & 4.00 & Melitz and Redding (2015) \\
\hline Returns to scale & $\alpha^{1-\rho}$ & 0.90 & Burnside et al. (1995) \\
\hline Returns to scale (Labor Share) & $\alpha_{l}$ & 0.80 & Cost share of variable inputs \\
\hline \multicolumn{4}{|l|}{ 2. Method of Moments } \\
\hline Efficiency depreciation & $\delta$ & $\begin{array}{c}0.900 \\
(0.003)\end{array}$ & Within-conglomerate distribution \\
\hline Dispersion of ln-ability $\phi$ & $\sigma_{m}$ & $\begin{array}{c}1.239 \\
(0.055)\end{array}$ & Firm size distribution \\
\hline Survival threshold & $\phi_{1}$ & $\begin{array}{c}0.609 \\
(0.166)\end{array}$ & Share of small firms \\
\hline \multicolumn{4}{|l|}{ 3. Policy Parameters } \\
\hline Policy threshold & $\bar{\phi}$ & 9.29 & Energy share of Top 1,000 firms \\
\hline Input quota & $1-\xi$ & 0.20 & 11th Five Year Plan \\
\hline
\end{tabular}

Notes: This table summarizes the parameters that we set or estimate to solve the model. Standard errors are calculated using a bootstrapped variance-covariance matrix of data moments. See Section 5.1 for the detailed estimation procedure. 
Table 8: Model Decomposition of Difference-in-Differences Estimates

\begin{tabular}{|c|c|c|c|c|}
\hline & $\begin{array}{c}\text { Allocation } \\
\text { Effect }\end{array}$ & $\begin{array}{c}\text { Residual Revenue } \\
\text { Effect }\end{array}$ & $\begin{array}{c}\text { Market } \\
\text { Effect }\end{array}$ & $\begin{array}{l}\text { Total } \\
\text { Effect }\end{array}$ \\
\hline \multicolumn{5}{|l|}{ A. Effect on Regulated Firms } \\
\hline Top 1,000 Firms & -0.129 & -0.037 & 0.026 & -0.140 \\
\hline Control Firms & 0 & 0.039 & 0.026 & 0.065 \\
\hline Difference-in-Differences & -0.129 & -0.076 & 0 & -0.205 \\
\hline \multicolumn{5}{|l|}{ B. Effect on Related Firms } \\
\hline Related Firms & 0.204 & -0.037 & 0.026 & 0.193 \\
\hline Control Firms & 0 & 0.039 & 0.026 & 0.065 \\
\hline Difference-in-Differences & 0.204 & -0.076 & 0 & 0.128 \\
\hline \multicolumn{5}{|l|}{ C. Within-Conglomerate Effect } \\
\hline Difference-in-Differences & -0.333 & 0 & 0 & -0.333 \\
\hline
\end{tabular}

Notes: This table reports the decomposition results for difference-in-differences estimates according to the model. Panels A, B, and C in this table correspond to Panel B of Table 3, Panel A of Table 4, and Table 9 separately by decomposing the difference-in-differences estimates first into the effects on treated and control firms and then further into allocation effects, residual revenue effects and market effects. See Section 5.3 for additional discussion.

Table 9: Within-Conglomerate Difference-in-Differences

\begin{tabular}{lcccc}
\hline Variables & \multicolumn{4}{c}{$\ln$ (Output) } \\
\hline Treat $\times$ Post & $-0.343^{* * *}$ & $-0.350^{* * *}$ & $-0.367^{* * *}$ & $-0.315^{* * *}$ \\
& $(0.067)$ & $(0.068)$ & $(0.070)$ & $(0.067)$ \\
\hline Observations & 15,174 & 15,149 & 15,146 & 14,745 \\
$R^{2}$ & 0.530 & 0.535 & 0.582 & 0.626 \\
\hline Treat & $\mathrm{Y}$ & $\mathrm{Y}$ & $\mathrm{Y}$ & $\mathrm{Y}$ \\
Conglomerate $\times$ Year FE & $\mathrm{Y}$ & $\mathrm{Y}$ & $\mathrm{Y}$ & $\mathrm{Y}$ \\
Industry $\times$ Year FE & & $\mathrm{Y}$ & $\mathrm{Y}$ & $\mathrm{Y}$ \\
Province $\times$ Year FE & & & $\mathrm{Y}$ & $\mathrm{Y}$ \\
Firm-level Controls & & & & $\mathrm{Y}$ \\
\hline
\end{tabular}

Notes: Authors' calculations using data from the ASIF. This table shows the output change of regulated firms relative to that of their (same 4-digit industry) related firms within the same conglomerate. Treat $\times$ Post is an indicator for regulated firms (Top 1,000 firms) interacted with an indicator for years after 2006, and the dependent variable is log firm output. The estimates in this table correspond to a pooled version of the regression displayed in Figure 8 and show that regulated firms experience a $31.5 \%-36.7 \%$ output decrease relative to the output of their related firms in the same conglomerate. See Section 5.3 for additional discussion. Conglomerate-by-year fixed effects are included, and standard errors clustered at the conglomerate level are shown in parentheses with p-values below. ${ }^{*} p<0.1,{ }^{* *} p<0.05,{ }^{* * *} p<0.01$. 